\title{
TLIF versus PLIF in spondylolisthesis
}

Citation for published version (APA):

de Kunder, S. L. (2018). TLIF versus PLIF in spondylolisthesis. [Doctoral Thesis, Maastricht University]. Ridderprint BV. https://doi.org/10.26481/dis.20180531sk

Document status and date:

Published: 01/01/2018

DOI:

10.26481/dis.20180531sk

Document Version:

Publisher's PDF, also known as Version of record

\section{Please check the document version of this publication:}

- A submitted manuscript is the version of the article upon submission and before peer-review. There can be important differences between the submitted version and the official published version of record.

People interested in the research are advised to contact the author for the final version of the publication, or visit the DOI to the publisher's website.

- The final author version and the galley proof are versions of the publication after peer review.

- The final published version features the final layout of the paper including the volume, issue and page numbers.

Link to publication

\footnotetext{
General rights rights.

- You may freely distribute the URL identifying the publication in the public portal. please follow below link for the End User Agreement:

www.umlib.nl/taverne-license

Take down policy

If you believe that this document breaches copyright please contact us at:

repository@maastrichtuniversity.nl

providing details and we will investigate your claim.
}

Copyright and moral rights for the publications made accessible in the public portal are retained by the authors and/or other copyright owners and it is a condition of accessing publications that users recognise and abide by the legal requirements associated with these

- Users may download and print one copy of any publication from the public portal for the purpose of private study or research.

- You may not further distribute the material or use it for any profit-making activity or commercial gain

If the publication is distributed under the terms of Article $25 \mathrm{fa}$ of the Dutch Copyright Act, indicated by the "Taverne" license above, 


\section{TLIF versus PLIF in spondylolisthesis}


Publication of this thesis was financially supported by: Maastricht University and $\mathrm{SBOH}$.

\section{Maastricht University}

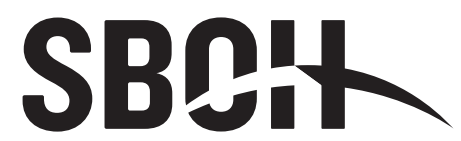

voor artsen in opleiding

TLIF versus PLIF in spondylolisthesis.

Thesis, Maastricht University, the Netherlands.

Copyright @ 2018 Suzanne de Kunder, The Netherlands.

No part of this thesis may be reproduced, stored or transmitted without prior permission of the author.

Cover design and layout

Printed by

ISBN evelienjagtman.com

Ridderprint, Ridderkerk, the Netherlands

978-94-6299-968-8 


\section{TLIF versus PLIF in spondylolisthesis}

PROEFSCHRIFT

ter verkrijging van de graad van doctor aan de Universiteit Maastricht, op gezag van de Rector Magnificus, prof. dr. Rianne M. Letschert volgens het besluit van het College van Decanen,

in het openbaar te verdedigen

donderdag 31 mei 2018 om 14:00 uur

door

Suzanne Levina de Kunder

geboren te Borsele op 15 april 1984 


\section{Promotor}

Prof. dr. R.A. de Bie

\section{Copromotores}

Dr. H. van Santbrink

Dr. K. Rijkers

\section{Beoordelingscommissie}

Prof. dr. L.W. van Rhijn (voorzitter)

Prof. dr. R.H.M.A. Bartels (Radboud Universiteit Nijmegen)

Dr. W.A. van den Brink (Isala Kliniek Zwolle)

Prof. dr. M.A. Joore

Prof. dr. J.M.P. Kleijnen 


\section{INDEX}

Chapter 1 Introduction 7

Chapter 2 Lumbar interbody fusion, a historical overview and a future per- 15 spective.

Chapter 3 Transforaminal lumbar interbody fusion (TLIF) versus posterior 35 lumbar interbody fusion (PLIF) in lumbar spondylolisthesis, a systematic review and meta-analysis.

Chapter 4 Transforaminal versus Posterior Lumbar Interbody Fusion as 59 operative treatment of lumbar spondylolisthesis, a retrospective case series.

Chapter 5 Cost-effectiveness of transforaminal lumbar interbody fusion 75 (TLIF) versus posterior lumbar interbody fusion (PLIF), a systematic review and economical evaluation.

Chapter 6 A protocol of a randomized controlled multicenter trial for surgi103 cal treatment of lumbar spondylolisthesis: The Lumbar Interbody Fusion Trial (LIFT).

Chapter 7 General discussion

Chapter 8 Summary

Chapter 9 Nederlandse samenvatting

Appendices Valorisation

Dankwoord

Curriculum Vitae

List of publications 



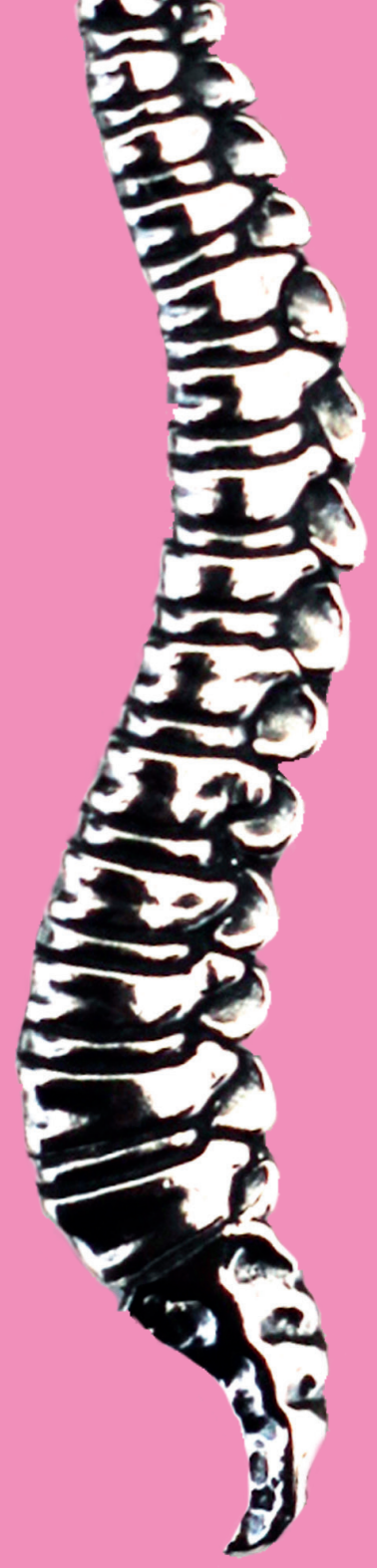

Chapter 1

Introduction 

Neurogenic leg pain is a frequent complaint in the general population (prevalence 1-43\%) 1 . This pain can be caused by compression or stretching of the nerve roots or cauda equina fibers (lumbar radiculopathy or neurogenic claudication respectively). Lumbar disc herniation and spinal canal stenosis are the classic and most common causes. Another cause of neurogenic leg pain is becoming more and more prevalent, namely lumbar spondylolisthesis (incidence in adulthood 6\%) ${ }^{2}$. In case of lumbar spondylolisthesis, there is lumbar vertebral displacement, resulting in compression or stretch of neurogenic structures. Lumbar spondylolisthesis is mostly of degenerative or isthmic nature. In case of degenerative spondylolisthesis, due to facet arthritis, joint remodeling and ligamentum flavum weakness, slippage of the vertebra may occur (figure 1 b). Isthmic spondylolisthesis is caused by a defect or fracture in the pars interarticularis of the vertebra, either of congenital origin or caused by spinal stress; this could also result in vertebral displacement (figure $1 \mathrm{c}$ ).

If conservative treatment for neurogenic leg pain fails, surgical treatment can be considered. In case of lumbar disc herniation or spinal canal stenosis, decompression surgery is performed. In case of spondylolisthesis, decompression alone is not deemed sufficient, and additional instrumented spinal fusion is recommended and common practice nowadays. In the US, between 1998 and 2008, the national bill for instrumented spinal fusion has increased 7.9-fold ${ }^{3}$.

This demand for instrumented spinal fusion is expected to only increase further in the next decades with an aging population. Also, in the Netherlands more and more instrumented spinal fusion procedures are executed every year and are therefore, a point of focus for the Dutch neurosurgical and orthopedic associations ${ }^{4}$.

Surgery aims at decompressing neurogenic structures and preventing progression of spondylolisthesis, therefore decompression is accompanied by lumbar pedicle screw fixation and spinal fusion using interbody cage(s). Several spinal fusion techniques are available, of which transforaminal lumbar interbody fusion (TLIF) and posterior lumbar interbody fusion (PLIF) are most frequently used.

The TLIF procedure consists of placement of a cage in the intervertebral space, using a unilateral approach. The PLIF procedure consists of placement of two identical cages bilaterally in the intervertebral space using a bilateral approach (figure 2).

There are no strict indications for using either technique, nor are literature or guidelines in this matter conclusive. As a result, the choice for the applied technique is largely based on the surgeon's experience and preference. 
Both techniques are proven to be effective in reducing leg pain ${ }^{5-10}$. Non-randomized studies comparing TLIF and PLIF suggest that TLIF is associated with fewer complications, less blood loss, shorter operative time and reduced hospital stay ${ }^{10-14}$. Due to this, health care costs for TLIF are expected to be lower. Quicker recovery of TLIF could also lead to a reduction in lost work productivity compared to treatment with PLIF.

\section{The aims of this thesis are;}

To describe the historical development of lumbar interbody fusion and to provide a future perspective,

- To compare the clinical effectiveness of TLIF and PLIF in patients with lumbar spondylolisthesis,

- To compare the cost effectiveness of TLIF and PLIF in patients with lumbar spondylolisthesis,

- To design a randomized controlled trial comparing clinical and cost effectiveness of TLIF and PLIF in patients with lumbar spondylolisthesis.

\section{Outlines of this thesis}

In chapter 2, a historical overview of lumbar interbody fusion is presented, to be able to understand and discuss the historical development and to give a future perspective. Chapter 3 compromises a systematic literature review and meta-analysis of the available literature comparing the effectiveness of TLIF and PLIF in lumbar spondylolisthesis/ lumbar instability. In chapter $\mathbf{4}$ the clinical outcomes of a retrospective study of spondylolisthesis patients who underwent TLIF or PLIF surgery are reported. Chapter $\mathbf{5}$ compromises a systematic literature review of the available literature comparing the cost-effectiveness of TLIF and PLIF in lumbar spondylolisthesis/ lumbar instability. Chapter 6 presents the study protocol of the LIFT (Lumbar Interbody Fusion Trial) study, a multi-center randomized controlled trial, comparing (cost-) effectiveness of TLIF and PLIF for patients with lumbar spondylolisthesis. A general discussion and considerations for the future are provided at the end of this thesis. 
a.

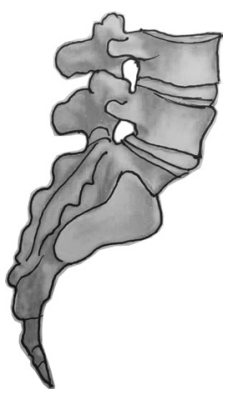

b

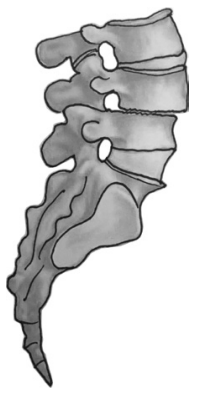

c.

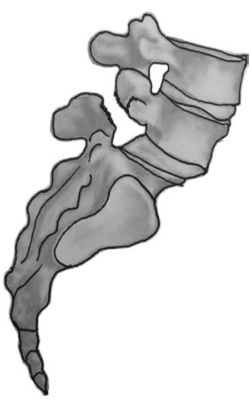

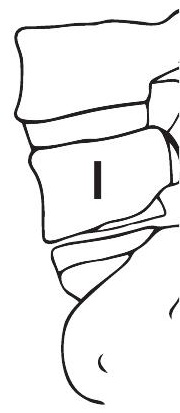

Figure 1: a. Normal anatomy of the lumbar spine; b. Degenerative spondylolisthesis due to facet arthritis, joint remodeling and ligamentum flavum weakness, slippage of the vertebra occured; c. Isthmic spondylolisthesis, slippage of the vertebra due to fracture in the pars interarticularis of the vertebra.

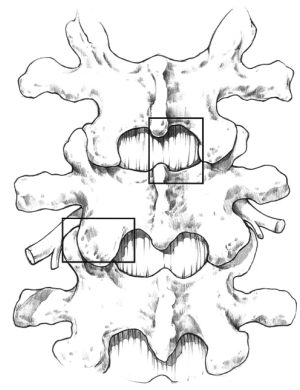

b.

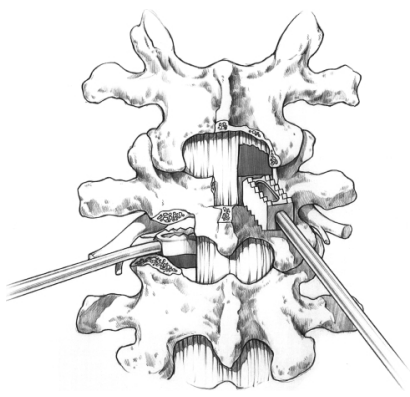

Figure 2: Schematic representation of lumbar spine demonstrating the area of bony removal and route of access to the intervertebral body space. a. (Top) Medial box represents area and access for the PLIF procedure; (bottom) lateral box represents area and access for the TLIF procedure.

b. Schematic representation of lumbar spine demonstrating the angle of interbody graft insertion for the PLIF procedure (top, medial) and TLIF procedure (bottom, lateral).

(Reprinted from "Comparison of low back fusion techniques: Transforaminal lumbar interbody fusion (TLIF) or posterior lumbar interbody fusion (PLIF) approaches" by Cole CD, MCCall TD, Schmidt MH, Dailey AT, (2009.) Curr Rev Musculoskelet Med 2:118-126.) 


\section{REFERENCES}

1. Konstantinou K, Dunn KM. Sciatica: review of epidemiological studies and prevalence estimates. Spine (Phila Pa 1976). 2008;33(22):2464-2472. doi:10.1097/BRS.0b013e318183a4a2.

2. Beutler WJ, Fredrickson BE, Murtland A, Sweeney C, Grant W, Baker D. The natural history of spondylolysis and spondylolisthesis. Spine (Phila Pa 1976). 2003;28(10):1027-1035. doi:10.1097/01. BRS.0000061992.98108.A0

3. Rajaee SS, Bae HW, Kanim LEA, Delamarter RB. Spinal Fusion in the United States. Spine (Phila Pa 1976). 2012;37(1):67-76. doi:10.1097/BRS.0b013e31820cccfb.

4. Willems P, Hoebink E, van Royen B, et al. Richtlijn: Geïnstrumenteerde Spinale Wervelkolomchirurgie.; 2017.

5. Tosteson ANA, Lurie JD, Tosteson TD, et al. Surgical treatment of spinal stenosis with and without degenerative spondylolisthesis: cost-effectiveness after 2 years. Ann Intern Med. 2008;149(12):845-853. doi:10.7326/0003-4819-149-12-200812160-00003.

6. Adogwa O, Parker SL, Davis BJ, et al. Cost-effectiveness of transforaminal lumbar interbody fusion for Grade I degenerative spondylolisthesis. J Neurosurg Spine. 2011;15(2):138-143. doi:10.3171/2011.3.SPINE10562.

7. Jalalpour K, Neumann P, Johansson C, Hedlund R. A Randomized Controlled Trial Comparing Transforaminal Lumbar Interbody Fusion and Uninstrumented Posterolateral Fusion in the Degenerative Lumbar Spine. Glob Spine J. 2015;5(4):322-328. doi:0.1055/s-0035-1549033.

8. Bydon M, Macki M, Abt NB, et al. The cost-effectiveness of interbody fusions versus posterolateral fusions in 137 patients with lumbar spondylolisthesis. Spine J. 2015;15(3):492-498. doi:10.1016/j. spinee.2014.10.007.

9. Zhou Z-J, Zhao F-D, Fang X-Q, Zhao X, Fan S-W. Meta-analysis of instrumented posterior interbody fusion versus instrumented posterolateral fusion in the lumbar spine. J Neurosurg Spine. 2011;15(3):295-310. doi:10.3171/2011.4.SPINE10330

10. Kunze B, Drasseck T, Kluba T. Posteriore und transforaminale lumbale interkorporelle Fusion (PLIF/ TLIF) zur Therapie des lokalisierten Segmentaufbrauchs der LWS. Z Orthop Unfall. 2011;149(3):312-316. doi:10.1055/s-0030-1250689.

11. Humphreys SC, Hodges SD, Patwardhan AG, EckJC, Murphy RB, Covington LA. Comparison of posterior and transforaminal approaches to lumbar interbody fusion. Spine (Phila Pa 1976). 2001;26(5):567-571. doi:10.1097/00007632-200103010-00023.

12. Sakeb N, Ahsan K. Comparison of the early results of transforaminal lumbar interbody fusion and posterior lumbar interbody fusion in symptomatic lumbar instability. Indian J Orthop. 2013;47(3):255. doi:10.4103/0019-5413.111484.

13. Yang E-Z, Xu J-G, Liu X-K, et al. An RCT study comparing the clinical and radiological outcomes with the use of PLIF or TLIF after instrumented reduction in adult isthmic spondylolisthesis. Eur Spine J. 2016;25(5):1587-1594. doi:10.1007/s00586-015-4341-z.

14. Parker SL, Mendenhall SK, Shau DN, et al. Minimally Invasive versus Open Transforaminal Lumbar Interbody Fusion for Degenerative Spondylolisthesis: Comparative Effectiveness and Cost-Utility Analysis. World Neurosurg. 2014;82(1-2):230-238. doi:10.1016/j.wneu.2013.01.041. 




\section{Chapter 2}

Lumbar interbody fusion, a historical overview and a future perspective

SL de Kunder, K Rijkers, IJMH Caelers, RA de Bie,

PJ Koehler and $\mathrm{H}$ van Santbrink 


\section{ABSTRACT}

In this historical study we present an overview of lumbar interbody fusion surgery, which is one of the most commonly performed instrumented spinal fusion surgeries. The present article focuses on the history of lumbar interbody fusion surgery, starting from the foundation which was laid in the 19th and 20th century until today. The development of material and techniques evolved from simple wiring to the combination of transforaminal interbody fusion with PEEK (polyether ether ketone) cages and pedicle screw fixation with poly axial screws. The possibilities of instrumented spinal fusion grew over the past 100 years, and a considerable increase in instrumented spinal surgery was seen over the past decades. Today, gain lies in perfection of techniques and deliberate indication and development of guidelines. Therefore, more standardized studies on instrumented spinal surgery are needed to be done and techniques should be personalized on the patients' specific needs. 


\section{INTRODUCTION}

Today, more and more patients worldwide are suffering from neurological problems related to instability of the spinal column. Even though today this number increases because of the ageing population, it is not 'new'. The first descriptions of spinal instability have been found in ancient Indian and Egyptian writings dating back over two thousand years ${ }^{1-3}$. Currently, patients are managed according to the available health care standards, including detailed imaging, psychosocial analysis, and treatment using one of the various instrumented surgical techniques. The ultimate aims of these procedures are alleviation of neurological symptoms and fusion of spinal elements. Historically, ideas on correction and stabilization of the spine exist for centuries, but the means to do so did not. As a result, the spinal column remained practically off limits for surgeons until the end of the $19^{\text {th }}$ century. Nowadays, a wide range of surgical techniques are to our disposal to stabilize the spine, and hereby treat neurological problems. In this article we present a historical overview of lumbar interbody fusion surgery, which is one of the most commonly performed instrumented spinal fusion surgeries. 


\section{METHODS}

To identify relevant studies concerning the historical overview of lumbar interbody fusion surgery, historical texts, historical overview articles and well-known books concerning spine surgery were analysed. A literature search of the following databases was performed: Medline (using PubMed) and Embase (using Ovid). With the use of search terms 'spine surgery', 'spinal fusion surgery', 'cage', 'screw', 'history' and (when possible) filter 'Historical Article', relevant articles were identified. References of selected articles were checked on relevancy and eligible articles identified. The following articles from 'The Classic' series published in Clinical Orthopaedics and Related Research were considered key articles since the early development of spinal fusion was described in these: BE Hadra. The Classic: Wiring of the vertebrae as a means of immobilization in fracture and Potts' disease, RA Hibbs. The Classic: An Operation for Progressive Spinal Deformities and FH Albee. The Classic: Transplantation of a portion of the tibia into the spine for Pott's disease: a preliminary report ${ }^{4-6}$. Furthermore, the following two standard books, Orthopedics: A History and Iconography (Peltier, 1993) and Who's Who in Orthopedics (Mostofi, 2005) were used to secure a representative list of articles 7,8. Important discoveries and developments in medical history relevant for (spinal) surgery as Pott's disease, antiseptics, anaesthesia and X-ray for medical purposes emerged in this time period and were therefore studied in common medical texts.

We confined ourselves to describe the development of interbody fusion in case of lumbar spondylolisthesis, and chose to omit all techniques concerning scoliosis, which would merit a study on its own. 


\section{RESULTS}

\section{Early history}

In the $15^{\text {th }}$ and $16^{\text {th }}$ century, knowledge of (spinal) anatomy increased, and the first concepts on biomechanical mechanisms emerged. Even though some external fixation devices have been described as early as the medieval period, the shift to surgery did not take place at that moment 9,10 . The real foundation for spinal fusion surgery for degenerative spine was laid in the $19^{\text {th }}$ and $20^{\text {th }}$ century.

The discovery of general anesthesia (1846, Boston, USA, William Morton) and antisepsis (1867, Glasgow, UK, Joseph Lister) opened a whole new window of surgical opportunities on larger scale ${ }^{11,12}$. Not much later, the development of X-ray for medical purposes (1895,

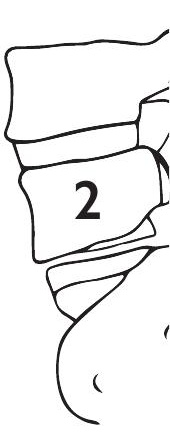
Würzburg, Germany, Wilhelm Röntgen) allowed an internal view of the spine ${ }^{13}$. All these factors combined provided surgical possibilities. Together with the enormous rise of tuberculosis in the $18^{\text {th }}$ and $19^{\text {th }}$ century with an incidence as high as 900 deaths per 100,000, and the accompanying spinal tuberculosis, Pott's disease (mentioned after Percival Pott, English surgeon, who described the affliction in 1756), frequently resulted in spinal instability. Pott's disease manifested itself as a combination of osteomyelitis and arthritis, involving both vertebral body and intervertebral disc, often secondary to an extraspinal source of tuberculosis infection. This eventually resulted in progressive bone destruction, leading to vertebral collapse and kyphosis ${ }^{14,15}$. The available external fixation devices were not sufficient to maintain spinal stability, and the demand for alternative stabilizing methods grew. Development started with a focus on the cervical spine and over the years slowly found its way to the lumbar spine, which finally led to the foundation of spinal instrumentation and fusion as we know it today.

\section{Evolution of lumbar surgical techniques and material}

The first attempts

The very first case of instrumented spinal fusion in modern medicine was described by Berthold Hadra (Breslau, Prussia 1842 - Dallas, USA 1903), a surgeon working in Austin, Texas, USA in 18917. He described a patient suffering from an eight-months old dislocated fracture of the sixth and seventh cervical vertebrae. X-ray was not available, but physical examination suggested that the sixth cervical vertebra was displaced and rotated, while the spinous process of the seventh vertebra appeared unusually prominent. The patient had developed severe pains in neck, arms and around the abdomen, and was unable to walk or retain bladder control. In order to reduce the suspected dislocation and to stabilize the fracture, Hadra used a posterior approach using an incision from occiput to the first thoracic vertebra. He subsequently held the adjacent spinous processes together using a silver wire that was wrapped around the spinous processes following the shape of a figure 
eight (figure 1). After closing the wound, a stiff collar was applied. Initially, the patient slowly improved but after a few weeks the aforementioned symptoms recurred. Re-operation followed and revealed that the dislocation had returned, due to loosening of the silver wire. It was reduced and fixated using the same wiring technique. During the following weeks the patient improved, but after periods without the stiff collar part of his symptoms returned. Hadra postulated the use of this wiring technique for patients with Pott's disease, but never actually reported on treating such a patient using this technique ${ }^{7,5}$.

Antoine Chipault (Orléans, France 1866 - 1920) (a French pioneer in neurosurgery) carried out the first internal fixation for Pott's disease in Paris, $1893^{7}$. In 1896 he described five cases of patients with Pott's disease, of whom he stabilized the spine with Hadra's wiring technique ${ }^{16}$.

In Munich, 1908, Fritz Lange (Dessau, Germany 1864 - Wackersberg, Germany 1952) attempted to stabilize the spine of patients with Pott's disease by applying $10 \times 0.5 \mathrm{~cm}$ long, tin-plated steel rods next to the spinous processes, fixed to the spine by sutures through the interspinous ligaments. Afterwards, patients were immobilized in a plaster of Paris brace for six weeks, followed by brace support for six months. Lange gave up on using steel rods due to corrosion problems 7,17 .

In 1911, orthopedic surgeons Fred Albee (Alna, Maine, USA, 1876 - 1945) and Russell Hibbs (Birdsville, Kentucky, USA 1869 - New York, USA 1932) independently reported on their experiences with spinal fusion procedures for patients with Pott's disease that were technically quite similar ${ }^{7}$. Working at the New York Orthopaedic Hospital, Hibbs described the technique he used on one child and two adults as follows: he incised to the periosteum, divided the periosteum over the tips of the spinous processes and stripped down to the base. The interspinous ligaments were split in the midline. Subsequently, the spinous processes were fractured close to their base. They were placed in contact with the adjacent vertebra, until a bridge of continuous bone was formed. Finally, the periosteum was replaced over this bone and sutured with chromic gut sutures. Postoperatively, patients were immobilized using a plaster of Paris brace or other spinal brace. Hibbs concluded that his procedure was successful in prevention of kyphosis ${ }^{6}$.

At the same time, Albee, practising at New York Postgraduate Medical School Clinic, reported on three patients. He split the spinous processes longitudinally, and produced Green-stick fractures at the base. He did this for two reasons: to obtain a bone graft for fusion, and to obtain a cavity in which he placed the graft, harvested from the tibia of the left leg. Finally, the bone graft was held in place by tightly closing the overlying fascia with chromic catgut sutures. Postoperatively, patients were immobilized with a spinal brace. 
Albee specifically noted the strength of bone grafting compared to internal metal splints; he noticed the bone getting thicker and stronger when using bone graft, whereas the use of metal lead to direct absorption and bone atrophy, resulting in failure of rods and wires, as had been concluded earlier by Lange as well ${ }^{4}$.

The rise of fusion for degenerative spine disease

Several small case series on instrumented spine surgery via a posterior approach have subsequently been described in literature and prelude the next important step of improvement in instrumented spine surgery. Orthopedic surgeon Willis Campbell (Jackson, Mississippi, USA 1880 - 1941) described the technique of trisacral fusion in $1920{ }^{18}$. This method consisted of placing an autograft from the iliac crest to the tips of the transverse processes of $L 5$ to obtain lumbar sacral fusion ${ }^{19}$. A similar method of 'transverse fusion' had been reported with good results for L4L5. The method of trisacral fusion however did not achieve many followers due the fact that fusion of the sacroiliac joint often failed. Simultaneously, Hibbs continued to use his wiring technique to treat Pott's disease patients and improved it. He used a larger area for bone grafting and fusion, increasing spinal stability.

His method was adapted by other surgeons. In 1929 he started to use the posterior wiring technique for degenerative spine disease and scoliosis 20,21.

A returning problem were the limited results due to the corrosive effects of the metals; the used material failed before fusion was obtained, frequently leading to non-union 4,22. Vitallium, an alloy of cobalt, chromium, molybdenum among other things was successfully used in dentistry and was introduced for spine surgery in 1936, by Charles Venable and Walter Stuck from San Antonio, Texas, USA. Vitallium is inert, and resistant to corrosion and therefore more reliable than the implants used so far ${ }^{23}$.

At Stanford University Medical School, orthopedic surgeon Donald King (Porterville, California, USA 1903 - San Francisco, California, USA 1987) further developed Hibbs' technique by adding facet screws in the late 1940s (figure 1) $24,8,25$. He was the first to use vertebral screw fixation and hereby immediately obtaining rigid fixation at time of surgery, thereby avoiding prolonged immobilization in a brace. His rationale was sound, but the placement of the short screws in the facets resulted in a 10\% incidence of failure of fusion. Upon using the same technique, in 1949 Walter Thompson and Edgar Relston from the New York Orthopedic Dispensary and Hospital even found a 55.1\% non-union rate ${ }^{26}$. 


\section{Anterior approaches and interbody fusion}

The first attempts of instrumented spinal fusion consisted of posterior approaches to the spinal column, the most convenient approach to reach the spinal column, comparable to the posterolateral fusion as we know it today. With this approach the vulnerable abdominal and thoracic cavities were avoided, while at the same time posterior anatomical structures were exposed relatively easy.

The first anterior approaches for treating spondylolisthesis emerged in the 1930s and were described by Burns and Capener 22,27. At St George's Hospital London, UK, orthopedic surgeon Burns performed several posterior approaches in patients with lumbar spondylolisthesis, but found the results with respect to pain relief unsatisfactory. He studied several cadavers, and deemed it possible to access the lumbar spine through an alternative anterior approach. In 1933 he performed anterior fusion of the lumbar spine in a 14-year old boy with a traumatic spondylolisthesis L5S1, back pain and pain in the calves. He described an anterior transperitoneal approach through a left paramedian incision. After packing the intestines, the posterior peritoneum was incised and the displaced lumbar vertebra visualized by blunt dissection. A hole was drilled in the fifth lumbar vertebra and an autograft peg, from the boy's tibia, tapped into place. The posterior peritoneum and abdomen were closed. The patient recovered uneventfully with strict bed rest in a plaster bed, and was able to walk pain free after two months. Burns suggested to use a steel pin in future cases, to avoid possible absorption of the autograft, but has not reported on additional cases ${ }^{22}$.

\section{The discovery of disc herniation and introduction of stand-alone interbody fusion}

The use of spinal fusion surgery rapidly increased after the publication of disc herniation in 1934 by neurosurgeon William Mixter (1880 - 1958) and orthopedic surgeon Joseph Barr (1901 - 1963) ${ }^{28}$. In their famous paper they proposed that disc herniation was the result of an unstable lesion of the lumbar spine. In their opinion, the preferred method to treat this unstable lesion, and prevent re-herniation of the nucleus pulposus, was by decompression of the nerve root and fusion of the unstable spine. A preferred fusion method was not mentioned, and as a result, all available fusion techniques (wiring, posterior and anterior approaches) became more widespread ${ }^{28}$. Fusion rates improved when surgeons became more experienced, but non-union still frequently occurred and led to unacceptable high levels of pseudo arthrosis. In 1944, Briggs and Milligan of East Orange, New Jersey, USA, described a novel technique to improve fusion rates further, combining a posterior approach to the spine with interbody fusion, notably the posterior lumbar interbody fusion (PLIF) technique (figure 1). Their series included seventy patients with low back pain, spondylolisthesis and disc herniation, who were treated using the following procedure: the spine was extensively exposed and spinous processes were removed and 
processed in small chips. The lamina and facet joints were partially removed to obtain entrance to the disc. The disc was removed and replaced by a round bone peg to obtain immediate stabilization. When necessary, additional bone material was obtained from the ilium. The small bone chips, derived from the spinous processes, were placed over and next to the dura, over the remaining facets and lateral of the sacrum. Postoperatively, the patient was immobilized for ten days, or, in case of spondylolisthesis, for six weeks, after which a lumbar brace was applied. Another two weeks later the patient was allowed to sit up. Briggs and Milligan reported in their series one patient with definite failure of fusion ${ }^{29}$.

Fusion rates further improved after the 1953 publication of Cloward's series of 321 patients that were treated using his adapted version of the PLIF technique of Briggs and Milligan. Neurosurgeon Ralph Cloward (Salt Lake City, Utah, USA 1908 - Honolulu, Hawaii, USA 2000) used several bone grafts instead of one bone peg, first autograft from patients' ilium, later allograft from cadaver bone, to shorten the procedure and limit complications of harvesting autograft 8,30 . Fusion rates up to $85 \%$ were described. However, the PLIF technique remained rather unpopular because of the technical difficulty and surgical complications such as severe bleeding, root damage, arachnoiditis, and dural tear.

\section{Harrington rod and biomechanical concepts of spinal instability}

Spinal internal fixation took flight with the development of the Harrington rod in 1962. The rod system was originally developed by orthopaedic surgeon Paul Harrington (1911 - Houston, Texas, USA 1980) for correction of severe scoliosis, but quickly was used for other conditions including trauma and spondylolisthesis 7,31,32. Harrington discovered that standalone spinal instrumentation without fusion often resulted in implant failure. He was aware of the continuous race between development of solid fusion and failing material. The insight that instrumentation and bone grafting should be combined was a revelation in spine surgery.

Simultaneously, orthopedic surgeon Frank Holdsworth (1904, Bradford, UK - 1969), working at the Spinal Injuries Centre, Sheffield, UK, was the first to relate internal fixation problems to a biomechanical concept of spinal instability rather than to a deformity concept alone. He studied a large number of patients with spinal injuries, and in 1963 published a two-column model of spinal instability, dividing subaxial spinal fractures into several categories ${ }^{8,33}$. His ideas about spinal instability were widely adapted and led to a permanent shift in general thinking about the spine.

Clowards' PLIF technique, as mentioned above, remained unpopular throughout the sixties and seventies because of technical difficulty and high complication rates. In 1977 neurosurgeon Paul Lin of Temple University Health Center, Philadelphia, Pennsylvania, 
USA, published a paper on his modified PLIF technique, that included four adaptations that reduced complication rate. The adaptations included 1) careful pre-operative positioning of the patient aimed at low epidural venous pressure, in order to reduce epidural bleeding; 2) the use of Surgicel ${ }^{\circledR}$ to reduce epidural bleeding; 3) to preserve the facet by using a more medial, interlaminar approach; 4) preservation and perforation of the cortical plate to stimulate osteosynthesis ${ }^{34}$. Despite all these modifications, standalone posterior interbody fusion fell out of favor due to technical difficulty, potential serious complications and low fusion rates.

\section{Biomechanics of the spine and the pedicle screw fixation}

As mentioned above, the first use of screws for fusion was in 1940-1959 period by King and later on in 1959 Boucher improved King's facet-screw technique of internal fixation by placing longer screws more medially, so they were placed in the pedicles ${ }^{35}$. The closeness to the neuroforamen was considered a hazard. The first to describe the use of screws positioned sagittaly through the pedicles and articulair processes, the pedicle screw, in combination with a plate was orthopedic surgeon Raymond Roy-Camille (1927, Fort-deFrance, Martinique - 1994 Paris, France) in 1970 25. Others refined this technique and also Harrington combined it with his rod system ${ }^{25}$. Improved knowledge of biomechanics of the spine, as reported in 1980 by Monahar Panjabi and orthopedic surgeon Augustus White, gave further insights in spine biomechanics and helped thinking along a biomechanical concept ${ }^{36}$.

In 1988 orthopedic surgeon Arthur Steffee (1934, Cleveland, Ohio, USA) proposed to combine pedicle screw fixation with interbody fusion to restore load sharing through the anterior column ${ }^{37-40}$. Steffee, like Holdsworth and Panjabi and White, explicitly considered the biomechanical aspects of the spine, and designed his system with this in mind. It could be fine-tuned according to the patient's anatomy. The addition of pedicle screw fixation led to increased stability and higher fusion rates compared to either procedure performed separately ${ }^{41}$.

In the ongoing search for optimization of spinal fusion procedures, Jürgen Harms (Darmstad, Germany, 1944) and Rolinger introduced transforaminal lumbar interbody fusion (TLIF) as an alternative for PLIF in 1982. They reported on the use of bone graft packed in titanium mesh that was inserted via a unilateral transforaminal route into the anterior part of the disc space. Harms and Blume developed the TLIF technique further, and Harms described this in detail together with Jeszensky in $1998{ }^{42,43}$. Pedicle screws were placed before cage insertion, the entire facet joint was removed, and hereby minimizing traction on the thecal sac, reducing the chance of potentially serious neurological deficits. Compared to PLIF, TLIF was less destructive due the unilateral approach, and therefore considered to be safer 44,45. 
Over the years, hundreds of systems and variations of the orthopedic screw have been developed. The pedicle screw fixation system proved to be biomechanically superior over others. The pedicle screws have been modified over the past twenty year to reduce stress on the construct and hereby breakage rate, and to facilitate easy application. Additionally; the development of polyaxial pedicle screws was found to reduce bending strength at the screw-rod mount, compared to monoaxial (rigid) screws ${ }^{46}$.

\section{Introduction of cages}

In 1977, veterinarians Barrie Grant and Pamela Wagner discussed Clowards' techniques for spinal stabilization, and the possibility for using it in horses with Wobbler syndrome (unsteady (wobbly) gait and weakness as a result of cervical spine disorders), with orthopedic surgeon George Bagby (1923, Waco, Texas, USA - 2016 Spokane, Washington, USA) 47,48. Although the value of Clowards' contribution was unmistakable, bone grafts for interbody fusion tended to collapse or fragment, requiring re-operation ${ }^{49}$. With this in mind Bagby created the 'Bagby Basket', a perforated stainless steel cylinder. The Bagby Basket was impacted through an anterior approach, thereby stabilizing the cervical spine. When secure in place, the basket was packed with morselized autologous bone. The perforations allowed bone in-growth, resulting in solid fusion in horses that were previously doomed. In 1984, Bagby presented his horse-work at the North American Spine Society Meeting in Banff, Canada ${ }^{50,51}$. In the following years excellent results and high fusion rates up to $88 \%$ were obtained in animal studies ${ }^{52,53}$. Other spine surgeons, including Kuslich, developed their own versions of the Bagby Basket for use in humans ${ }^{37,54,55}$. The first experimental use of titanium interbody cages in humans was in 1989, and the first successful use of standalone cages in the lumbar spine was in 1992 reported by orthopedic surgeon Stephen Kuslich ${ }^{54}$. Kuslich described the use of the BAK ('Bagby and Kuslich') implant, a modified Bagby Basket (figure 1). The BAK implants could be impacted in pairs, either through a posterior laminotomy or an anterior retroperitoneal approach, as standalone devices, without additional screws or rods. In both ventral and dorsal approaches, the BAK implants were packed with bone graft and aligned in the intervertebral disc space.

A drawback of titanium implants was the incompatibility with imaging as MR and CT. Especially in case of re-operation, the essential visualizing of the spinal cord and soft tissue was bothered severely. In 1987 the potential of PEEK (polyether ether ketone) polymers in medical applications was suggested by Williams (University of Liverpool, UK) ${ }^{56}$. PEEK implants were considered strong enough, and at the same time not too rigid, wear and fatigue resistant as well as naturally radiolucent, thus compatible with common imaging. PEEK had all the necessary characteristics to replace titanium implants. The first PEEK implants reinforced with carbon fibers were used in 1999 by Brantigan, namely the Brantigan I/F cage ${ }^{37,57}$. When patients received a Brantigan I/F cage combined with pedicle 
screw fixation, this led to the very high fusion rate of $98.9 \%{ }^{37}$. Over the past decade a great variety of PEEK implants have been introduced and the cage technology has exploded. Cages in all shapes and forms were added to the available arsenal.

\section{Current and new developments}

Autograft, and later allografts, were both used since early days of spinal fusion 4,19,21,22,30,45. However, with the use of bone grafts an ever returning issue was pseudo arthrosis. Therefore, several bone graft substitutes were developed in order to reduce the risk of pseudo arthrosis. Unfortunately, most existing bone grafts substitutes lack appropriate osteoinduction, osteoconduction and osteogenecity. Some have exhibited potentials like members of the transforming growth factor beta family, recombinant human bone morphogenetic protein-2 and osteogenic protein-1 (rhBMP-2 and OP-1). rhBMP-2 and OP-1 were successfully used as bone enhancers for posterior spine fusion, but they were also associated with potential serious complications including ectopic bone formation and possible cancer risks and therefore not always more effective and beneficiary to the patient ${ }^{58,59}$. Besides these substitutes, current research and new developments focuses on surface engineering technology. Due to different surface properties cagesurfaces could hypothetically stimulate osteogenisis with the use of macro, micro and nano techniques ${ }^{60,61}$. Also the development of screws with bioactive coatings like hydroxyapatite for promotion of osteointegration are upcoming. New innovational technologies as mesenchymal stem cells, gene therapy and tissue engineering with cell-based bone grafts, show promising results in animal studies. Future research will evaluate their clinical relevance and efficacy in humans ${ }^{62}$. Next to all these developments, there is more attention for tailored personalized medicine. Patient-specific rods, the use of 3-dimensional navigation and patient-specific templating of lumbar disk replacements are examples of developments in personalized medicine within spine surgery ${ }^{63}$. 


\section{DISCUSSION}

The aim of instrumented spine surgery has shifted in the past decades from a method to correct deformities to a method to restore stability and maintain natural balance. The development of material and techniques evolved from simple wiring to the combination of transforaminal interbody fusion with PEEK cages and pedicle screw fixation with poly axial screws. Hereby possibilities for instrumented spinal fusion grew, hence a considerable increase of surgery was seen over the past decades. Furthermore, increased biomechanical insights contributed substantially to 'state of the art instrumented spinal surgery' as we know it today. A closer look at these developments in the past had learned us that, from a biomechanical point of view, it is wise to share the load of the column and to combine interbody and posterior fixation techniques for compression of the intervertebral space, leading to optimal stability direct postoperatively, minimized cage migration and optimized clinical results.

The possible gain in further development for lumbar interbody surgery lies in a focus on restoring natural balance and mobility and to do as little harm as possible to the spinal musculature and neural tissue, all personalized on the patients' specific needs. Minimal invasive spine surgery plays an important role in this. Currently, spine surgery does not involve a long incision as applied in the early days, and the shift to avoid significant damage to the muscles surrounding the spine has already occurred.

Where in the past absolute indications for lumbar interbody surgery were lumbar spondylolisthesis, severe scoliosis, spinal tuberculosis, and fractures, this has gradually shifted towards broader/relative indications including back pain, degenerative disc disease and spinal stenosis ${ }^{64}$. This shift takes place in the absence of solid evidence based medicine; randomized trials on the effectiveness of lumbar interbody surgery are virtually non-existent. Nevertheless, instrumented spinal surgery has gone through a five-fold increase in number of procedures between 1990 to 2011, and an increase of industry sales from $\$ 225$ million in 1994 to $\$ 6.6$ billion in 2011 (a 30-fold increase) in the USA ${ }^{65}$. The influence of industry in this matter is undeniable, and the issue of conflict of interest in industry-sponsored clinical research is ongoing ${ }^{59}$. Moreover, we must bear in mind that instrumented spinal fusion is not always necessary: recent studies showed decompression alone suffices in the majority of patients with lumbar spondylolisthesis ${ }^{66,67}$. For these reasons, critical and dedicated spine surgeons and more solid evidence based medicine is needed in the future to control the increasing problem of degenerative spine disease and to be able to advise spine surgeons with use of reliable guidelines. 


\section{CONCLUSION}

Spinal diseases and injuries have been known since the common era, but treatment was limited due the lack of surgical possibilities. However, new discoveries including anesthesia, antisepsis and x-ray and further development and subspecializing in medicine in the $19^{\text {th }}$ century were turning points in the development of instrumented spinal fusion. Great steps forward have been made over the past 100 years, culminating in exceptional growth and possibilities in instrumented spinal fusion procedures today. With the steep increase in instrumented spinal surgery, and the expected further rise in the near future, gain lies in perfection of techniques and deliberate indication and development of guidelines, all based on solid evidence based medicine and personalized on the patients' specific needs, As professionals it is our duty to remain a critical party in accepting the use of newly developed devices, and to keep asking the question if they really provide benefits for the patient. 
The discovery of general anesthesia

The discovery of antisepsis

WIRING HADRA
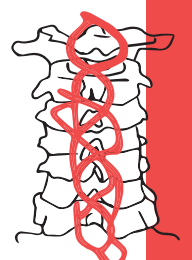

Introduction of stainless steel

First publication of disc herniation

Introduction of Vitallium

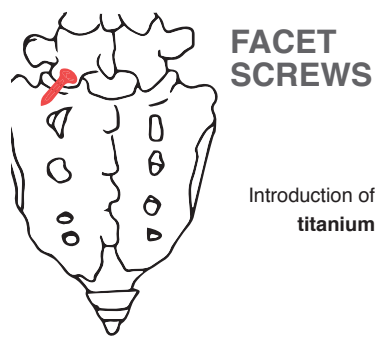

\section{BAK IMPLANT}

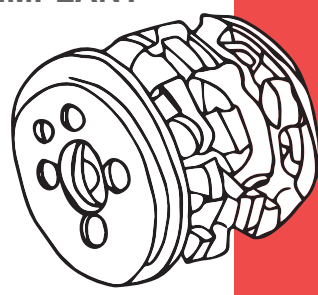

189

A fusion of the lumbar spine with autograft in traumatic spondylolisthesis ALIF

Addition of facet screws

to posterior fixation technique

\section{PLIF}

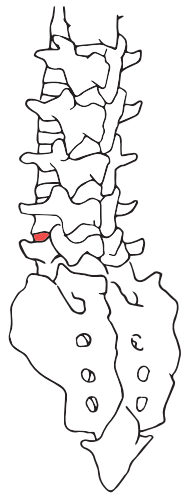

1962 Harrington rod

1963 FIRST BIOMECHANICAL CONCEPTS

a two-column model of spinal instability

1980 Improved knowledge of biomechanics of the spine

1982 Introduction of transforaminal lumbar interbody fusion TLIF

1986 Pedicle screws in combination with a plate

1988 Pedicle screw fixation with lumbar interbody fusion

1989 Experimental use of titanium interbody cages in humans

First use of standalone cages in the lumbar spine, BAK ('Bagby and Kuslich') implant

Introduction of polyaxial screws

Experimental use of carbon fiber interbody cages in humans

PEEK cages

Minimal invasive spine surgery

Introduction of fusion-inducing bone morphogenetic proteins (BMPs)

Figure 1: Time line 


\section{REFERENCES}

1. Kumar K. Spinal Deformity and Axial Traction. Spine (Phila Pa 1976). 1996;21(5):653-655. doi:10.1097/00007632199603010-00024.

2. Hughes J. The Edwin Smith Surgical Papyrus: an analysis of the first case reports of spinal cord injuries. Paraplegia. 1988;Apr;26(2):(2):71-82. doi:10.1038/sc.1988.15.

3. Naderi S, Andalkar N, Benzel EC. History of spine biomechanics: Part I - The pre-Greco-Roman, Greco-Roman, and medieval roots of spine biomechanics. Neurosurgery. 2007;60(2):382-390. doi:10.1227/01. NEU.0000249276.94933.8D.

4. Albee FH. The Classic: Transplantation of a portion of the tibia into the spine for Pott's disease: a preliminary report. Clin Orthop Relat Res. 2007;460:14-16. doi:10.1097/BLO.0b013e3180686aOf.

5. Hadra BE. The Classic: Wiring of the vertebrae as a means of immobilization in fracture and Potts' disease. Clin Orthop Relat Res. 2007;460:11-13. doi:10.1097/BLO.0b013e318068692a.

6. Hibbs RA. The Classic: An Operation for Progressive Spinal Deformities. Clin Orthop Relat Res. 2007;460:17-20. doi:10.1097/BLO.0b013e3180686b30.

7. Peltier LF. Orthopedics: A History and Iconography. Norman Publishing; 1993.

8. Mostofi SB. Who's Who in Orthopedics. Springer International Publishing; 2005.

9. Sari H, Misirlioglu TO, Akarirmak U, Hussain S, Kecebas HD. The Historical Development and Proof of Lumbar Traction Used in Physical Therapy. J Pharm Pharmacol. 2014;2:87-94.

10. Silver JR. History of the Treatment of Spinal Injuries. Springer US; 2003. doi:10.1007/978-1-4419-8991-8.

11. Lister J. Antiseptic Principle In The Practice Of Surgery. Br Med J. 1867;2(351):246-248.

12. Robinson DH, Toledo AH. Historical Development of Modern Anesthesia. J Investig Surg. 2012;25(3):141-149. doi:http://dx.doi.org/10.3109/08941939.2012.690328.

13. Underwood E. Wilhelm Conrad Röntgen (1845-1923) and the Early Development of Radiology. Proc R Soc Med. 1945;38 (12):697-706.

14. Dobson J. Percivall Pott. Ann R Coll Surg England. 1972;50(1):54-65. doi:10.1093/nq/s8-VII.172.293-C.

15. Daniel TM. The history of tuberculosis. Respir Med. 2006;100(11):1862-1870. doi:10.1016/j.rmed.2006.08.006.

16. Chipault A. Travaux De Neurologie Chirurgicale.; 1986.

17. Lange F. Support for the Spondylitic Spine by Means of Buried Steel Bars, Attached to the Vertebrae. Clin Orthop Relat Res. 1986;February(203):3-6.

18. Obituary. Willis Cohoon Campbell 1880-1941. J Bone Jt Surg Am. 1941;23(3):716-717.

19. Campbell W. An operation for extra-articular fusion of sacroiliac joint. Surg Gynecol Obs. 1939;45:218-219.

20. Hibbs R, Swift W. Developmental abnormalities at the lumbosacral juncture causing pain and disability: report of 147 patients treated by the spinal fusion operation. Surg Gynecol Obs. 1929;48:604

21. Hibbs R. A report of fifty-nine cases of scoliosis treated by fusion operation. J Bone Jt Surg. 1924;6:3-34.

22. Burns B. An operation for spondylolisthesis. Lancet. 1933;224:1233-1239.

23. Venable CS, Stuck WG. Three years' experience with vitallium in bone surgery. Ann Surg. 1941;114(2):309-315.

24. King D. Internal Fixation for Lumbosacral Fusion. J Bone Jt Surg Am. 1948;30-A(3):560-578.

25. Kabins MB, Weinstein JN. The History of Vertebral Screw and Pedicle Screw Fixation. Iowa Orthop J. 1991;11:127136.

26. Thompson WAL, Ralson EL. Pseudoarthrosis following spine fusion. J Bone Jt Surg Am. 1949;31(2):400-405.

27. Capener N. Spondylolisthesis. BrJ Surg. 1932;19(75):374-386.

28. Mixter WJ, Barr JS. Rupture of the Intervertebral Disc with Involvement of the Spinal Canal. N Eng/ J Med. 1934;211(5):210-215. doi:10.1056/NEJM193408022110506. 
29. Briggs H, Milligan PR. Chip fusion of the low back following exploration of the spinal canal. J Bone Jt Surg Am. 1944;26(1):125-130.

30. Cloward RB. The treatment of ruptured lumbar intervertebral discs by vertebral body fusion. I. Indications, operative technique, after care. J Neurosurg. 1953;10(2):154-168. doi:10.3171/jns.1953.10.2.0154.

31. Harrington P, Dickson J. Spinal instrumentation in the treatment of severe progressive spondylolisthesis. Clin Orthop Relat Res. 1976;(117):157-163.

32. Harrington P, Tullos H. Reduction of Severe Spondylolisthesis in Children. South Med J. 1969;62(1):1-7.

33. Holdsworth F. Fractures, dislocations, and fracture-dislocations of the spine. J Bone Joint Surg Am. 1970;52(8):1534-1551.

34. Lin PM. A technical modification of Cloward's posterior lumbar interbody fusion. Neurosurgery. 1977;1(2):118124.

35. Boucher H. A Method of Spinal Fusion. J Bone Jt Surg. 1959;41 B:248-259.

36. Panjabi MM, White AA. Basic biomechanics of the spine. Neurosurgery. 1980;7(1):76-93.

37. Brantigan JW, Steffee AD, Lewis ML, Quinn LM, Persenaire JM. Lumbar interbody fusion using the Brantigan I/F cage for posterior lumbar interbody fusion and the variable pedicle screw placement system: two-year results from a Food and Drug Administration investigational device exemption clinical trial. Spine (Phila Pa 1976). 2000;25(11):1437-1446. doi:10.1097/00007632-200006010-00017.

38. Ani N, Keppler L, Biscup R, Steffee AD. Reduction of High-Grade Slips (Grades III-V) with VSP Instrumentation. Spine (Phila Pa 1976). 1991;16(Supplement):S302-S310.

39. Steffee AD, Sitkowski DJ. Posterior lumbar interbody fusion and plates. Clin Orthop Relat Res. 1988;227(6):99102.

40. Steffee AD, Biscup RS, Sitkowski DJ. Segmental Spine Plates with Pedicle Screw Fixation. Clin Orthop Relat Res. 1986:45-53.

41. Suk SI, Lee CK, Kim WJ, Lee JH, Cho KJ, Kim HG. Adding posterior lumbar interbody fusion to pedicle screw fixation and posterolateral fusion after decompression in spondylolytic spondylolisthesis. Spine (Phila Pa 1976). 1997;22(2):210-9-20.

42. Harms JG, Jeszenszky D. Die posteriore, lumbale, interkorporelle Fusion in unilateraler transforaminaler Technik. Oper Orthop Traumatol. 1998;10(2):90-102. doi:10.1007/s00064-006-0112-7.

43. Blume H, Rojas C. Unilateral lumbar interbody fusion (posterior approach) utilizing dowel graft.J Neuro/ Orthop Surg. $1981 ;(2): 171-175$.

44. Cole CD, McCall TD, Schmidt MH, Dailey AT. Comparison of low back fusion techniques: Transforaminal lumbar interbody fusion (TLIF) or posterior lumbar interbody fusion (PLIF) approaches. Curr Rev Musculoskelet Med. 2009;2(2):118-126. doi:10.1007/s12178-009-9053-8.

45. Harms J, Rolinger H. A one-stager procedure in operative treatment of spondylolistheses: dorsal traction-reposition and anterior fusion. Z Orthop Ihre Grenzgeb. 1981;120(3):343-347. doi:10.1055/s-2008-1051624.

46. Chen S-H, Mo Lin R, Chen H-H, Tsai K-J. Biomechanical effects of polyaxial pedicle screw fixation on the lumbosacral segments with an anterior interbody cage support. BMC Musculoskelet Disord. 2007;8(1):28. doi:10.1186/1471-2474-8-28.

47. Conley K. Stud: Adventures in Breeding. Bloomsbury Publishing; 2003.

48. Obituary. Dr. George William BAGBY II (1923 - 2016). http://www.legacy.com/obituaries/spokesman/obituary. aspx?pid=183113101. Published 2016.

49. Brantigan JW, Cunningham BW, Warden K, McAfee PC, Steffee AD. Compression strength of donor bone for posterior lumbar interbody fusion. Spine (Phila Pa 1976). 1993;18(9):1213-1221.

50. Bagby GW. Arthrodesis by the distraction-compression method using a stainless steel implant. Orthopedics. 1988;11(6):931-934. 
51. DeBowes RM, Grant BD, Bagby GW, Gallina AM, Sande RD, Ratzlaff MH. Cervical vertebral interbody fusion in the horse: a comparative study of bovine xenografts and autografts supported by stainless steel baskets. Am J Vet Res. 1984;45(1):191-199.

52. Otero JM. Anterior cervical interbody fusion with threaded cylindrical bone. J Neurosurg. 1985;63:750-753.

53. Crawley GR, Grant BD, White KK, Barbee DD, Gallina AM, Ratzlaff MH. A modified Cloward's technique for arthrodesis of the normal metacarpophalangeal joint in the horse. Vet Surg. 1988;17(3):117-127.

54. Kuslich SD, Ulstrom CL, Griffith SL, Ahern JW, Dowdle JD. The Bagby and Kuslich Method of Lumbar Interbody Fusion: History, Techniques, and 2-Year Follow-up Results of a United States Prospective, Multicenter Trial. Spine (Phila Pa 1976). 1998;23(11):1267-1279.

55. Ray CD. Threaded titanium cages for lumbar interbody fusions. Spine (Phila Pa 1976). 1997;22(6):667-79-80.

56. Williams D, McNamara A, Turner R. Potential of polyetheretherketone (PEEK) and carbon fibre reinforced peek in medical applications. J Mater. 1987;18(3):267. doi:10.1016/0010-4361(87)90474-5.

57. Kurtz SM, Devine JN. PEEK biomaterials in trauma, orthopedic, and spinal implants. Biomaterials. 2007;28(32):4845-4869. doi:10.1016/j.biomaterials.2007.07.013.

58. Carragee EJ, Ghanayem AJ, Weiner BK, Rothman DJ, Bono CM. A challenge to integrity in spine publications: Years of living dangerously with the promotion of bone growth factors. Spine J. 2011;11(6):463-468. doi:10.1016/j.spinee.2011.06.001.

59. Hart RA. Acknowledging the elephant in the room: Conflict of interest in industry-sponsored clinical research. Spine J. 2011;11(8):703-704. doi:10.1016/j.spinee.2011.08.011.

60. Gittens RA, Olivares-Navarrete R, Schwartz Z, Boyan BD. Implant osseointegration and the role of microroughness and nanostructures: Lessons for spine implants. Acta Biomater. 2014;10(8):3363-3371. doi:10.1016/j. actbio.2014.03.037.

61. Olivares-Navarrete R, Hyzy SL, Berg ME, et al. Osteoblast Lineage Cells Can Discriminate Microscale Topographic Features on Titanium-Aluminum-Vanadium Surfaces. Ann Biomed Eng. 2014;42(12):2551-2561. doi:10.1007/s10439-014-1108-3.

62. Gupta A, Kukkar N, Sharif K, Main BJ, Albers CE, El-Amin lii SF. Bone graft substitutes for spine fusion: A brief review. World J Orthop. 2015;6(6):449-456. doi:10.5312/wjo.v6.i6.449.

63. D’Ambrosia RD. Precision Medicine: A New Frontier in Spine Surgery. Orthopedics. 2016;39(2):75-76. doi:10.3928/01477447-20160304-03.

64. Deyo RA, Nachemson A, Mirza SK. Spinal-Fusion Surgery - The Case for Restraint. N Eng/J Med. 2004;350(7):722726. doi:10.1056/NEJMsb031771.

65. Malhotra D, Kalb S, Rodriguez-Martinez N, et al. Instrumentation of the posterior thoracolumbar spine: From wires to pedicle screws. Neurosurgery. 2014;10(4):497-505. doi:10.1227/NEU.0000000000000489.

66. Försth P, Ólafsson G, Carlsson T, et al. A Randomized, Controlled Trial of Fusion Surgery for Lumbar Spinal Stenosis. N Eng/J Med. 2016;374(15):1413-1423. doi:10.1056/NEJMoa1513721.

67. Ghogawala Z, Dziura J, Butler WE, et al. Laminectomy plus Fusion versus Laminectomy Alone for Lumbar Spondylolisthesis. N Eng/ J Med. 2016;374(15):1424-1434. doi:10.1056/NEJMoa1508788. 



\section{Chapter 3}

\section{Transforaminal lumbar interbody fusion (TLIF) versus posterior lumbar interbody fusion (PLIF) in lumbar spondylolisthesis, a systematic review and meta-analysis}

SL de Kunder, SMJ van Kuijk, K Rijkers, IJMH Caelers, WLW van Hemert, RA de Bie and $\mathrm{H}$ van Santbrink 


\section{ABSTRACT}

\section{Background context}

Transforaminal lumbar interbody fusion (TLIF) and posterior lumbar interbody fusion (PLIF) are both frequently used as a surgical treatment for lumbar spondylolisthesis. Because of the unilateral transforaminal route to the intervertebral space used in TLIF, as opposed to the bilateral route used in PLIF, TLIF could be associated with fewer complications, shorter duration of surgery, and less blood loss, whereas the effectiveness of both techniques on back or leg pain is equal.

\section{Purpose}

The objective of this study was to compare the effectiveness of both TLIF and PLIF in reducing disability, and to compare the intra- and postoperative complications of both techniques in patients with lumbar spondylolisthesis.

\section{Study design/setting}

A systematic literature review and meta-analysis were carried out.

\section{Methods}

We conducted a Medline (using PubMed), Embase (using Ovid), Cochrane Library, Current Controlled Trials, ClinicalTrials.gov and NHS Centre for Review and Dissemination search for studies reporting TLIF, PLIF, lumbar spondylolisthesis and disability, pain, complications, duration of surgery, and estimated blood loss. A meta-analysis was performed to compute pooled estimates of the differences between TLIF and PLIF. Forest plots were constructed for each analysis group.

\section{Results}

A total of 192 studies were identified; nine studies were included (one randomized controlled trial and eight case series), including 990 patients (450 TLIF and 540 PLIF). The pooled mean difference in postoperative Oswestry Disability Index (ODI) scores between TLIF and PLIF was -3.46 (95\% confidence interval [CI] -4.72 to $-2.20, \mathrm{p} \leq .001$ ). The pooled mean difference in the postoperative VAS scores was $-0.05(95 \% \mathrm{Cl}-0.18$ to $0.09, p=0.480$ ). The overall complication rate was $8.7 \%$ (range $0 \%-25 \%$ ) for TLIF and 17.0\% (range 4.7-28.8\%) for PLIF; the pooled odds ratio was 0.47 (95\% Cl 0.28-0.81, p $=0.006$ ). The average duration of surgery was 169 minutes for TLIF and 190 minutes for PLIF (mean difference $-20.1,95 \% \mathrm{Cl}-33.5$ to $-6.6, \mathrm{p}=0.003$ ). The estimated blood loss was $350 \mathrm{~mL}$ for TLIF and $418 \mathrm{~mL}$ for PLIF (mean difference $-43.9 \mathrm{~mL}, 95 \% \mathrm{Cl}-71.2$ to $-16.6, p=0.002$ ). 


\section{Conclusions}

TLIF has advantages over PLIF in the complication rate, blood loss, and operation duration. The clinical outcome is similar, with a slightly lower postoperative ODI score for TLIF. 


\section{INTRODUCTION}

Lumbar spondylolisthesis describes a forward displacement of a lumbar vertebra. The most common types are degenerative or isthmic lumbar spondylolisthesis. Symptoms of lumbar spondylolisthesis may include intermittent neurogenic claudication, lumbar radiculopathy, and back pain. The primary treatment for lumbar spondylolisthesis is medical interventional with physical therapy, motion restriction (by means of a lumbar brace), or analgesics. When unsuccessful, or in case of clinical deterioration of neurologic deficits, surgery can be considered to decompress neural structures and to stabilize the spine.

Several surgical techniques are available and debate remains whether additional instrumentation is required ${ }^{1,2}$. Instrumentation consists of pedicle-screw fixation, interbody cages, or a combination of both. In case of spinal interbody fusion in addition to decompression and pedicle-screw fixation, two widely used techniques for spinal fusion are posterior lumbar interbody fusion (PLIF) and transforaminal lumbar interbody fusion (TLIF). The PLIF technique for instrumented spinal fusion was introduced more than a half century ago in 1952 by Cloward. The first attempt for TLIF was by Harms and Rolinger, who reported on the use of bone graft packed in titanium mesh that was inserted via an unilateral transforaminal route into the anterior part of the disc space. Harms and Blume developed the TLIF technique further, and Harms described this in detail together with Jeszensky in $1998^{3-6}$. Currently, both techniques are used for the treatment of lumbar spondylolisthesis, albeit modified with the development and introduction of newer implants.

The TLIF procedure was developed to reduce the risks associated with a PLIF procedure 7,8. For TLIF, a unilateral transforaminal route to the intervertebral space was used, with a unilateral facetectomy and insertion of one cage. For PLIF, a bilateral approach was used to insert a cage at each side in the intervertebral space. For both techniques, additional pedicle-screw fixation was used ${ }^{7}$. We postulated that the unilateral approach used in TLIF could result in a lower a priori chance of damaging the back muscles and the thecal sac: first, because of less chance of damaging the nerve root during decompression, because for PLIF, two nerve roots need to be exposed, whereas for TLIF, only one nerve root is exposed; second, because of less traction on this nerve root as a result of the more lateral approach for TLIF; and third, because in TLIF, the cage passes only one nerve root, whereas in PLIF, the cage passes two nerve roots. Therefore, the TLIF technique could be associated with fewer complications, shorter duration of surgery, and less blood loss than the PLIF technique, whereas the effectiveness of both techniques on back or leg pain is equal ${ }^{9-12}$. We performed a systematic review of the literature and 
a meta-analysis on the effectiveness of both procedures in reducing disability to verify this hypothesis and to compare the intra- and postoperative complications in patients with lumbar spondylolisthesis. 


\section{METHODS}

\section{Research protocol}

This systematic review was executed in accordance with the PRISMA statement, with the use of a review protocol that consisted of a research question, a search strategy, and eligibility criteria for assessing full-text articles ${ }^{13,14}$. The research question was formulated as follows:

Is transforaminal lumbar interbody fusion (TLIF) in adults with back and/or leg complaints as a result of lumbar spondylolisthesis, more effective than posterior lumbar interbody fusion (PLIF) with respect to reduction of disability and intra- and postoperative complications?

\section{Search strategy and eligibility criteria}

To identify all studies addressing TLIF and PLIF in lumbar spondylolisthesis, we performed a comprehensive systematic literature search of the following databases: Medline (using PubMed), Embase (using Ovid), Cochrane Library, Current Controlled Trials, ClinicalTrials. gov, and NHS Centre for Review and Dissemination. We used Medline and Embase as our primary data sources. The other databases were searched to find additional literature. We included full-text studies written in the English, Dutch, or German language. No other restrictions were used. Our last search was conducted on September 4, 2016. Detailed search strategies can be found in Appendix 1.

Articles were included if they met all of the following eligibility criteria: (1) the patients were adults (aged 18 years or older), (2) the patients underwent TLIF and PLIF, (3) the patients had lumbar spondylolisthesis, and (4) the outcome was disability and pain or complications, and duration of surgery and blood loss.

\section{Study selection and data collection process}

Selection of articles that potentially met the eligibility criteria was performed in a standardized manner by one author (SdK). First, duplicate records were deleted. Second, the articles were analyzed by the screening title and the abstract. Third, after screening, full texts were reviewed on the eligibility criteria by two authors (SdK and IC). For final inclusion, all eligibility criteria had to be fulfilled.

The data from the included studies were independently extracted by two authors (SdK and IC) in a predesigned data abstraction sheet. The following data items were considered: study design (author, year, country, prospective or retrospective study); study population (number of included patients, age, and indication for surgery); patient-related outcome measurements (PROMs) considering disability (Oswestry Disability Index [ODI] scores and 
visual analog scale [VAS] pain scores); and parameters concerning intra- and postoperative complications (complications, estimated blood loss, and duration of surgery). If necessary, consensus was reached by both authors through discussion.

For the meta-analysis, we included available results on the ODI scores, the (average) VAS scores, complications, the estimated blood loss, and the operation duration from all eligible studies.

\section{Risk of bias and quality of study}

We assessed the risk of bias with the bias assessment tool of the Cochrane Handbook for Systematic Reviews of Interventions. Two authors (SdK and IC) independently evaluated the selected studies based on six different domains and scored the criteria with "low" or "high" risk of bias, or "unclear" 15.

Levels of evidence were determined for all studies with the Oxford Centre for Evidence-based Medicine-Levels of Evidence (2011) ${ }^{16}$.

\section{Statistical analysis}

We computed the pooled estimates of differences between TLIF and PLIF with respect to ODI scores, VAS pain scores, the proportion of complications, the estimated blood loss, and the duration of surgery. Because of the perceived heterogeneity in the study designs and outcome definitions, we used random-effects models for the meta-analyses because these do not assume a common effect size. Within all outcome variables, the results of different studies were transformed to a similar scale if necessary, and a common measure of precision was computed. If a measure of precision could not be determined from the original manuscript, it was imputed using the mean of all studies that did report such measure.

We used the Egger's test to test for the asymmetry of the funnel plots for each outcome to assess publication bias.

Because the power of this test is low if only a small number of studies are included, we visually inspected the funnel plots in addition to testing. In case of sufficient evidence of funnel plot asymmetry (ie, evidence of publication bias), we compared our results with those after using the trim-and-fill method as a sensitivity analysis to assess their robustness. The trim- and fill method is a non-parametric method to test for the presence of publication bias ${ }^{17}$. All meta-analyses were performed in R version 3.2.3 (R Foundation for Statistical Computing, Vienna, Austria) using the metafor package ${ }^{18}$. 


\section{RESULTS}

\section{Study selection}

The results of the study selection are summarized in a flowchart (figure 1). Database searching resulted in the identification of 204 studies, and one study was obtained from a personal archive. After the removal of duplicates (12 in total), 192 studies were screened on the title and the abstract. A total of 179 studies were excluded, and 13 studies remained for fulltext review. After the full-text review, four studies were excluded. Studies were excluded for the following reasons: in two studies, a mixed cohort TLIF-PLIF was compared with other techniques, and a comparison between TLIF and PLIF could not be made 19,20. Two studies were excluded because the indications for surgery were very broad (besides spondylolisthesis and lumbar instability, spinal stenosis, and facet arthropathy) and no subgroup analyses were performed ${ }^{21,22}$. Nine studies were included, of which one was a prospective study and eight were retrospective studies (table 1) 11,12,23-29. There was no discussion on any of the inclusions between reviewers.

\section{Study characteristics}

One out of nine studies was a prospective randomized controlled trial. Publication years ranged from 2005 to 2016. The majority of the studies were performed in Asian hospitals. All studies specified the indication as lumbar spondylolisthesis. To objectify disability, ODI scores were measured in three studies. Pain was measured with the use of a VAS in each study. Five studies reported data on pre- and postoperative pain. All studies reported on the complication rate and specified the kind and the number of complications. The duration of surgery was reported in six studies, and the estimated blood loss was reported in five studies.

\section{Risk of bias and quality of study}

All included studies had an overall high risk of bias. Selection bias was high in all but Yang et al.'s study, because of the retrospective nature ${ }^{29}$. There was a high risk of performance bias because there was no blinding of patients or personnel in any of the studies. Attrition bias was high in all studies, because loss as a result of follow-up or other excluding factors contributing to attrition bias were notmentioned. Additionally, potential funding bias was found in one study. There was no disclosure about funding sources in five studies. Only for the comparison of blood loss the presence of publication bias seemed likely, the Eggers test was significant ( $p=0.010)$, and the funnel plot showed a clear asymmetry, indicating that publication could be present. The results after the trim-and-fill method did not change the conclusion (mean difference -33.59 , 95\% confidence interval [Cl] -66.3 to $-0.9, p=0.043)$. 
All studies were of level 4 evidence, except for the study of Yang et al., which was scored a level $2 \mathrm{~A}^{29}$.

\section{Results of studies}

In total, 990 adult patients (450 TLIF and 540 PLIF) were included, with an average age of 52.5 years old (standard deviation 6.3 years) at the time of surgery. To objectify disability, the ODI scores were used in three studies. Preoperative ODI scores ranged from 49.6 to 67.5 in TLIF and from 47.9 to 68.08 in PLIF. Postoperative ODI scores were generally lower, ranging from 7.46 to 24.5 in TLIF and from 11.25 to 25.15 in PLIF. This decrease in ODI scores was significantly larger in patients who underwent TLIF (pooled mean difference in postoperative ODI score was -3.46 points lower in patients who underwent TLIF; $95 \% \mathrm{Cl}$ -4.72 to $-2.20, p \leq .001$ ) (figure 2). In five studies, there were data on pre- and postoperative pain. The preoperative VAS scores ranged from 4.72 to 7.18 in TLIF and from 4.88 to 7.12 in PLIF. The postoperative VAS scores ranged from 1.33 to 2.84 in TLIF and from 1.26 to 2.84 in PLIF. The pooled mean difference in postoperative VAS scores was $-0.05(95 \% \mathrm{Cl}$ -0.18 to $0.09, p=0.480$ ) (figure 3 ).

Complications were reported in all nine studies. The average complication rate was $8.7 \%$ (range 0\%-25.0\%) for TLIF and 17.0\% (range 4.7-28.8\%) for PLIF, using data of 990 patients with spondylolisthesis (TLIF, n=450; PLIF, n=540). All complications occurred more frequently in the PLIF group (table 2). A pooled odds ratio for complications was 0.47 (95\% $\mathrm{Cl} 0.28-0.81, \mathrm{p}=0.006$ ) (figure 4 indicating a significantly lower complication rate for TLIF. Detailed results of the complications can be found in table 2 .

The duration of the surgery was reported in six studies (N=680; TLIF, n=296; PLIF, n=384). The average duration of surgery was 169 minutes for TLIF and 190 minutes for PLIF (mean difference $-20.1,95 \% \mathrm{Cl}-33.5$ to $-6.6, \mathrm{p}=0.003$ ) (figure 5).

The estimated blood loss was reported in five studies ( $N=552 ;$ TLIF, $n=267 ;$ PLIF, $n=285$ ), with the average blood loss being $350 \mathrm{~mL}$ for TLIF and $418 \mathrm{~mL}$ for PLIF (mean difference $-43.9 \mathrm{~mL}, 95 \% \mathrm{Cl}-71.2$ to $-16.6, \mathrm{p}=0.002$ ) (figure 6).

The results of the one available prospective, randomized controlled trial are reported separately: Yang et al. reported on 66 patients (32 TLIF and 34 PLIF) with isthmic spondyIolisthesis ${ }^{29}$. Patients had a mean age of 43 years. Disability was measured with the ODI. A reduction in disability was reported; pre- and postoperative ODI scores were 49.6 \pm 14.3

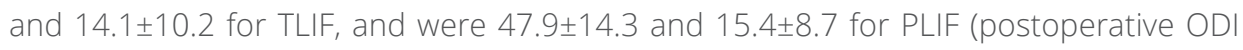
difference $-1.30,95 \% \mathrm{Cl}-5.89$ to 3.29) (all were not significant). Also pain reduction (VAS pain) was described for both groups: from $4.72 \pm 1.96$ preoperatively to $1.33 \pm 0.89$ postop- 
eratively for TLIF and $4.88 \pm 1.77$ to $1.26 \pm 0.76$ for PLIF (postoperative VAS difference 0.07, $95 \% \mathrm{Cl}-0.33$ to 0.47 ) (all were not significant). The Duration of surgery was 113.2 minutes for TLIF and 124.8 for PLIF $(-11.6,95 \% \mathrm{Cl}-29.5$ to 6.3, $\mathrm{p}=0.008)$. Blood loss was 432.5 $\mathrm{mL}$ for TLIF and $521.3 \mathrm{~mL}$ for PLIF $(-88.8,95 \% \mathrm{Cl}-184.9$ to $7.3, \mathrm{p}=0.043)$. A complication rate of $9.4 \%$ for patients who underwent TLIF and $11.8 \%$ for patients who underwent PLIF (odds ratio 0.78, 95\% Cl 0.16-3.77, p = unknown) was reported. 


\section{DISCUSSION}

In this systematic review and meta-analysis, we compared the effectiveness of TLIF and PLIF in reducing disability and pain in patients with lumbar spondylolisthesis, and evaluated intra- and postoperative complications, the duration of surgery, and blood loss between the two techniques.

\section{Summary of evidence}

The clinical outcomes of TLIF and PLIF were expected to be similar, because the main goal of interbody fusion surgery for spondylolisthesis was to decompress neural structures and to stabilize the spine. The change in ODI scores was 3.46 points larger for TLIF. Even though this difference is statistically significant, it is not clinically relevant, because to be clinically important, the change in ODI score needs to be at least seven points ${ }^{30}$. The found difference can be explained by a greater preservation of musculature of the lumbar spine by the unilateral approach of TLIF. It can quicken and improve the patient's recovery and hereby reduce postoperative disability, as measured with ODI ${ }^{10}$. The VAS scores showed no difference in clinical outcome.

The VAS scores showed no difference in clinical outcome.

The complication rate of TLIF was 50\% lower compared with PLIF. This significant difference was not only the case for surgery-related complications as infections, nerve root damage, and dural tears, but also for hardware problems and other complications. Severe complications as iatrogenic nerve root dysfunction were more often described for PLIF. The significant difference in the complication rate can be explained by the higher a priori chance because of a bilateral instead of a unilateral approach, although in the case of TLIF the resection of bony structures is more extensive compared with PLIF. Because of the less extensive resection of bony structures, there is possibly a larger chance on traction on the nerve root when inserting the cages for PLIF compared with TLIF ${ }^{8}$. In the case of TLIF, there is a more extensive resection of bony components resulting in more room to insert the cage, so nerve root damage and dural tearing are less likely. Less hardware problems in TLIF could be the result of a more equal distribution of the axial load of the spinal column and the preservation of the facet joint in TLIF compared with PLIF, as a result of the shape and the placement of the cage and the technique ${ }^{7,31}$.

Also for the duration of the surgery and the estimated blood loss, overall, we found TLIF to be superior compared with PLIF. 


\section{Limitations}

We initially planned to produce a review with only prospective studies. However, exploration of the literature indicated a limited availability of prospective studies. We decided to include case-control studies and case series as well. This resulted in nine studies reporting on both TLIF and PLIF in lumbar spondylolisthesis: one prospective study and eight retrospective studies. All studies had an overall high risk of bias and most were of level 4 evidence. The retrospective nature of most studies was an important contributing factor.

The majority of the included studies were of Asian origin. In the Asian practice, the indication of TLIF and PLIF seems restricted to lumbar spondylolisthesis, whereas in Europe and in the United States, the indication has broadened to back pain, degenerative disc disease, and spinal stenosis ${ }^{32}$. For this review, only studies with patients with lumbar spondylolisthesis were included. Patients with other indications, or whenever the indications were unknown, were excluded. However, also for other indications, TLIF and PLIF could be interchangeable; in case of bilateral foraminal compression, one can still choose unilateral foraminal compression, by resection of the unilateral facet joint, and insertion of a TLIF cage, and relay on indirect decompression for the contralateral side, because of the reduction and the stabilization of the spondylolisthesis and the increase in the disc height. TLIF or PLIF could serve as true alternative techniques.

Few studies reported on different PROMs. The measurement instruments varied from a pain score to an extensive 36-Item Short Form Health Survey (SF-36). Disability, measured with ODI, being our main outcome parameter, was reported in three studies only. The pooled mean difference in postoperative ODI scores between TLIF and PLIF was not a clinical important difference. VAS was also sparsely reported and not specified specifically for leg or back pain. Two studies reported the equal results for pre- and postoperative VAS scores. However remarkable, the editor of the concerning journal assured us the data were correct and original. Overall clinical outcome is reported similar in other case series 9-11,33. With such limited available data, solid conclusions on differences in PROMs for TLIF and PLIF cannot be drawn.

Complications were described in nine studies. There was a great variation in reporting complications: sometimes only major complications (eg, permanent neurologic injury) were reported. Early and late complications were described separately, or complications of permanent and passing nature. Because of the variability, it was difficult to compare complication rates. We therefore reported the overall complication rate, and the kind and number of complications (table 2). The overall complication rate described in TLIF was lower compared with that in PLIF. This finding is similar to other reports ${ }^{21,34}$. However, we suspect an underreporting of the number of infections. In a few studies, infections were 
only described whenever patients needed a reoperation. Superficial wound infections were sparsely described. In this review, pooled results of infections showed: 1.7\% for TLIF and 3.0\% for PLIF, considered lower than other case series. In the literature, the overall infection rate has been described from $0 \%$ to $9 \%$, with peaks at 37.5\% 22,34-37.

The duration of surgery was superior for TLIF over PLIF, as expected. Because a duration of surgery over 3 hours is associated with higher infection risks, the duration of surgery could be considered an important influencing factor for the development of complications, especially infections ${ }^{38,39}$. Of note, a minor difference in surgical techniques and used materials could also result in different complication numbers, durations of surgery, and blood loss. The extent of the resection and the resulting damage to the musculature of the lumbar spine and the number of surgeons working simultaneously on one patient were not included in the evaluation, but could influence the outcome. 


\section{CONCLUSIONS AND RECOMMENDATIONS FOR FUTURE RESEARCH}

This article is the first systematic review and meta-analysis comparing TLIF and PLIF. Although the level of evidence is limited, mostly because of the retrospective nature of the included articles, a few recommendations based on the results of this review can be made.

Both TLIF and PLIF procedures are techniques frequently used for the surgical treatment of lumbar spondylolisthesis. Nowadays, the choice of technique is still greatly based on the surgeons' preference and experience. Evidence of the superiority of one technique over the other is sparse. In this review, we showed that TLIF has advantages over PLIF in complication rate, blood loss, and operation duration in case of lumbar spondylolisthesis. Clinical outcome seems to be similar, with a slightly lower postoperative ODI score for TLIF. Quality of life reports with validated instruments as ODI, SF-36, or EQ-5D should be a standard part of treatment to enable physicians to objectify the clinical results. Complication reports should be detailed and more extensive to obtain a more realistic complication rate. More randomized controlled trials are needed to obtain a higher level of evidence. With the increasing demand for spinal surgery and the increasing use of interbody fusion for additional indications (back pain and disc herniation), and the ever-rising health-care costs, information from these trials is needed. In this perspective, a randomized controlled trial is planned to compare TLIF and PLIF for cost-effectiveness, complication rate, and clinical result, for patients with a single-level spondylolisthesis, with either a bilateral or a unilateral compression of neurologic structures ${ }^{40}$. 


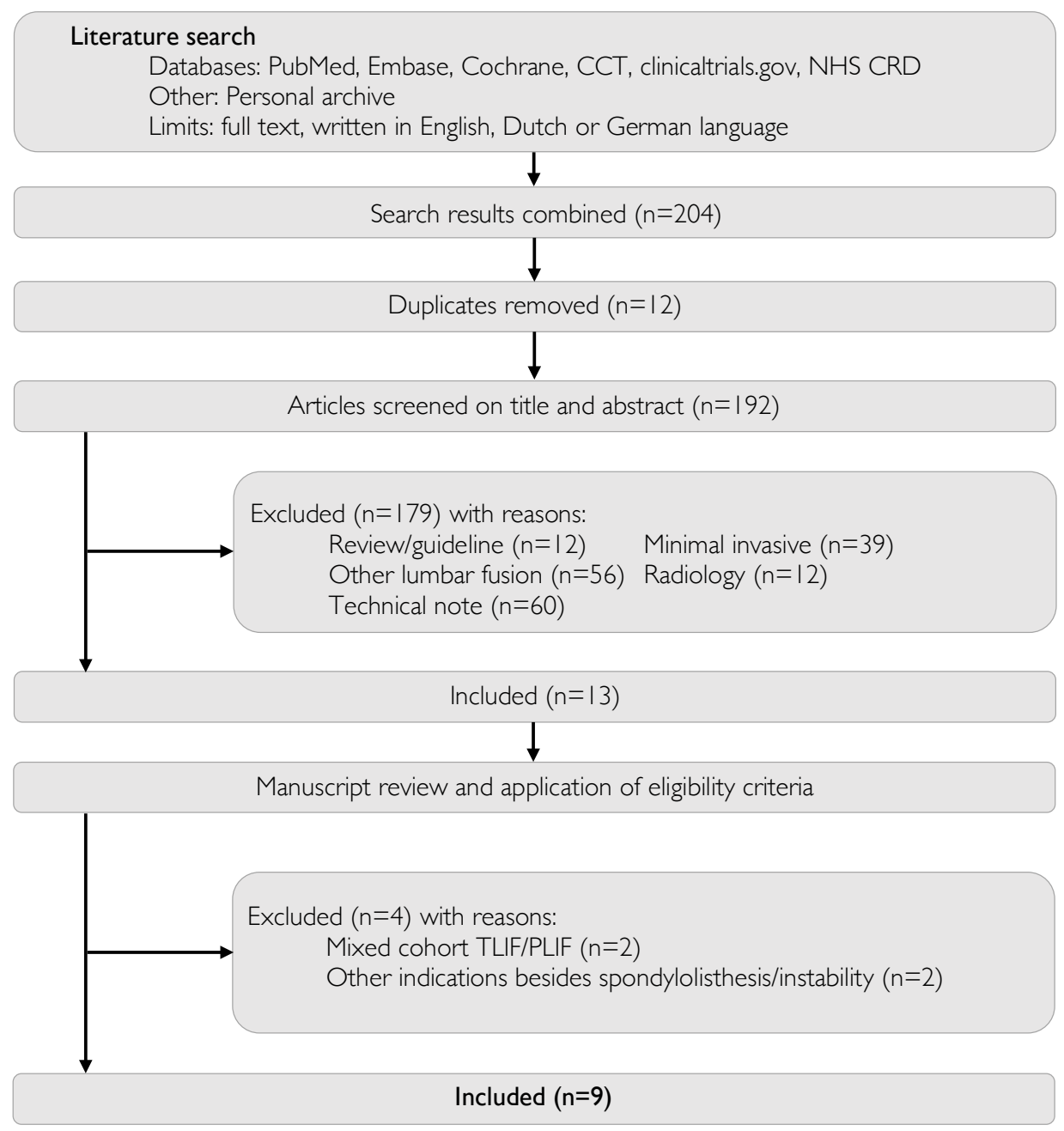

Figure 1: Flowchart of study selection 


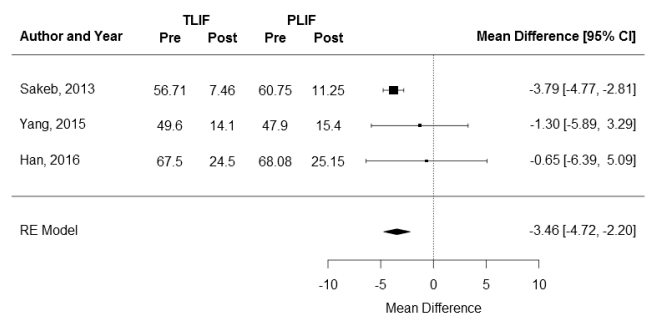

Figure 2: Pre-and postoperative ODI scores in TLIF and PLIF, pooled results of postoperative ODI scores

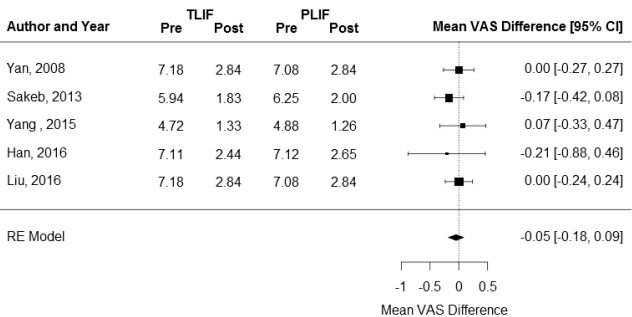

Figure 3: Pre-and postoperative VAS scores in TLIF and PLIF, pooled results of postoperative VAS scores

\begin{tabular}{|c|c|c|c|c|c|c|}
\hline Author and Year & $\begin{array}{l}\text { TLI } \\
\text { comp }\end{array}$ & & $\begin{array}{c}\text { PLI } \\
\text { comp }\end{array}$ & & & Odds Ratio $[95 \% \mathrm{Cl}]$ \\
\hline Park, 2005 & 0 & 29 & 9 & 99 & 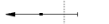 & $0.16[0.01,2.86]$ \\
\hline Yan, 2008 & 3 & 91 & 4 & 85 & $\bullet$ & $0.69[0.15,3.18]$ \\
\hline Sakeb, 2013 & 3 & 50 & 15 & 52 & $\because$ & $0.16[0.04,0.58]$ \\
\hline Yang, 2015 & 3 & 32 & 4 & 34 & 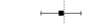 & $0.78[0.16,3.77]$ \\
\hline Fariborz, 2016 & 2 & 30 & 2 & 30 & $\longmapsto$ & $1.00[0.13,7.60]$ \\
\hline Han, 2016 & 1 & 36 & 3 & 26 & $\cdot$ & $0.22[0.02,2.24]$ \\
\hline de Kunder, 2016 & 12 & 48 & 11 & 48 & -1 & $1.12[0.44,2.86]$ \\
\hline Asil, 2016 & 4 & 33 & 8 & 41 & 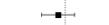 & $0.57[0.16,2.09]$ \\
\hline Liu, 2016 & 11 & 101 & 36 & 125 & + & $0.30[0.14,0.63]$ \\
\hline \multirow[t]{3}{*}{ RE Model } & & & & & - & $0.47[0.28,0.81]$ \\
\hline & & & & & $1 \quad 1$ & \\
\hline & & & & & $\begin{array}{lll}.01 & 1 & 10\end{array}$ & \\
\hline
\end{tabular}

Figure 4: Outcome of complications in TLIF and PLIF 


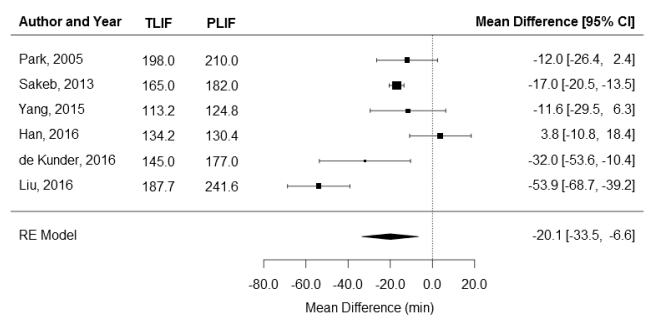

Figure 5: Outcome of duration of surgery in TLIF and PLIF

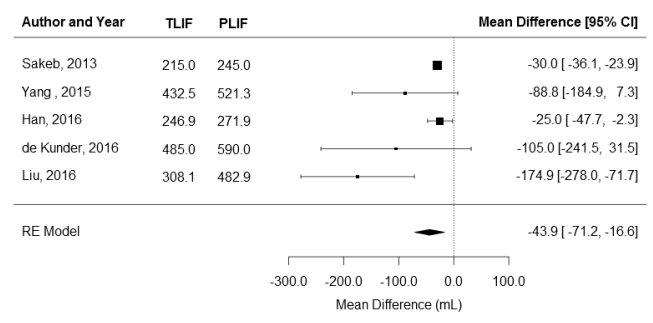

Figure 6: Outcome of estimated blood loss (in milliliter) in TLIF and PLIF 
Table 1: Study characteristics

\begin{tabular}{llll}
\hline Author & Country & Design & Date collection \\
\hline & & & \\
\hline Park et al (2005) & Korea & Case series & Retrospective \\
Yan et al (2008) & China & Case series & Retrospective \\
Sakeb et al (2013) & Bangladesh & Case series & Retrospective \\
Yang et al (2016) & China & Randomized controlled trial & Prospective \\
Liu et al (2016) & China & Case series & Retrospective \\
Fariborz et al (2016) & Iran & Case series & Retrospective \\
Han et al (2016) & China & Case series & Retrospective \\
de Kunder et al (2016) & the Netherlands & Case series & Retrospective \\
Asil et al (2016) & Turkey & Case series & Retrospective \\
\hline
\end{tabular}

Table 2: Complications

\begin{tabular}{|c|c|c|c|c|c|}
\hline \multirow[t]{2}{*}{ Author } & \multirow[t]{2}{*}{ Country } & \multicolumn{2}{|c|}{ Number of patients } & \multicolumn{2}{|c|}{ Complications } \\
\hline & & TLIF & PLIF & TLIF & PLIF \\
\hline Park et al (2005) & Korea & 29 & 99 & 0 & 9 \\
\hline Yan et al (2008) & China & 91 & 85 & 3 & 4 \\
\hline Sakeb et al (2013) & Bangladesh & 50 & 52 & 3 & 15 \\
\hline Yang et al (2016) & China & 32 & 34 & 3 & 4 \\
\hline Liu et al (2016) & China & 101 & 125 & 11 & 36 \\
\hline Fariborz et al (2016) & Iran & 30 & 30 & 2 & 2 \\
\hline Han et al (2016) & China & 36 & 26 & 1 & 3 \\
\hline de Kunder et al (2016) & the Netherlands & 48 & 48 & 12 & 11 \\
\hline \multirow[t]{2}{*}{ Asil et al (2016) } & Turkey & 33 & 41 & 4 & 8 \\
\hline & & 450 & 540 & 39 & 92 \\
\hline
\end{tabular}




\begin{tabular}{|c|c|c|c|c|c|}
\hline \multicolumn{3}{|c|}{ Number of patients } & \multirow[t]{2}{*}{ Mean age (in year) (SD) } & \multirow[t]{2}{*}{ Level of evidence } & \multirow[t]{2}{*}{ Risk of bias } \\
\hline & TLIF & PLIF & & & \\
\hline 128 & 29 & 99 & 56 & 4 & High \\
\hline 187 & 91 & 85 & 58 & 4 & High \\
\hline 102 & 50 & 52 & 48 & 4 & High \\
\hline 66 & 32 & 34 & 43 & $2 \mathrm{~B}$ & High \\
\hline 226 & 101 & 125 & 55 & 4 & High \\
\hline 60 & 30 & 30 & 35 & 4 & High \\
\hline 62 & 36 & 26 & 58 & 4 & High \\
\hline 96 & 48 & 48 & 48 & 4 & High \\
\hline 74 & 33 & 41 & 55 & 4 & High \\
\hline 990 & 450 & 540 & 52.5 (SD 6.3) & & \\
\hline
\end{tabular}

$\% \quad$ infections Nerve root

$\begin{array}{llll}\begin{array}{c}\text { Nerve root } \\ \text { damage }\end{array} & \text { Dural tear } & \begin{array}{l}\text { Hardware } \\ \text { problems }\end{array} & \text { Other }\end{array}$

\begin{tabular}{cccccccccccc} 
TLIF & PLIF & TLIF & PLIF & TLIF & PLIF & TLIF & PLIF & TLIF & PLIF & TLIF & PLIF \\
\hline $0.0 \%$ & $9.1 \%$ & 0 & 0 & 0 & 4 & 0 & 0 & 0 & 2 & 0 & 3 \\
$3.3 \%$ & $4.7 \%$ & 0 & 0 & 2 & 3 & 0 & 0 & 1 & 1 & 0 & 0 \\
$6.0 \%$ & $28.8 \%$ & 0 & 2 & 0 & 3 & 0 & 4 & 1 & 1 & 2 & 5 \\
$9.4 \%$ & $11.8 \%$ & 1 & 1 & 0 & 2 & 2 & 1 & 0 & 0 & 0 & 0 \\
$10.9 \%$ & $28.8 \%$ & 5 & 9 & 2 & 12 & 4 & 15 & 0 & 0 & 0 & 0 \\
$6.7 \%$ & $6.7 \%$ & 0 & 0 & 1 & 0 & 1 & 2 & 0 & 0 & 0 & 0 \\
$2.8 \%$ & $11.5 \%$ & 0 & 0 & 0 & 1 & 1 & 2 & 0 & 0 & 0 & 0 \\
$25.0 \%$ & $22.9 \%$ & 1 & 3 & 0 & 1 & 5 & 4 & 2 & 2 & 4 & 1 \\
$12.1 \%$ & $19.5 \%$ & NA & NA & 0 & 0 & 2 & 5 & 2 & 3 & 0 & 0 \\
\hline $\mathbf{8 . 7 \%}$ & $17.0 \%$ & $\mathbf{7}$ & $\mathbf{1 5}$ & $\mathbf{5}$ & $\mathbf{2 6}$ & $\mathbf{1 5}$ & $\mathbf{3 3}$ & $\mathbf{6}$ & $\mathbf{9}$ & $\mathbf{6}$ & $\mathbf{9}$ \\
\hline
\end{tabular}




\section{APPENDIX 1.}

\section{Search strategies:}

1. National library of medicine (Medline):

- Search: (((lumbar spondylolisthesis) OR lumbar instability) OR "Spondylolisthesis"[Mesh])) AND ((((TLIF) OR transforaminal lumbar interbody fusion)) AND ((PLIF) OR posterior lumbar interbody fusion))

- Filter: Language Restriction English, Dutch, German

- Hits: 118

2. Embase:

- Search: lumbar spondylolisthesis AND TLIF AND PLIF

- Filter: none

- Hits: 67

3. Cochrane Library: http://www.cochrane.org/

- Search: spondylolisthesis

- Filter: none

- Hits: 2

4. Current Controlled Trials (CCT): http://controlled-trials.com/

- Search: TLIF, PLIF

- Hit: 1

5. ClinicalTrials.gov: http://clinicaltrials.gov/

- Search: TLIF, PLIF

- Hits: 15

6. NHS Centre for Reviews and Dissemination (CRD): http://www.york.ac.uk/inst/crd/

- Search: TLIF, PLIF

- Hits: 0 


\section{REFERENCES}

1. Försth P, Ólafsson G, Carlsson T, et al. A Randomized, Controlled Trial of Fusion Surgery for Lumbar Spinal Stenosis. N Eng/J Med. 2016;374(15):1413-1423. doi:10.1056/NEJMoa1513721.

2

3

4.

5.

6.

7.

8.

9.

10

11.

Weinstein JN, Lurie JD, Tosteson TD, et al. Surgical compared with nonoperative treatment for lumbar degenerative spondylolisthesis. four-year results in the Spine Patient Outcomes Research Trial (SPORT) randomized and observational cohorts. J Bone Joint Surg Am. 2009;91(6):1295-1304. doi:10.2106/ JBJS.H.00913.

. Cloward RB. The treatment of ruptured lumbar intervertebral discs by vertebral body fusion. I. Indications, operative technique, after care. J Neurosurg. 1953;10(2):154-168. doi:10.3171/jns.1953.10.2.0154.

Harms J, Rolinger H. A one-stager procedure in operative treatment of spondylolistheses: dorsal traction-reposition and anterior fusion. Z Orthop Ihre Grenzgeb. 1981;120(3):343-347. doi:10.1055/s-2008-1051624. Harms JG, Jeszenszky D. Die posteriore, lumbale, interkorporelle Fusion in unilateraler transforaminaler Technik. Oper Orthop Traumatol. 1998;10(2):90-102. doi:10.1007/s00064-006-0112-7.

Blume H, Rojas C. Unilateral lumbar interbody fusion (posterior approach) utilizing dowel graft. J Neurol Orthop Surg. 1981;(2):171-175.

7. Cole CD, McCall TD, Schmidt MH, Dailey AT. Comparison of low back fusion techniques: Transforaminal lumbar interbody fusion (TLIF) or posterior lumbar interbody fusion (PLIF) approaches. Curr Rev Musculoskelet Med. 2009;2(2):118-126. doi:10.1007/s12178-009-9053-8.

Mura PP, Costaglioli M, Piredda M, Caboni S, Casula S. TLIF for symptomatic disc degeneration: A retrospective study of 100 patients. Eur Spine J. 2011;20(SUPPL. 1):57-60. doi:10.1007/s00586-011-1761-2.

Hee HT, Castro FP, Majd ME, Holt RT, Myers L. Anterior/posterior lumbar fusion versus transforaminal lumbar interbody fusion: analysis of complications and predictive factors. J Spinal Disord. 2001;14(6):533540. doi:10.1097/00002517-200112000-00013.

Humphreys SC, Hodges SD, Patwardhan AG, EckJC, Murphy RB, Covington LA. Comparison of posterior and transforaminal approaches to lumbar interbody fusion. Spine (Phila Pa 1976). 2001;26(5):567-571. doi:10.1097/00007632-200103010-00023.

- Sakeb N, Ahsan K. Comparison of the early results of transforaminal lumbar interbody fusion and posterior lumbar interbody fusion in symptomatic lumbar instability. Indian J Orthop. 2013;47(3):255. doi:10.4103/0019-5413.111484.

ParkJ-S, Kim Y-B, Hong H-J, Hwang S-N. Comparison between Posterior and Transforaminal Approaches for Lumbar Interbody Fusion. J Korean Neurosurg Soc. 2005;37:340-344.

3. Moher D, Liberati A, Tetzlaff J, Altman DG, Grp P. Preferred Reporting Items for Systematic Reviews and Meta-Analyses: The PRISMA Statement (Reprinted from Annals of Internal Medicine). Phys Ther. 2009;89(9):873-880. doi:10.1371/journal.pmed.1000097.

Liberati A, Altman DG, Tetzlaff J, et al. The PRISMA statement for reporting systematic reviews and meta-analyses of studies that evaluate healthcare interventions: explanation and elaboration. Bmj. 2009;339(jul21 1):b2700-b2700. doi:10.1136/bmj.b2700.

Higgins JPT AD. Chapter 8. Assessing risk of bias in included studies. In: Higgins JPT, Green S (editors). Cochrane Handbook for systematic Reviews of Interventions. Version 5.1.0 [updated March 2011]. Cochrane Collab. 2011.

Howick J, Chalmers I, Glasziou P, et al. The Oxford 2011 Levels of Evidence. Oxford Centre Evidence-Based Medicine. Vol 1.; 2011.

Duval S, Tweedie R. Trim and fill: a simple funnel- plot-based method of testing and adjusting for publication bias in meta-analysis. Biometrics. 2000;56(2):455-463. 
18. Viechtbauer W. Conducting Meta-Analyses in R with the metafor Package. J Stat Softw. 2010;36(3):1-48.

19. Macki M, Bydon M, Weingart R, et al. Posterolateral fusion with interbody for lumbar spondylolisthesis is associated with less repeat surgery than posterolateral fusion alone. Clin Neurol Neurosurg. 2015;138:117123. doi:10.1016/j.clineuro.2015.08.014.

20. Bydon M, Macki M, Abt NB, et al. The cost-effectiveness of interbody fusions versus posterolateral fusions in 137 patients with lumbar spondylolisthesis. Spine J. 2015;15(3):492-498. doi:10.1016/j. spinee.2014.10.007.

21. Villavicencio AT, Burneikiene S, Bulsara KR, Thramann Jj. Perioperative complications in transforaminal lumbar interbody fusion versus anterior-posterior reconstruction for lumbar disc degeneration and instability. J Spinal Disord Tech. 2006;19(2):92-97. doi:10.1097/01.bsd.0000185277.14484.4e.

22. Figueiredo N, Martins J, Arruda A, et al. Transforaminal lumbar interbody fusion (TLIF). Arq Neuropsiquiatr. 2004;62(May):815-820. doi:10.1007/978-0-387-89831-5_15.

23. Asil K, Yaldiz C. Retrospective Comparison of Radiological and Clinical Outcomes of PLIF and TLIF Techniques in Patients Who Underwent Lumbar Spinal Posterior Stabilization. Medicine (Baltimore). 2016;95(17):1-7. doi:10.1097/MD.0000000000003235.

24. de Kunder SL, Rijkers K, van Hemert WLW, Willems PCPH, ter Laak - Poort MP, van Santbrink H. Transforaminal versus posterior lumbar interbody fusion as operative treatment of lumbar spondylolisthesis, a retrospective case series. Interdiscip Neurosurg. 2016;5:64-68. doi:10.1016/j.inat.2016.07.001.

25. Fariborz S, Gharedaghi M, Khosravi A, et al. Comparison of Results of 4 Methods of Surgery in Grade 1 Lumbosacral Spondylolisthesis. Neurosurg Q. 2016;26(1):14-18. doi:10.1097/WNQ.0000000000000197.

26. Han S, Xiao Q, Zhu G, Dai J, Tang X, Sun H. Comparison between transforaminal lumbar interbody fusion and posterior lumbar interbody fusion in treatment of lumbar spondylolisthesis. Int J Clin Exp Med. 2016;9(2):3932-3938.

27. Liu J, Deng H, Long X, Chen X, Xu R, Liu Z. A comparative study of perioperative complications between transforaminal versus posterior lumbar interbody fusion in degenerative lumbar spondylolisthesis. Eur spine J. 2015. doi:10.1007/s00586-015-4086-8.

28. Yan DL, Pei FX, Li J, Soo CL. Comparative study of PILF and TLIF treatment in adult degenerative spondylolisthesis. Eur Spine J. 2008;17(10):1311-1316. doi:10.1007/s00586-008-0739-1.

29. Yang E-Z, Xu J-G, Liu X-K, et al. An RCT study comparing the clinical and radiological outcomes with the use of PLIF or TLIF after instrumented reduction in adult isthmic spondylolisthesis. Eur Spine J. 2016;25(5):1587-1594. doi:10.1007/s00586-015-4341-z.

30. Parker SL, McGirt MJ. Determination of the Minimum Improvement in Pain, Disability, and Health State Associated With Cost-Effectiveness. Neurosurgery. 2012;71(6):1149-1155. doi:10.1227/ NEU.0b013e318271ebde.

31. Tsitsopoulos PP, Serhan H, Voronov LI, et al. Would an Anatomically Shaped Lumbar Interbody Cage Provide Better Stability? An In Vitro Cadaveric Biomechanical Evaluation. J Spinal Disord Tech. 2012;25(8):1. doi:10.1097/BSD.0b013e31824c820c.

32. Deyo RA, Nachemson A, Mirza SK. Spinal-Fusion Surgery - The Case for Restraint. N Eng/ J Med. 2004;350(7):722-726. doi:10.1056/NEJMsb031771.

33. Xu H, Tang H, Li Z. Surgical treatment of adult degenerative spondylolisthesis by instrumented transforaminal lumbar interbody fusion in the Han nationality. J Neurosurg Spine. 2009;10(5):496-499. doi:10.3171/2009.2.SPINE08623.

34. Mehta V, McGirt M, Garcés Ambrossi G, et al. Trans-foraminal versus posterior lumbar interbody fusion: comparison of surgical morbidity. Neurol Res. 2011;33(1).

35. Hey HW, Hee H. Lumbar degenerative spinal deformity: Surgical options of PLIF, TLIF and MI-TLIF. Indian J Orthop. 2010;44(2):159. doi:10.4103/0019-5413.62066. 
36. Faundez AA, Schwender JD, Safriel Y, et al. Clinical and radiological outcome of anterior--posterior fusion versus transforaminal lumbar interbody fusion for symptomatic disc degeneration: a retrospective comparative study of 133 patients. Eur Spine J. 2009;18(2):203-211. doi:10.1007/s00586-008-0845-0.

37. Chrastil J, Patel AA. Posterior and Transforaminal Lumbar Interbody Fusion Abstract. J Am Acad Orthop Surg. 2012;20(5):283-291.

38. Dubory A, Giorgi $\mathrm{H}$, Walter A, et al. Surgical-site infection in spinal injury: incidence and risk factors in a prospective cohort of 518 patients. Eur Spine J. 2014;24(3):543-554. doi:10.1007/s00586-014-3523-4.

39. Xing D, Ma J-X, Ma X-L, et al. A methodological, systematic review of evidence-based independent risk factors for surgical site infections after spinal surgery. Eur Spine J. 2012:605-615. doi:10.1007/s00586012-2514-6.

40. de Kunder SL, Rijkers K, van Kuijk SMJ, Evers SMAA, de Bie RA, van Santbrink H. A protocol of a randomized controlled multicenter trial for surgical treatment of lumbar spondylolisthesis: the Lumbar Interbody Fusion Trial (LIFT). BMC Musculoskelet Disord. 2016;17(1):417. doi:10.1186/s12891-016-1280-8. 



\section{Chapter 4}

Transforaminal versus Posterior Lumbar Interbody Fusion as operative treatment of lumbar spondylolisthesis, a retrospective case series

SL de Kunder, K Rijkers, WLW van Hemert, PCPH Willems, MP ter Laak - Poort and H van Santbrink 


\section{ABSTRACT}

\section{Objective}

Spondylolisthesis can be treated by transforaminal lumbar interbody fusion (TLIF) and posterior lumbar interbody fusion (PLIF). The effectiveness of both techniques is assumed to be equal. TLIF may have advantages over PLIF concerning complication rate, blood loss, surgical time and hospital duration. In order to verify these assumed advantages of TLIF we retrospectively compared a case series of patients that have undergone PLIF or TLIF surgery for lumbar spondylolisthesis in our hospital.

\section{Methods}

96 patients with spondylolisthesis (isthmic or degenerative) were analysed. Patient characteristics and surgical details were recorded.

\section{Results}

TLIF procedures were associated with significantly shorter surgical time. Overall complication rate was $25 \%$. There was no difference in blood loss, hospital duration or occurrence or postoperative pain.

\section{Conclusion}

In this case series, TLIF was associated with shorter surgical time. Other assumed advantages of TLIF could not be verified in this retrospective patient series. Further prospective research is needed to confirm these results. 


\section{INTRODUCTION}

Spinal instability caused by lumbar spondylolisthesis can lead to intermittent neurogenic claudication, lumbar radiculopathy and low back pain. If conservative measurements fail or if patients develop neurological deficits, surgical treatment by decompression and instrumented spinal fusion is more frequently considered: in the US, the national bill for instrumented spinal fusion increased 7.9 fold between 1998 and 2008 1.

Classically, posterolateral fusion with pedicle screw fixation is performed, combined with interbody fusion surgery. The rationale for adding lumbar interbody fusion surgery is to improve fusion ${ }^{2,3}$, thereby restoring balance and redeeming stability ${ }^{4}$. Different fusion techniques have been developed, including transforaminal lumbar interbody fusion (TLIF) and posterior lumbar interbody fusion (PLIF) (figure 1 and 2), ${ }^{5,6}$. Most spine surgeons are familiar with both and technical difficulty is similar. The unilateral approach to the intervertebral disc is a theoretical advantage of TLIF, based on a number of items ${ }^{6}$. First of all; the a priori chance of damaging nerve or dural sac is $50 \%$ less in TLIF. Secondly; in TLIF one facet joint remains unaffected while in PLIF both facet joints are involved in decompression necessary to place interbody cages. Thirdly; TLIF may affect the musculoligamentous complex of the lumbar spine to a lesser extent. Data from retrospective patient series suggest that TLIF may require less surgical time and is associated with less blood loss and fewer complications ${ }^{7-9}$, while effectiveness of both techniques on back and/or leg pain is equal $4,8,9$

TLIF may thus be as effective as PLIF, technically equivalent and theoretically safer, suggesting that TLIF is a better technique to treat the instable lumbar spine. 


\section{MATERIAL AND METHODS}

All patients that underwent single level TLIF for lumbar spondylolisthesis in our hospital between January 2011 and December 2014 were retrospectively analysed. These TLIF patients were matched with PLIF patients, matched on indication for surgery, grade of spondylolisthesis, age and BMI. Surgery was always preceded by exploration of non-surgical interventions such as physical therapy or analgesics. Exclusion criteria were: <18 years at time of surgery or other spinal disorders (trauma, scoliosis, tumour or infection). Patient data were obtained from medical records. Clinical parameters including gender, age, body mass index (BMI), smoking habits and history of previous back surgery were assessed (table 1). Surgical details including surgical time, blood loss, operated level and dural tear, as well as postoperative details including infection, hematoma, hardware failure and neurological deficits, were recorded. Medical complications as pneumonia or urinary tract infection were evaluated and referred to as 'medical other'. The presence of leg and/or back pain, defined as: yes/no, was recorded pre-operatively and two months postoperatively. Follow-up was done at two, six or twelve months. Long-term fusion was not evaluated by radiological exams.

\section{Operative methods}

All patients were operated after receiving antibiotic prophylaxis under general anaesthesia in prone position. A midline posterior approach was performed, exposing posterior lumbar elements including facet joints. Poly-axial pedicle screws were placed bilaterally, using fluoroscopy or frameless navigation. In case of spinal canal stenosis, the central part of the spinal canal was decompressed by laminectomy. For TLIF, unilateral exposure to the intervertebral disc was assured by total unilateral facetectomy, decompressing the descending and leaving roots. For PLIF, bilateral access to the intervertebral disc was assured by resection of the pars articularis inferior and partial resection of the pars articularis superior of the facet joint, decompressing descending and leaving roots bilaterally. Subsequently, the intervertebral disc was removed and endplate cartilage was prepared to provide a host bed of bleeding subchrondral bone for placement of the cage(s). Using trial cages, appropriate cage size and position were determined. Definite cage(s) were packed using morcellized autologous bone from resected elements. For TLIF a banana shaped cage or a rectangular cage was used, based soley on the surgeons' preference. Morcellized autologous bone was inserted in the intervertebral disc space as scaffold for fusion. Two titanium rods interconnected the poly-axial screws. The wound was thoroughly irrigated and closed in several layers without suction drainage. All patients received postoperative analgesics adjusted to their needs and antithrombotic prophylaxis. All patients followed a standard mobilisation programme, including physical therapy. They were advised to mobilize with brace support for a period of 6 weeks postoperatively (figure 3). 


\section{Statistical analysis}

Data were processed and analysed with the Statistical Package for the Social Sciences (IBM SPSS Statistics, v22 for Mac). Before testing the following data were stratified: age under and over 57 years (57 being the mean in both groups), BMI in normal weight (BMI under 25), overweight (BMI 25-30) and obese (BMI over 30). Data were tested for normal distribution using Kolmogorov-Smirnov and Shapiro-Wilk Tests. All data were normally distributed, hence classic t-testing was used to compare means between two groups and Chi-square test was used to compare percentages. Values represent means with their respective range and standard deviations, or percentages. Differences between treatment groups were established with a statistical significance of $p<0.05$. 


\section{RESULTS}

\section{Patient characteristics}

We included 96 patients (table 1). 48 TLIF patients were matched with 48 PLIF patients, matching was based on; indication for surgery, grade of spondylolisthesis, age and BMI. Gender, age, BMI and smoking were similar in both groups. There was a female preponderance, especially in the TLIF group. Patients with a history of previous back surgery were slightly overrepresented in the TLIF group, albeit not significantly (38\% vs. 31\%, p = 0.519). Indication for surgery, degree of spondylolisthesis and operated level were also similar in both groups.

\section{Surgical details}

Surgical details are summarized in table 2. The intraoperative blood loss was similar for both procedures (485 mL vs. $590 \mathrm{~mL}, \mathrm{p}=0.202$ ). TLIF was associated with significantly shorter surgical time (149 minutes vs. 182 minutes, $p=0.005$ ). Duration of hospitalization was similar for both procedures (TLIF 6.2 days (3-15, sd 3) vs. PLIF 6.4 (4-25, sd 4), p = $0.748)$.

\section{Complications}

Complications are summarized in table 3. Complications occurred in 23 patients (24\%), of which 23\% in the PLIF group and 25\% in the TLIF group. Infection occurred less frequent in the TLIF group (2\% vs. 6\%), while medical other complications as pneumonia or urinary tract infection occurred more frequent in the TLIF group (8\% vs. 2\%).

Higher BMI, age >58 years old, smoking habits, operative time and blood loss were not associated with more frequent occurrence of complications.

\section{Pain}

For 90 patients (92\%) data on the occurrence of postoperative pain at two months were available.

Presence of leg and/or back pain was recorded pre-operatively and postoperatively, see table 4. Pre-operatively, the occurrence of back pain was more frequent in the PLIF group. At two months postoperatively there were no differences in leg and/or back pain. A great reduction of occurrence of both leg and back pain was seen in both groups. 


\section{DISCUSSION}

We have retrospectively analysed a case series of 96 TLIF and PLIF patients. Several non-randomized studies and one small randomized controlled trial comparing TLIF and PLIF suggest that TLIF is associated with fewer complications, less blood loss, shorter operative time and hospital duration, leading to lower health care costs and an improvement in quality of life $\mathrm{T}^{7-11}$. In the last decade the demand for instrumented spinal fusion has increased steeply ${ }^{1,12}$, and with an aging population this is expected to rise further. Therefore, we sought to verify these presumed advantages of TLIF over PLIF.

In contrast to the literature we did not find a difference in estimated intraoperative blood loss or duration of hospitalization between both procedures. A shorter surgical time was observed in the TLIF group. Twenty-three patients suffered a complication, 23\% in the PLIF group and 25\% in the TLIF group. The kind of complications, as infection, hardware failure, neurological deficits, hematoma and dural tear, were similar in both groups. Four patients (5\%) underwent subsequent surgery for hardware failure (migrated or broken pedicle screws) and one patient suffered a permanent neurological deficit (foot drop). Medical other complications as pneumonia or urinary tract infection occurred more frequently in TLIF group. Both techniques reduced the occurrence of back pain, and reduced leg pain even more. We expect the efficacy of both techniques to be even higher at later time, because healing is not complete after only two months.

Comparing our series to other reported series, we observe some similarities as well as some differences 7,8,13. Less blood loss for TLIF is reported by several authors. However, we did not found a significant difference in blood loss between both procedures ${ }^{9}$. Possibly we did not find statistical significance due to the small sample size, because we found $485 \mathrm{~mL}$ for TLIF and $590 \mathrm{~mL}$ for PLIF. Earlier reported significant differences were also in the range of $100-200 \mathrm{~mL}^{9,11,14}$.

Previously published complication rates, vary from 9\% (TLIF) 7,13 to 29\% (for PLIF) ${ }^{8}$. Our overall complication rate of $24 \%$ is in accordance with these reported rates. The relatively high complication rate we reported depends on our definition: we included intra-operative, early and late postoperative direct surgical related complications as well as 'medical other', while others only reported major complications (e.g. neurological injury) or described early and late complications separately 7,8,13. We still feel both procedures are safe and acceptable, since most complications were of passing nature and only four patients required repeated surgery. Patients satisfaction concerning pain reduction was similar as reported in a number of prospective studies; both techniques effectively reduced leg and/or back pain 2,15-18. 
TLIF patients spent less days in hospital than PLIF patients in one study, a difference we did not observe ${ }^{4}$. This is explained by the fact that our patients all enrol in standard mobilisation programmes requiring the same number of hospitalisation days for both procedures 7,8 . Also it is hypothesized that TLIF increases the approximate biomechanical stability more compared to PLIF and reduces stress at the cage-endplate interface better thereby maintaining spinal alignment ${ }^{19,20}$, which could influence long term outcome. In our study, two types of TLIF cages were used, banana shaped and rectangular, but no sufficient data were available on (long) term fusion or patients' satisfaction.

Our study has a number of limitations. It was a retrospective study with a probable bias in patient selection. To obtain homogeneous patient groups and to reduce bias due to confounding, we matched the data of TLIF patients with similar PLIF patients, matching was based on; indication for surgery, grade of spondylolisthesis, age and BMI. The size of the patient group was not sufficient to obtain statistical significant differences, and subsequently confirm or deny advantages over one technique over the other. 


\section{CONCLUSION}

In this study TLIF is associated with shorter operative time compared to PLIF. Other presumed advantages could not be verified in this retrospective patient series. A randomized controlled trial of sufficient size is needed for further investigation. 


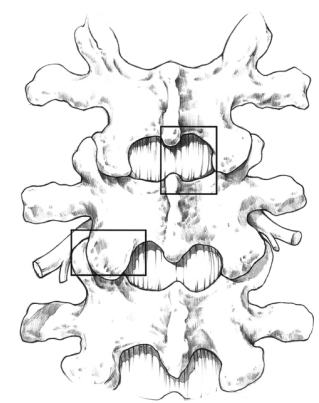

Figure 1: Schematic representation of lumbar spine demonstrating the area of bony removal and route of access to the intervertebral body space. (Top) Medial box represents area and access for the PLIF procedure; (bottom) lateral box represents area and access for the TLIF procedure.

(Reprinted from "Comparison of low back fusion techniques: Transforaminal lumbar interbody fusion (TLIF) or posterior lumbar interbody fusion (PLIF) approaches" by Cole CD, McCall TD, Schmidt MH, Dailey AT, (2009.) Curr Rev Musculoskelet Med 2:118-126.)

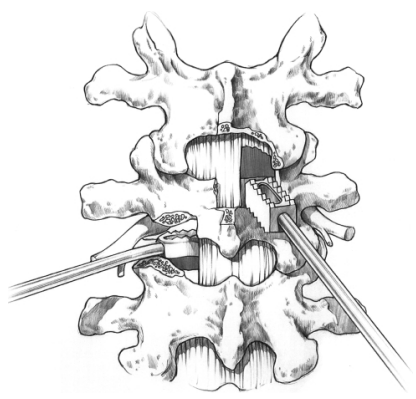

Figure 2: Schematic representation of lumbar spine demonstrating the angle of interbody graft insertion for the PLIF procedure (top, medial) and TLIF procedure (bottom, lateral).

(Reprinted from "Comparison of low back fusion techniques: Transforaminal lumbar interbody fusion (TLIF) or posterior lumbar interbody fusion (PLIF) approaches" by Cole CD, McCall TD, Schmidt MH, Dailey AT, (2009.) Curr Rev Musculoskelet Med 2:118-126.) 

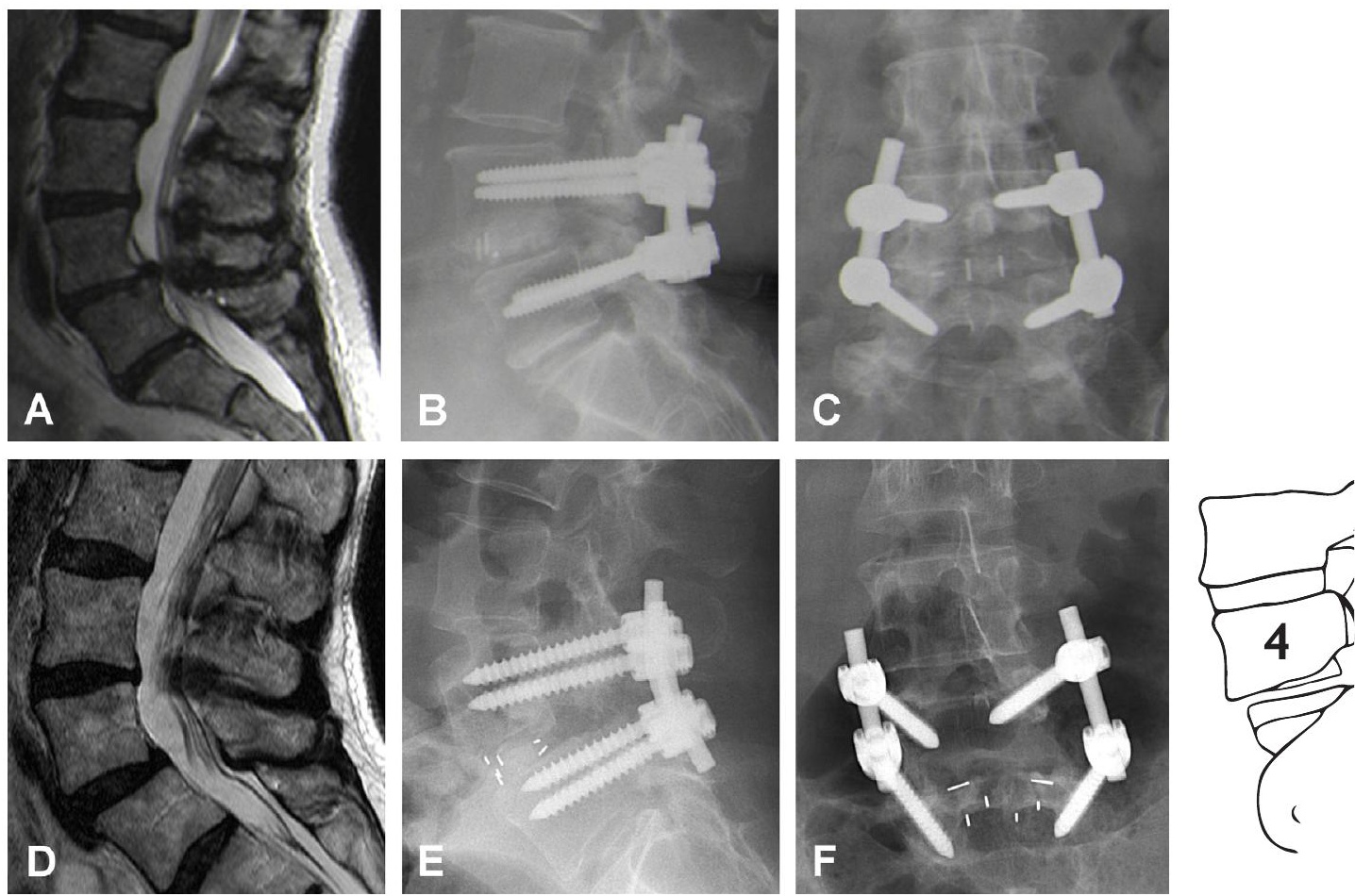

Figure 3: Preoperative T2-weighted MR images of lumbar spondylolisthesis (A), postoperative lateral (B) and anteroposterior (C) plain radiographs with a single cage inserted with TLIF technique. Preoperative T2-weighted MR images of lumbar spondylolisthesis (D), postoperative lateral (E) and anteroposterior (F) plain radiographs with two cages inserted with PLIF technique. 
Table 1: Patient characteristics

\begin{tabular}{|c|c|c|c|c|}
\hline & TLIF & PLIF & Total & $p$ value \\
\hline Number of patients & $48(50 \%)$ & $48(50 \%)$ & 96 & - \\
\hline \multirow[t]{2}{*}{ Gender } & Male 17 (35\%) & Male 23 (48\%) & Male $40(42 \%)$ & 0.214 \\
\hline & Female 31 (65\%) & Female 25 (52\%) & Female 56 (58\%) & \\
\hline Age (in years) & $58(18-80$, SD 13) & $58(18-78$, SD 12) & 58 & 0.917 \\
\hline BMI & $28(19-43$, SD 5) & $27(19-37$, SD 4) & 27 & 0.842 \\
\hline Smoking & $40 \%$ & $38 \%$ & $39 \%$ & 0.834 \\
\hline Previous back surgery & $38 \%$ & $31 \%$ & $34 \%$ & 0.519 \\
\hline \multicolumn{5}{|l|}{ Indication for surgery } \\
\hline Isthmic spondylolisthesis & $16(33 \%)$ & $16(33 \%)$ & $32(33 \%)$ & 1.000 \\
\hline Degenerative spondylolisthesis & $32(67 \%)$ & $32(67 \%)$ & $64(67 \%)$ & 1.000 \\
\hline \multicolumn{5}{|l|}{ Grade of spondylolisthesis } \\
\hline Grade 1 & $38(79 \%)$ & $38(79 \%)$ & $76(79 \%)$ & 1.000 \\
\hline Grade 2 & $10(21 \%)$ & $10(21 \%)$ & $20(21 \%)$ & 1.000 \\
\hline Operated level & & & & 0.515 \\
\hline$L 2-L 3$ & $1(2 \%)$ & $0(0 \%)$ & $2(1 \%)$ & - \\
\hline$L 3-L 4$ & $7(15 \%)$ & $7(15 \%)$ & $14(15 \%)$ & - \\
\hline$\angle 4-L 5$ & 30 (63\%) & $26(54 \%)$ & 56 (58\%) & 0.408 \\
\hline L5-S1 & 10 (21\%) & 15 (31\%) & $25(26 \%)$ & 0.245 \\
\hline
\end{tabular}

Table 2: Surgical details

\begin{tabular}{lllll}
\hline & TLIF & PLIF & Total & $p$ value \\
\hline Intra operative blood loss in $\mathrm{mL}$ & $485(150-1700$, SD 355) & $590(150-1600$, SD 327) & 533 & 0.202 \\
Operative time in min & $145(54-272$, SD 52) & $177(75-286$, SD 56) & 161 & 0.005 \\
Days hospitalization & $6.2(3-15$, SD 3) & $6.4(4-25$, SD 4) & 6.3 & 0.748 \\
\hline
\end{tabular}


Table 3: Complications

\begin{tabular}{llll}
\hline & TLIF & PLIF & Total \\
\hline Total complications & $12(25 \%)$ & $11(23 \%)$ & $23(24 \%)$ \\
Infection & $1(2 \%)$ & $3(6 \%)$ & $4(4 \%)$ \\
Hardware failure & $2(4 \%)$ & $2(4 \%)$ & $4(4 \%)$ \\
Neurological deficits & 0 & $1(2 \%)$ & $1(1 \%)$ \\
Hematoma & 0 & 0 & 0 \\
Dural tear & $5(10 \%)$ & $4(8 \%)$ & $9(10 \%)$ \\
Medical other* & $4(8 \%)$ & $1(2 \%)$ & $5(5 \%)$ \\
\hline
\end{tabular}

*urinary tract infection or pneumonia

Table 4: Occurrence of pre- and postoperative pain

\begin{tabular}{llll}
\hline & TLIF & PLIF & \multicolumn{1}{c}{ Total } \\
& $\mathrm{N}=\mathbf{4 3}$ & $\mathrm{N}=\mathbf{4 7}$ & $\mathrm{N}=\mathbf{9 0}$ \\
\hline Pre-operative back pain & $25(58 \%)$ & $37(77 \%)$ & $62(69 \%)$ \\
Pre-operative leg pain & $40(93 \%)$ & $42(89 \%)$ & $82(91 \%)$ \\
Pre-operative leg and back pain & $23(54 \%)$ & $33(70 \%)$ & $56(62 \%)$ \\
& & & \\
Postoperative back pain at two months & $8(19 \%)$ & $9(19 \%)$ & $9(19 \%)$ \\
Postoperative leg pain at two months & $5(12 \%)$ & $4(9 \%)$ & $3(3 \%)$ \\
Postoperative leg and back pain at two months & $2(5 \%)$ & $1(2 \%)$ & $3(10 \%)$ \\
\hline
\end{tabular}

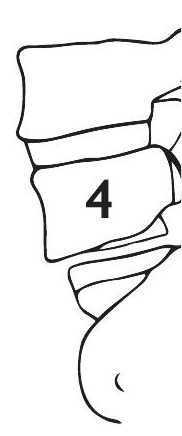




\section{REFERENCES}

1. Rajaee SS, Bae HW, Kanim LEA, Delamarter RB. Spinal Fusion in the United States. Spine (Phila Pa 1976). 2012;37(1):67-76. doi:10.1097/BRS.0b013e31820cccfb.

2. Zhou Z-J, Zhao F-D, Fang X-Q, Zhao X, Fan S-W. Meta-analysis of instrumented posterior interbody fusion versus instrumented posterolateral fusion in the lumbar spine. J Neurosurg Spine. 2011;15(3):295-310. doi:10.3171/2011.4.SPINE10330

3. Audat Z, Moutasem O, Yousef K, Mohammad B. Comparison of clinical and radiological results of posterolateral fusion, posterior lumbar interbody fusion and transforaminal lumbar interbody fusion techniques in the treatment of degenerative lumbar spine. Singapore Med J. 2012;53(3):183-187

4. Hee HT, Castro FP, Majd ME, Holt RT, Myers L. Anterior/posterior lumbar fusion versus transforaminal lumbar interbody fusion: analysis of complications and predictive factors. J Spinal Disord. 2001;14(6):533540. doi:10.1097/00002517-200112000-00013.

5. Cloward RB. The treatment of ruptured lumbar intervertebral discs by vertebral body fusion. I. Indications, operative technique, after care. J Neurosurg. 1953;10(2):154-168. doi:10.3171/jns.1953.10.2.0154.

6. Harms J, Rolinger H. A one-stager procedure in operative treatment of spondylolistheses: dorsal traction-reposition and anterior fusion. Z Orthop Ihre Grenzgeb. 1981;120(3):343-347. doi:10.1055/s-2008-1051624.

7. ParkJ-S, Kim Y-B, Hong H-J, Hwang S-N. Comparison between Posterior and Transforaminal Approaches for Lumbar Interbody Fusion. J Korean Neurosurg Soc. 2005;37:340-344.

8. Humphreys SC, Hodges SD, Patwardhan AG, EckJC, Murphy RB, Covington LA. Comparison of posterior and transforaminal approaches to lumbar interbody fusion. Spine (Phila Pa 1976). 2001;26(5):567-571. doi:10.1097/00007632-200103010-00023.

9. Sakeb N, Ahsan K. Comparison of the early results of transforaminal lumbar interbody fusion and posterior lumbar interbody fusion in symptomatic lumbar instability. Indian J Orthop. 2013;47(3):255. doi:10.4103/0019-5413.111484.

10. Kunze B, Drasseck T, Kluba T. Posteriore und transforaminale lumbale interkorporelle Fusion (PLIF/ TLIF) zur Therapie des lokalisierten Segmentaufbrauchs der LWS. Z Orthop Unfall. 2011;149(3):312-316. doi:10.1055/s-0030-1250689

11. Yang EZ, Xu JG, Liu XK, et al. An RCT study comparing the clinical and radiological outcomes with the use of PLIF or TLIF after instrumented reduction in adult isthmic spondylolisthesis. Eur Spine J. 2015:1-8. doi:10.1007/s00586-015-4341-z.

12. Tosteson ANA, Lurie JD, Tosteson TD, et al. Surgical treatment of spinal stenosis with and without degenerative spondylolisthesis: cost-effectiveness after 2 years. Ann Intern Med. 2008;149(12):845-853. doi:10.7326/0003-4819-149-12-200812160-00003.

13. Mura PP, Costaglioli M, Piredda M, Caboni S, Casula S. TLIF for symptomatic disc degeneration: A retrospective study of 100 patients. Eur Spine J. 2011;20(SUPPL. 1):57-60. doi:10.1007/s00586-011-1761-2.

14. Liu J, Deng H, Long X, Chen X, Xu R, Liu Z. A comparative study of perioperative complications between transforaminal versus posterior lumbar interbody fusion in degenerative lumbar spondylolisthesis. Eur spine J. 2015. doi:10.1007/s00586-015-4086-8.

15. Tosteson ANA, Tosteson TD, Lurie JD, et al. Comparative Effectiveness Evidence From the Spine Patient Outcomes Research Trial. Spine (Phila Pa 1976). 2011;36(24):2061-2068. doi:10.1097/ BRS.0b013e318235457b.

16. Adogwa O, Parker SL, Davis BJ, et al. Cost-effectiveness of transforaminal lumbar interbody fusion for Grade I degenerative spondylolisthesis. J Neurosurg Spine. 2011;15(2):138-143. doi:10.3171/2011.3.SPINE10562.

17. Jalalpour K, Neumann P, Johansson C, Hedlund R. A Randomized Controlled Trial Comparing Transforam- 
inal Lumbar Interbody Fusion and Uninstrumented Posterolateral Fusion in the Degenerative Lumbar Spine. Glob Spine J. 2015;5(4):322-328. doi:0.1055/s-0035-1549033.

18. Bydon M, Macki M, Abt NB, et al. The cost-effectiveness of interbody fusions versus posterolateral fusions in 137 patients with lumbar spondylolisthesis. Spine J. 2015;15(3):492-498. doi:10.1016/j. spinee.2014.10.007.

19. Xu H, Tang H, Guan X, et al. Biomechanical comparison of posterior lumbar interbody fusion and transforaminal lumbar interbody fusion by finite element analysis. Neurosurgery. 2013;72(March):21-26. doi:10.1227/NEU.0b013e3182742a69.

20. Gödde S, Fritsch E, Dienst M, Kohn D. Influence of cage geometry on sagittal alignment in instrumented posterior lumbar interbody fusion. Spine (Phila Pa 1976). 2003;28(15):1693-1699. doi:10.1097/01. BRS.0000083167.78853.D5. 



\section{Chapter 5}

\section{Cost-effectiveness of transforaminal lumbar interbody fusion (TLIF) versus posterior lumbar interbody fusion (PLIF), a systematic review and economical evaluation}

SL de Kunder, IJMH Caelers, K Rijkers, RA de Bie, $H$ van Santbrink and SMAA Evers 


\section{ABSTRACT}

\section{Background Context}

The demand and expenditures for spinal fusion surgery have increased steeply over the last decades. With the increasing costs health care providers should take cost-effectiveness of spinal fusion surgery in account. Transforaminal lumbar interbody fusion (TLIF) and posterior lumbar interbody fusion (PLIF) are two widely used techniques for lumbar spinal fusion. Earlier research revealed TLIF is associated with less complications, less blood loss, shorter surgical time and sometimes shorter hospital duration, while effectiveness of both techniques on back and/or leg pain is assumed to be equal. Therefore, TLIF could be more cost-effective than PLIF.

\section{Purpose}

To compare the cost-effectiveness of both TLIF and PLIF in patients with lumbar instability and to assess the methodologic quality of the included studies.

\section{Study Design/Setting}

A systematic literature review and economical evaluation.

\section{Methods}

We conducted a Medline (using Pubmed), Embase (using Ovid), Cochrane Library, Current Controlled Trials, ClinicalTrials.gov, NHS Centre for Review and Dissemination, Econlit and Web of Science search for studies reporting TLIF, PLIF, lumbar spondylolisthesis, lumbar instability and cost. For comparison all costs were converted to United States dollars with reference year 2015 .

\section{Results}

336 studies were identified, fifteen studies were included (eight studies with a cost-effectiveness or cost-utility design, six financial studies and one prospective cohort design reporting on quality of life (QALY)). There were no studies comparing TLIF and PLIF directly. There was great heterogeneity in healthcare perspective costs and societal costs due to different in- and exclusion factors and different calculations. The main difference between studies was the use of hospital costs or hospital charges to calculate the expenditures. The overall quality of the studies was low.

\section{Conclusions}

This review shows that instrumented spine surgery with TLIF and PLIF is an expensive technique within the healthcare system. Randomized prospective trials and economical evaluations are needed to obtain high levels of evidence. 


\section{INTRODUCTION}

With the growing possibilities in health care, the question rises whether the increasing costs due to new expensive treatment options are justified in perspective to declining financial resources. In spinal fusion surgery, the national US bill for instrumented spinal fusion has increased 7.9 fold between 1998 and $2008^{1}$. The increase in the aging populations ensures that demand for spinal surgery will rise further in the near future. Therefore, decision makers demand health care providers to evaluate the (cost-)effectiveness of these types of treatment. Two widely used techniques for spinal fusion are transforaminal lumbar interbody fusion (TLIF) and posterior lumbar interbody fusion (PLIF). The TLIF procedure makes use of a unilateral transforaminal route to the intervertebral space, instead of a bilateral approach for PLIF ${ }^{2-4}$. Earlier research revealed TLIF is associated with less complications, less blood loss, shorter surgical time and sometimes shorter hospital duration, while effectiveness of both techniques on back and/or leg pain is assumed to be equal resulting in the same improvement in quality of life ${ }^{5-14}$. However, cost-effectiveness data on instrumented spinal surgery are scarce. In this regard, we aimed at evaluating the cost-effectiveness of TLIF and PLIF 2,3. For aforementioned reasons we think TLIF could be more cost-effective than PLIF. The aim for this review is to present an overview of trial based economical evaluations comparing cost-effectiveness of TLIF and PLIF in patients with lumbar instability. Furthermore, the methodologic quality of the included studies will be assessed. 


\section{METHODS}

\section{Research protocol}

This systematic review was executed in accordance with the PRISMA statement and the five-step approach on preparing a systematic review of economic evaluations by Van Mastrigt et al. ${ }^{15-19}$. The review protocol consisted of a research question, search strategy, and eligibility criteria for assessing full-text studies. The research questions were formulated as follows:

1. Is transforaminal lumbar interbody fusion (TLIF) in adults with lumbar spondylolisthesis/ lumbar instability more cost-effective than posterior lumbar interbody fusion (PLIF)?

2. What is the methodologic quality of the included studies?

\section{Search strategy and eligibility criteria}

To identify all studies addressing costs in TLIF or PLIF for patients with lumbar spondyIolisthesis/lumbar instability, a comprehensive systematic literature search of the following databases was performed: Medline (using Pubmed), Embase (using Ovid), Cochrane Library, Current Controlled Trials, ClinicalTrials.gov, NHS Centre for Review and Dissemination, Econlit and Web of Science. The search results were filtered on language (English, Dutch or German). No other restrictions were used. Detailed search strategies are available in Appendix 1. Our last search was conducted on November 3rd, 2016.

Studies were included if they met all of the following eligibility criteria: (i) TLIF (transforaminal lumbar interbody fusion) or PLIF (posterior lumbar interbody fusion), (ii) lumbar spondylolisthesis or lumbar instability, (iii) cost.

\section{Study selection and data collection process}

Selection of studies was performed by two authors (SdK and IC). First, duplicate studies were removed. Second, potential studies were screened on title and abstract. Third, for final inclusion, full text screening on all eligibility criteria was performed.

Data were collected using a prospectively designed data collection sheet, independently extracted by two authors (SdK and IC). The following data items were considered: study design, study population, utility measurement tool, cost resources, (healthcare and societal perspective) costs, total costs, Quality Adjusted Life Years (QALYs) gained and costs per QALY. If necessary, consensus was reached by both authors through discussion. For comparison all costs were converted to United States dollars with reference year 2015. This with the use of a web-based tool developed by the Campbell and Cochrane Economics Methods Group (CCEMG) and the Evidence for Policy and Practice Information and Coordinating Centre (EPPI-Centre) (v.1.5) which automatically adjusts estimates for 
costs and price year, taking purchasing power parities between countries into account 20 . In case of no information of inflation, the year for index calculation was the last year of patient inclusion or when not available, the year of publication was used to convert costs.

\section{Quality assessment}

Risk of bias was assessed with the bias assessment tool of the Cochrane Handbook for systematic Reviews of Interventions ${ }^{21}$. Two authors (SdK and IC) evaluated the selected studies based on six different domains, and scored the criteria with "low" or "high" risk of bias, or "unclear".

Levels of evidence were determined for all studies with the Oxford Centre for Evidence-based Medicine - Levels of Evidence for Economic and Decision Analysis (March 2009) 22 .

The quality of the economical evaluations was analyzed by one author (IC) using the CHEClist, for assessment of the methodological quality of economic evaluations in systematic reviews ${ }^{23}$. 


\section{RESULTS}

\section{Overview of studies}

\section{Study selection}

Results of study selection are summarized in a flowchart (figure 1). Database searching resulted in identification of 336 studies. After removal of duplicates (70 in total), 266 studies were screened for title and abstract. 245 studies were excluded, 21 remained for full text analysis. After full text analysis six studies were excluded: Two were excluded because of unavailability of full text, two were systematic reviews, one study was excluded because of insufficient outcome measurements. Also two studies used the same patient cohort, therefore one of those studies was excluded ${ }^{24-28}$. There was no discussion on any of the inclusions between reviewers.

\section{Study characteristics}

Study characteristics are summarized in table 1.

Of the fifteen included studies, there were eight studies with a cost-effectiveness or cost-utility design 26,28-34. The other studies were financial studies (six studies) and one prospective cohort design reporting on quality of life (QALY) ${ }^{35-41}$. The publication years ranged from 2001 to 2016. Follow-up time ranged from 60 days to three years. The majority of included studies were of USA origin, one European (Danish) and one Asian (Chinese) ${ }^{26,28-41}$. The most frequently mentioned indication for surgery was degenerative spondylolisthesis. Other indications were: degenerative disc disease, spinal stenosis and failed back syndrome.

In twelve studies, TLIF was compared with another instrumented spine surgery technique 26,29-36,38,39,41. In three studies, PLIF was compared with other interventions ${ }^{28,37,40}$. There were no studies comparing TLIF and PLIF directly. Healthcare perspective costs were mentioned in twelve studies ${ }^{26,28-33,36-40}$. Healthcare perspective cost resources included hospital financial departments, Medicare and Redbook (healthcare drug pricing resource)) ${ }^{42,43}$. The majority of studies used hospital costs (actual hospital expenditures for treatment) to determine costs ${ }^{26,29-32,36-38}$. Five studies used hospital charges (amount charged by hospital for treatment) to calculate costs; three TLIF-studies and two PLIF-studies 28,33,35,39,40. Societal perspective costs and total costs in were mentioned in six studies 26,29-31,33,36. To determine total societal perspective costs, different calculations were used. In four studies the Human Capital Approach was used 26,29,31,33. The human capital approach counts every hour not worked as an hour lost ${ }^{44}$. One study used the DREAM database, a database including information on all public transfer payments administered by Danish ministries ${ }^{30,45}$. By determining the length of paying sick benefit, the loss of productivity was determined. Several definitions of productivity were used; most studies defined loss of productivity 
as loss of workdays for those employed and missed homemaking days for those who reported housekeeping as their primary activity 26,29,31. Some studies only included loss of workdays, resulting in lower societal costs ${ }^{30,33}$. Another difference was the expression of the loss of workdays, expressed in mean or median loss of workdays ${ }^{26,31}$. Since there were no studies available comparing TLIF and PLIF directly, there was no ICER available. Six studies reported on cumulative QALY or QALY gain measured with EQ-5D 26,29,31,33,34,41. Cost-utility was calculated in two studies 29,33 .

\section{Quality of identified studies}

Risk of bias is summarized in Appendix 2 and quality of economical evaluations is summarized in Appendix 3.

All included studies had an overall high risk of bias. Performance and detection bias were high in all of the studies, because there was no blinding of patients nor personnel. Selection bias was appropriate in one study (Christensen et al), all other studies did not use randomization ${ }^{30}$. Attrition bias was high in four studies, because neither follow-up time nor loss-to-follow-up were mentioned 28,35,37,38. Reporting bias was not described appropriately in three studies, because baseline characteristics of the study population were not compared 32,35. There was no funding bias in any of the studies. Studies scoring the highest on quality did not receive any funding. The studies of Christensen et al. and Gandhoke et al. were level 3B of evidence ${ }^{30,33}$. All other studies were level 4 evidence 26,28,29,31,32,34-41.

When analyzed with the CHEC-list, the mean quality score of the studies was 12.1 (7 - 15.5) out of 19. Four studies were of average quality with a score of 15 or more $26,30,31,33$. The other studies were all of low quality. Information on study population was sufficient in most studies, while important and relevant costs, appropriately validated measurements and outcomes were scarcely reported. Description of surgical techniques, sensitivity analysis and appropriate discounts of costs were lacking in most studies. The included studies consisted of both economical evaluations (costs, QALY gain and cost-utility analysis) as well as financial studies (costs only) ${ }^{35-40}$.

\section{Synthesis of results of studies}

Results of studies are summarized in table 2.

Healthcare related costs for instrumented fusion techniques were calculated in 13 studies, with a range from $\$ 14,081$ to $\$ 86,112^{26,28-33,35-40}$.

Health related costs calculated by using hospital costs ranged from $\$ 25,871$ to $\$ 39,134$, with a range for TLIF from $\$ 25,871$ to $\$ 39,314$ and for PLIF $\$ 29,699$ 26,29-32,36-38. 
Health related costs determined by using hospital charges ranged from $\$ 14,081$ to $\$ 86,112$, with a range for TLIF from $\$ 25,539$ to $\$ 47,029$ and for PLIF from $\$ 14,081$ up $\$ 86,11228,33,35,39,40$. The lowest healthcare costs for PLIF were $\$ 14,081$, described by Fei et al. ${ }^{40}$. This Asian study included only index hospitalization; costs for follow-up and readmission were not taken into account. For TLIF the lowest healthcare costs determined using charges were reported by Singh et al. to be $\$ 25,539$ for TLIF and Lucio et al. to be $\$ 29,699$ for PLIF ${ }^{37,39}$. The difference in costs could be explained by the fact that Singh does not include residual events while Lucio does. The highest healthcare costs determined using charges of USA origin were reported by Whitecloud et al. to be $\$ 47,029$ for TLIF and by Wang et al. to be $\$ 86,112$ for PLIF ${ }^{28,35}$. Wang et al. compared an acute setting to elective surgery. The difference in charge between both studies is less clear, as included factors seem quite similar.

Societal perspective costs for TLIF ranged from $\$ 6,717$ to $\$ 36,537$ for TLIF $26,29-31,33,36$. For PLIF societal perspective costs were not reported. Christensen et al., the only European study, reported high societal costs $(\$ 36,537)$, but also the longest period of work loss (34.2 weeks $)^{30}$. Pelton et al. calculated the lowest costs $(\$ 6,717)$, but did not further specify this outcome ${ }^{36}$. We think these low costs are the result of less work days off in a population not receiving any workers' compensation.

Total costs (healthcare related costs and societal perspective costs combined) for TLIF ranged from $\$ 35,786$ to $\$ 62,458$ 26,29-31,33,36. Total costs for PLIF were not reported.

The mean QALY gain for TLIF ranged from 0.25 QALY to 0.47 QALY 26,29,31,33,34,41. Cumulative QALY gain for TLIF ranged from 0.67 QALY to 0.86 QALY, with a follow-up period of two years $29,31,33$. Mean QALY gain nor cumulative QALY gain were reported for PLIF. Cost-utility was calculated only for TLIF, with a range from $\$ 46,475 /$ QALY to $\$ 66,914 /$ QALY 29,33 . The difference in cost-utility for TLIF can be explained by the use of healthcare costs determined by hospital costs and hospital charges. 


\section{DISCUSSION}

In this systematic review, we have compared costs and cost-effectiveness of TLIF and PLIF in patients with lumbar spondylolisthesis or lumbar instability. The aim of this review was to present an overview of economical evaluations comparing cost-effectiveness of TLIF and PLIF in patients with lumbar instability and to assess the methodologic quality of the included studies. The overall quality of the studies was low. All studies had a high risk of bias and quality of economical evaluations as well as financial studies was low. Both level of evidence and the origin of studies, resulted in a difficulty in transferability of results ${ }^{46}$.

There were no studies comparing TLIF and PLIF directly. Furthermore, there was great heterogeneity in societal costs and healthcare perspective costs due to different in- and exclusion factors and different calculations between studies. Studies defined societal costs as patients' missed productivity or as occupational productivity losses of patient and caregivers $29,31,33$. A standardized method of reporting and analyzing societal costs was lacking. When determining healthcare perspective costs the main difference between studies was the use of hospital costs or hospital charges to calculate the expenditures. With hospital costs defined as actual hospital expenditures for treatment and hospital charges defined as the amount charged by hospital for treatment. This is an important and relevant difference; recent publications suggest some US hospitals charge 10 times the costs of services, resulting in extreme mark-up ${ }^{47,48}$. Comparing them leads to an unrealistic comparison 49. Also, very often prices of medical supplies, e.g. implants for interbody surgery, are often concerned confidential due to confidentiality clauses between hospitals, manufactures and insurance companies and most surgeons have very little knowledge of the costs of the devices they implant ${ }^{50}$. It is important to obtain transparency to determine the influence on the hospital costs and charges.

Quality of life is considered a common good, but the accepted threshold for cost per QALY is currently subject of debate, and differs per country. In this study, QALY gain and cost-utility was calculated only for TLIF, with a range from $\$ 46,475 /$ QALY to $\$ 66,914 /$ QALY 29,33. Compared to other surgeries, with the same goal as TLIF and PLIF, namely increase mobility and reduce pain, as hip- (\$22,331/QALY to $\$ 41,922 / \mathrm{QALY})$, and knee-replacement $(\$ 16,244 /$ QALY to $\$ 45,804 /$ QALY), instrumented spine surgery with TLIF and PLIF is an expensive technique within the healthcare system ${ }^{51-54}$.

We can conclude that TLIF is associated with less complications, less blood loss, shorter surgical time and sometimes shorter hospital duration. In theory TLIF is a better candidate to be more cost-effective compared to PLIF, but this cannot be concluded from this review ${ }^{5-14}$. 


\section{Limitations}

This systematic review has several limitations: 1) We have restricted our search on the following languages: English, Dutch and German, this may have introduced a language bias and therefore may not represent all of the evidence. 2) This study included only published studies and did not search for conference proceedings of PhD dissertations. As a result, the results may be subject to a (minor) time lag. 3) For this review, we would have preferred to include prospective studies comparing costs-effectiveness of TLIF and PLIF, in patients with lumbar instability. Unfortunately, an explorative search resulted in no economic evaluations comparing TLIF and PLIF in a prospective design. We therefore have included economic evaluations concerning both TLIF or PLIF, based on any design. 4.) As a result it was sometimes difficult to score the quality of studies, since the scoring tool not always matched the study design of the included studies. 


\section{CONCLUSIONS \\ AND RECOMMENDATIONS FOR FUTURE RESEARCH}

Cost-effectiveness was limitedly and differently reported in 15 studies. The reported healthcare related costs and societal costs varied greatly and were not always transparent, the overall quality of the studies was low considering bias related to overall design and quality of economic evaluations. Although TLIF and PLIF are both frequently used techniques for similar indications, no economic evaluations are available directly comparing both techniques. Therefore, it is not possible to draw firm conclusions and being able to discern which technique is most cost-effective. Nevertheless, this review shows that instrumented spine surgery with TLIF and PLIF is an expensive technique within the healthcare system. Since TLIF is associated with less complications, less blood loss, shorter surgical time and sometimes shorter hospital duration, TLIF is better candidate to be more cost-effective compared to PLIF. With the burden on the financial aids ever increasing and the demand of instrumented spinal fusion only to rise further, such a difference would be of great importance. Physicians are obliged to use the best, but also most cost-effective methods, to keep healthcare affordable. Randomized prospective trials and economical evaluations to obtain high levels of evidence are needed. Quality of life reports with validated instruments and economical evaluations conducted according standardized approach should be a standard part of treatment, to able physicians and decision makers to objectify the clinical results and fill knowledge gaps in this specific area. 


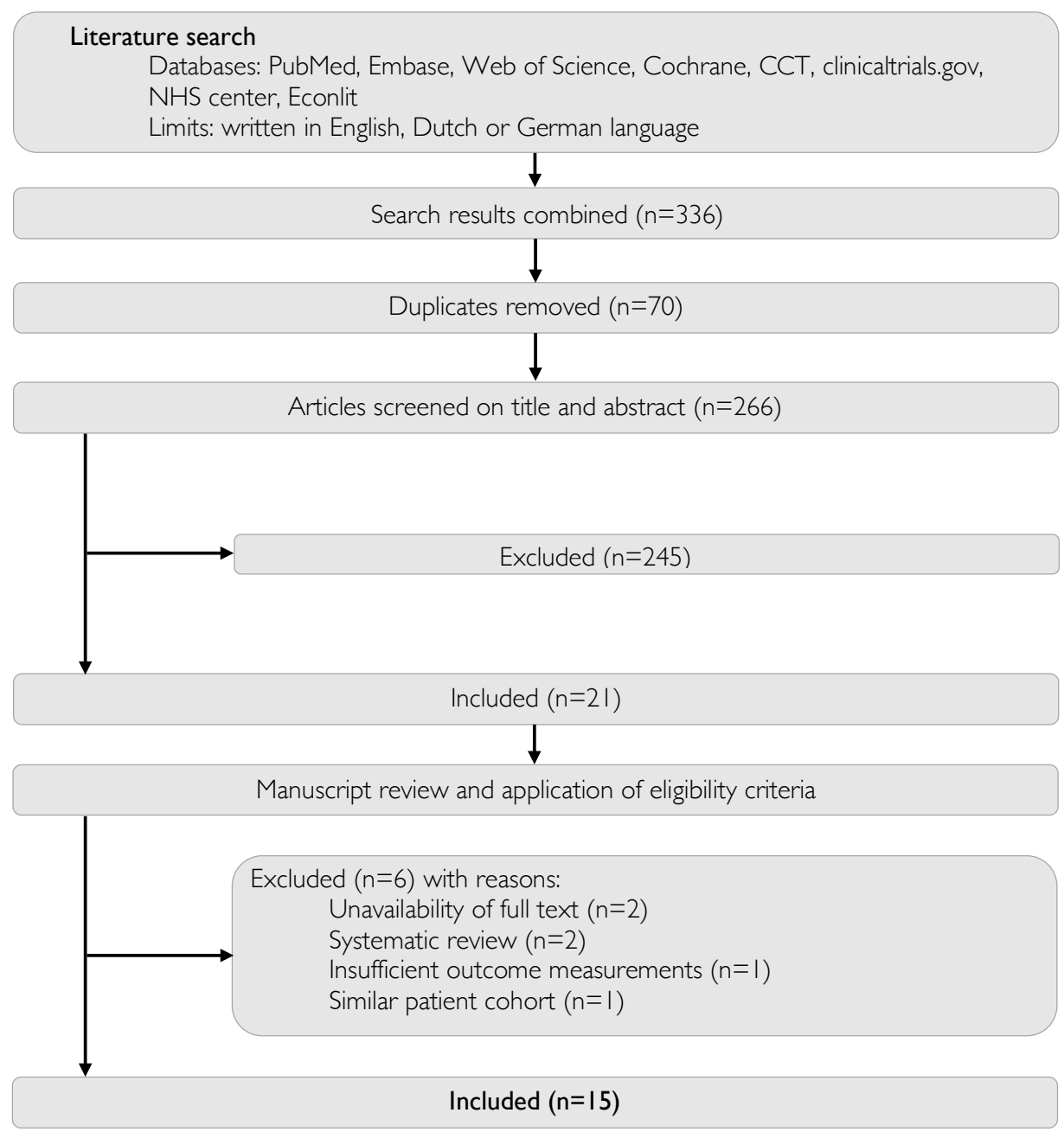

Figure 1: Flowchart of study selection 
Table 1. Study characteristics of included studies.

\begin{tabular}{|c|c|c|c|c|c|}
\hline Author & $\begin{array}{l}\text { Country } \\
\text { of origin }\end{array}$ & $\begin{array}{l}\text { Design } \\
\text { Economic } \\
\text { evaluation }\end{array}$ & $\begin{array}{l}\text { Date } \\
\text { collection }\end{array}$ & $\begin{array}{l}\text { Follow-up } \\
\text { time }\end{array}$ & $\begin{array}{l}\text { Number of } \\
\text { patients }\end{array}$ \\
\hline & & & & & TLIF \\
\hline Whitecloud et al. (2001) & USA & Financial study & Retrospective & 1 year & 80 \\
\hline
\end{tabular}

\begin{tabular}{lllllll}
\hline Wang et al. (2010) & USA & Cost-utility study & Retrospective & NA & 74 & -
\end{tabular}

\begin{tabular}{|c|c|c|c|c|c|c|}
\hline Adogwa et al. (2011) & USA & Cost-utility study & Retrospective & 2 years & 45 & 45 \\
\hline Parker et al. (2012) & USA & Cost-utility study & Prospective & 2 years & 30 & 15 \\
\hline Pelton et al. (2012) & USA & Financial study & Retrospective & 6 months & 66 & 33 \\
\hline
\end{tabular}

\begin{tabular}{|c|c|c|c|c|c|c|c|}
\hline Lucio et al. (2012) & USA & Financial study & Retrospective & NA & 210 & - & 101 \\
\hline Andres et al. (2013) & USA & $\begin{array}{l}\text { Chart review and } \\
\text { financial study }\end{array}$ & Retrospective & NA & 269 & 90 & - \\
\hline Singh et al. ( 2014) & USA & Financial study & Prospective & $\begin{array}{l}60 \text { days } \\
\text { postoperative }\end{array}$ & 66 & 33 & - \\
\hline Christensen et al. (2014) & Denmark & Cost-utility study & Retrospective & 2 years & 100 & 51 & - \\
\hline Parker et al. (2014) & USA & Cost-utility study & Prospective & 2 years & 100 & 50 & - \\
\hline Sulaiman et al. (2014) & USA & Cost-utility study & Retrospective & 1 year & 68 & 11 & - \\
\hline Godil et al. (2014) & USA & Cohort study & Prospective & 2 years & 58 & 58 & - \\
\hline Gandhoke et al. (2015) & USA & Cost-utility study & Prospective & 2 years & 45 & 29 & - \\
\hline
\end{tabular}

\begin{tabular}{llllllll}
\hline Fei et al. (2015) & China & Financial study & Prospective & 3 years & 176 & - & 81 \\
\hline Carreon et al. (2016) & USA & Cost-utility study & Retrospective & 1 year & 202 & 101 & -
\end{tabular}


Mean age

(in year)
Indication for surgery

\section{Level of Level of CHEC-list \\ surgery evidence score}

44.7

Isthmic spondylolisthesis, degenerative

NA

4

11.5

spondylolisthesis, degenerative disc disease, failed

back surgery syndrome.

55 Spondylolisthesis, degenerative disc disease and $\quad$ 1-, or 2-level $\quad 4 \quad 10.5$

lumbar spondylotic disease.

51 Grade I degenerative spondylolisthesis. $\quad$ NA $\quad 4 \quad 11.5$

$50 \quad$ Grade I degenerative spondylolisthesis. $\quad 1$ level $\quad 4 \quad 15.5$

49.85

Spondylolisthesis grade I or II), degenerative disc

1 level

4

11

disease and spinal stenosis.

$\begin{array}{llccc}58 & \text { Low-grade spondylolisthesis and spinal stenosis } & \text { 2 level } & 4 & 13 \\ 51.4 & - & \text { NA } & 4 & 11\end{array}$

51

Degenerative spondylolisthesis, degenerative disc

1-, or 2 level

4

12.5

disease, and spinal stenosis.

49

History of long lasting back-pain (including

NA

$3 b$

16

spondylolisthesis grade I and II).

52.6

Grade I degenerative spondylisthesis.

1 level

4

15.5

56

Grade I or II degenerative spondylolisthesis.

1-, or 2-level

4

11.5

54.4

Grade I degenerative spondylolisthesis

1 level

4

7

57.6

Degenerative spondylolisthesis, recurrent disc

NA $\quad 3 b$

15

herniation, failed back syndrome, synoviale cyst,

facet arthorpathy and mechanical backpain.

$\begin{array}{lllll}52.9 & \text { Degenerative disc disease. } & \text { NA } & 4 & 11 \\ 63.3 & \text { Grade I spondylolisthesis. } & 1 \text {-, or 2-level } & 4 & 9\end{array}$


Table 2. Results of included studies.

\begin{tabular}{llccll}
\hline \multirow{2}{*}{ Author } & Country & Number of & Utility & & \\
of origin & patients & $\begin{array}{c}\text { measurement } \\
\text { tool }\end{array}$ & Cost resources & Charges & or costs
\end{tabular} QALY gain

\begin{tabular}{|c|c|c|c|c|c|c|c|c|}
\hline & & $T L I F$ & PLIF & & $\begin{array}{l}\text { Healthcare } \\
\text { perspective }\end{array}$ & $\begin{array}{c}\text { Societal } \\
\text { perspective }\end{array}$ & & TLIF \\
\hline $\begin{array}{l}\text { Whitecloud } \\
\text { et al. (2001) }\end{array}$ & USA & 40 & - & - & - & - & Charges & - \\
\hline $\begin{array}{l}\text { Wang et al. } \\
\text { (2010) }\end{array}$ & USA & - & 22 & - & $\begin{array}{l}\text { Hospital } \\
\text { Finance } \\
\text { department }\end{array}$ & & Charges & - \\
\hline $\begin{array}{l}\text { Adogwa et } \\
\text { al. (2011) }\end{array}$ & USA & 45 & - & EQ-5D & Medicare. & & Costs & $\begin{array}{c}\text { Mean gain } 0.43 \\
\text { (2 year } \\
\text { Cumulative } 0.86 \text { ) }\end{array}$ \\
\hline $\begin{array}{l}\text { Parker et al. } \\
\text { (2012) }\end{array}$ & USA & 15 & - & EQ-5D & $\begin{array}{l}\text { Medicareand } \\
\text { Redbook prices }\end{array}$ & $\begin{array}{c}\text { Recorded } \\
\text { missed workdays } \\
\text { or homemaking } \\
\text { days at follow-up }\end{array}$ & Costs & Mean gain 0.41 \\
\hline $\begin{array}{l}\text { Pelton et al. } \\
\text { (2012) }\end{array}$ & USA & 33 & - & - & $\begin{array}{c}\text { Administrative } \\
\text { databases }\end{array}$ & $\begin{array}{c}\text { Administrative } \\
\text { databases }\end{array}$ & Costs & - \\
\hline
\end{tabular}

\begin{tabular}{llll}
\hline $\begin{array}{l}\text { Lucio et al. } \\
\text { (2012) }\end{array}$ & USA & - & 101 \\
\hline $\begin{array}{l}\text { Andres et al. } \\
\text { (2013) }\end{array}$ & USA & 90 & - \\
\hline $\begin{array}{l}\text { Singh et al. ( } \\
\text { 2014) }\end{array}$ & USA & 33 & - \\
\hline
\end{tabular}

-
-

Christensen
et al. (2014) $\quad$ Denmark $51 \quad$ -

$\begin{array}{lll}\text { Parker et al. } & \text { USA } & 50 \quad- \\ (2014) & & \end{array}$

Hospital financial
department

Costs

Hospital financial

department

Costs

$\begin{array}{cc}\begin{array}{c}\text { Hospital financial } \\ \text { department }\end{array} & \text { Costs and } \\ \text { charges }\end{array}$

National Health

Insurance
Service register, DREAM database Costs
DRG register.

$\begin{array}{ccc}\text { Hospital financial } & \text { Recorded } & \\ \text { departmet, } & \text { missed workdays } & \text { Mean gain } 0.44 \\ \text { Eedicare, } & \text { Costs } & \text { (2 year } \\ \text { Redbook, DRG } & \text { or homemaking } \\ \text { register. } & \text { days at follow-up } & \text { cumulative } \\ & & 0.695)\end{array}$

\begin{tabular}{|c|c|c|c|c|c|c|c|c|}
\hline $\begin{array}{l}\text { Sulaiman et } \\
\text { al. (2014) }\end{array}$ & USA & 11 & - & - & $\begin{array}{l}\text { Hospital financial } \\
\text { department }\end{array}$ & - & Costs & - \\
\hline $\begin{array}{l}\text { Godil et al. } \\
\text { (2014) }\end{array}$ & USA & 58 & - & EQ-5D & - & - & - & Mean gain 0.47 \\
\hline $\begin{array}{l}\text { Gandhoke et } \\
\text { al. (2015) }\end{array}$ & USA & 29 & - & EQ-5D & $\begin{array}{c}\text { Databaseand } \\
\text { costs healthcare } \\
\text { system }\end{array}$ & $\begin{array}{c}\text { Recorded } \\
\text { missed workdays } \\
\text { at follow-up }\end{array}$ & charges & $\begin{array}{c}\text { Mean } 0.34(2 \\
\text { year cumulative } \\
0.67)\end{array}$ \\
\hline
\end{tabular}

\begin{tabular}{|c|c|c|c|c|c|c|c|c|}
\hline $\begin{array}{l}\text { Fei et al. } \\
\text { (2015) }\end{array}$ & China & - & 81 & - & & - & charges & - \\
\hline $\begin{array}{l}\text { Carreon et } \\
\text { al. (2016) }\end{array}$ & USA & 101 & - & EQ-5D & & - & - & Mean gain 0.25 \\
\hline
\end{tabular}

*WC: Workers'compensation

**Non-WC: No workers'compensation 


\begin{tabular}{|c|c|c|c|c|c|c|c|c|}
\hline $\begin{array}{c}\text { Healthcare } \\
\text { perspective } \\
\text { Costs } \\
\text { (US Dollars) }\end{array}$ & $\begin{array}{l}\text { societal } \\
\text { perspective } \\
\text { costs (US } \\
\text { Dollars) }\end{array}$ & $\begin{array}{c}\text { Total costs } \\
\text { (US } \\
\text { Dollars) }\end{array}$ & $\begin{array}{l}\text { Cost-utility } \\
\text { score } \\
\text { (US Dollars/ } \\
\text { QALY) }\end{array}$ & $\begin{array}{l}\text { QALY } \\
\text { gain }\end{array}$ & $\begin{array}{l}\text { Healthcare } \\
\text { perspective } \\
\text { Costs } \\
\text { (US Dollars) }\end{array}$ & $\begin{array}{l}\text { societal } \\
\text { perspective } \\
\text { costs (US } \\
\text { Dollars) }\end{array}$ & $\begin{array}{l}\text { Total } \\
\text { costst } \\
\text { (US } \\
\text { Dollars) }\end{array}$ & $\begin{array}{c}\text { Cost-Utility } \\
\text { score (US } \\
\text { Dollars/QALY) }\end{array}$ \\
\hline
\end{tabular}

PLIF

47,029

86,112

$\begin{array}{llll}27,385 & 12,563 & 39,949 & 46,475\end{array}$

$\begin{array}{lll}27,926 & 19,599 & 47,525\end{array}$

$\begin{array}{ccc}\text { WC*: 26,153 } & \text { WC*: 10,571 }^{*} & \text { WC*: } \\ \text { Non-WC**: } & \text { Non-WC**: } & \text { Non-W23 } \\ 29,069 & 6,717 & 35,786\end{array}$

29,699

25,871

25,539

$\begin{array}{lll}25,922 & 36,537 & 62,458\end{array}$
29,199
19,933
49,132

39,314

$33,412 \quad 45,241 \quad 66,914$

12,833 


\section{APPENDIX 1.}

\section{Search strategies:}

1. National library of medicine (Medline):

- Search: ((((lumbar spondylolisthesis) OR lumbar instability) OR "Spondylolisthesis"[Mesh])) AND (((((Transforaminal lumbar interbody fusion) OR TLIF)) OR ((Posterior lumbar interbody fusion) OR PLIF)) OR "Spinal Fusion/methods"[Mesh])) AND (((()((((cost) OR ("Costs and Cost Analysis"[Mesh])) OR ("Cost-Benefit Analysis"[Mesh])) OR (economic evaluation)) OR (pricing))OR (cost-utility analysis)) OR (cost-effectiveness analysis )) OR (cost-effectiveness))

- $\quad$ Filter: Language Restriction English, Dutch, German.

- Hits: 65

\section{Embase:}

- $\quad$ Search: ((((lumbar spondylolisthesis) OR lumbar instability) OR Spondylolisthesis)) AND (((((TLIF) OR transforaminal lumbar interbody fusion)) OR ((PLIF) OR posterior lumbar interbody fusion)) OR Spinal Fusion/methods)) AND (((((((cost) OR (Costs and Cost Analysis)) OR (Cost-benefit analysis)) OR (economic evaluation)) OR (Pricing)) OR (cost-utility analysis)) OR (cost-effectiveness analysis)) OR (cost-effectiveness))

- $\quad$ Filter: None

- Hits: 97

3. Cochane Library: http://www.cochrane.org/

- Search: Lumbar interbody fusion AND cost.

- Filter: none

- Hits: 1

4. Current Controlled Trials (CCT): http://controlled-trials.com/

- $\quad$ Search: Lumbar interbody fusion AND cost

- Hits: 2

5. ClinicalTrials.gov: http://clinicaltrials.gov/

- Search: Lumbar interbody fusion AND cost

- Hits: 4 
6. NHS Centre for Reviews and Dissemination (CRD): http://www.york.ac.uk/inst/crd/

- Search: Lumbar interbody fusion AND cost

- Hits: 13

7. Web of science: https://apps.webofknowledge.com/

- Search: ((((lumbar spondylolisthesis) OR lumbar instability) OR Spondylolisthesis)) AND (((((TLIF) OR transforaminal lumbar interbody fusion)) OR ((PLIF) OR posterior lumbar interbody fusion)) OR Spinal Fusion/methods)) AND (((((((cost) OR (Costs and Cost Analysis)) OR (Cost-benefit analysis)) OR (economic evaluation)) OR (Pricing)) OR (cost-utility analysis)) OR (cost-effectiveness analysis)) OR (cost-effectiveness))

- Filter: Language English, German or Dutch

- Hits: 150

8. Econlit:

- Search: ((((lumbar spondylolisthesis) OR lumbar instability) OR "Spondylolisthesis"[Mesh])) AND (((((Transforaminal lumbar interbody fusion) OR TLIF)) OR ((Posterior lumbar interbody fusion) OR PLIF)) OR "Spinal Fusion/methods"[Mesh])) AND (((()(((cost) OR ("Costs and Cost Analysis"[Mesh])) OR ("Cost-Benefit Analysis"[Mesh])) OR (economic evaluation)) OR (pricing))OR (cost-utility analysis)) OR (cost-effectiveness analysis )) OR (cost-effectiveness))

- Filter: none

- Hits: 4 


\section{APPENDIX 2.}

\section{Risk of bias of included studies.}

\begin{tabular}{|c|c|c|c|}
\hline Author & Design & Date collection & Selection bias \\
\hline Whitecloud et al. (2001) & Financial study & Retrospective & + \\
\hline Wang et al. (2010) & Cost-utility study & Retrospective & + \\
\hline Adogwa et al. (2011) & Cost-utility study & Retrospective & + \\
\hline Parker et al. (2012) & Cost-utility study & Prospective & + \\
\hline Pelton et al. (2012) & Financial study & Retrospective & + \\
\hline Lucio et al. (2012) & Financial study & Prospective & + \\
\hline Andres et al. (2013) & Chart review and financial study & Retrospective & + \\
\hline Singh et al. ( 2014) & Cohort study & Prospective & + \\
\hline Christensen et al. (2014) & Cost-utility study & Retrospective & - \\
\hline Parker et al. (2014) & Cost-utility study & Prospective & + \\
\hline Sulaiman et al. (2014) & Cost-utility study & Retrospective & + \\
\hline Godil et al. (2014) & Cohort study & Prospective & + \\
\hline Gandhoke et al. (2015) & Cost-utility study & Prospective & + \\
\hline Fei et al. (2015) & Cohort study & Prospective & + \\
\hline Carreon et al. (2016) & Cost-effectiveness study & Retrospective & + \\
\hline
\end{tabular}




\begin{tabular}{ccccc} 
Performance bias & Detection bias & Attrition bias & Reporting bias & Total score \\
\hline+ & + & + & + & High \\
+ & + & + & High \\
+ & + & - & High \\
+ & + & - & High \\
+ & + & $+/-$ & High \\
+ & + & + & High \\
+ & + & + & High \\
+ & + & $+/-$ & High \\
+ & + & - & High \\
+ & + & - & High \\
+ & + & $+/-$ & High \\
+ & + & - & High \\
+ & + & - & High \\
+ & + & - & High
\end{tabular}




\section{APPENDIX 3.}

Economical evaluation assessment scores of included studies.

\begin{tabular}{|c|c|c|c|c|c|c|c|c|c|}
\hline & 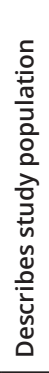 & 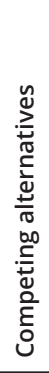 & 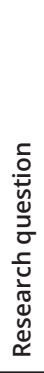 & 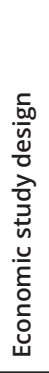 & 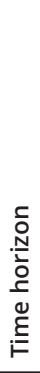 & 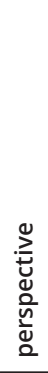 & 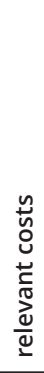 & 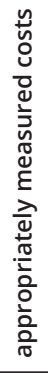 & 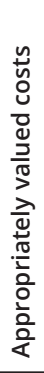 \\
\hline Whitecloud et al. (2001) & + & + & + & - & + & - & + & + & + \\
\hline Wang et al. (2010) & + & + & +- & - & + & - & + & - & - \\
\hline Adogwa et al. (2011) & + & - & + & - & - & + & + & + & +- \\
\hline Parker et al. (2012) & + & + & + & + & + & + & + & + & +- \\
\hline Pelton et al. (2012) & + & + & + & - & + & - & - & + & + \\
\hline Lucio et al. (2012) & + & - & + & - & + & - & + & + & + \\
\hline Andres et al. (2013) & + & - & + & - & + & - & + & + & - \\
\hline Singh et al. ( 2014) & + & + & + & - & + & - & + & + & +- \\
\hline Christensen et al. (2014) & + & - & + & + & + & + & + & + & + \\
\hline Parker et al. (2014) & + & + & + & + & + & + & + & + & +- \\
\hline Sulaiman et al. (2014) & +- & + & + & + & + & - & + & + & - \\
\hline Godil et al. (2014) & + & - & + & - & - & - & - & - & - \\
\hline Gandhoke et al. (2015) & + & - & + & + & + & + & + & + & + \\
\hline Fei et al. (2015) & + & + & + & - & + & - & + & + & - \\
\hline Carreon et al. (2016) & + & - & + & + & + & - & - & - & - \\
\hline
\end{tabular}



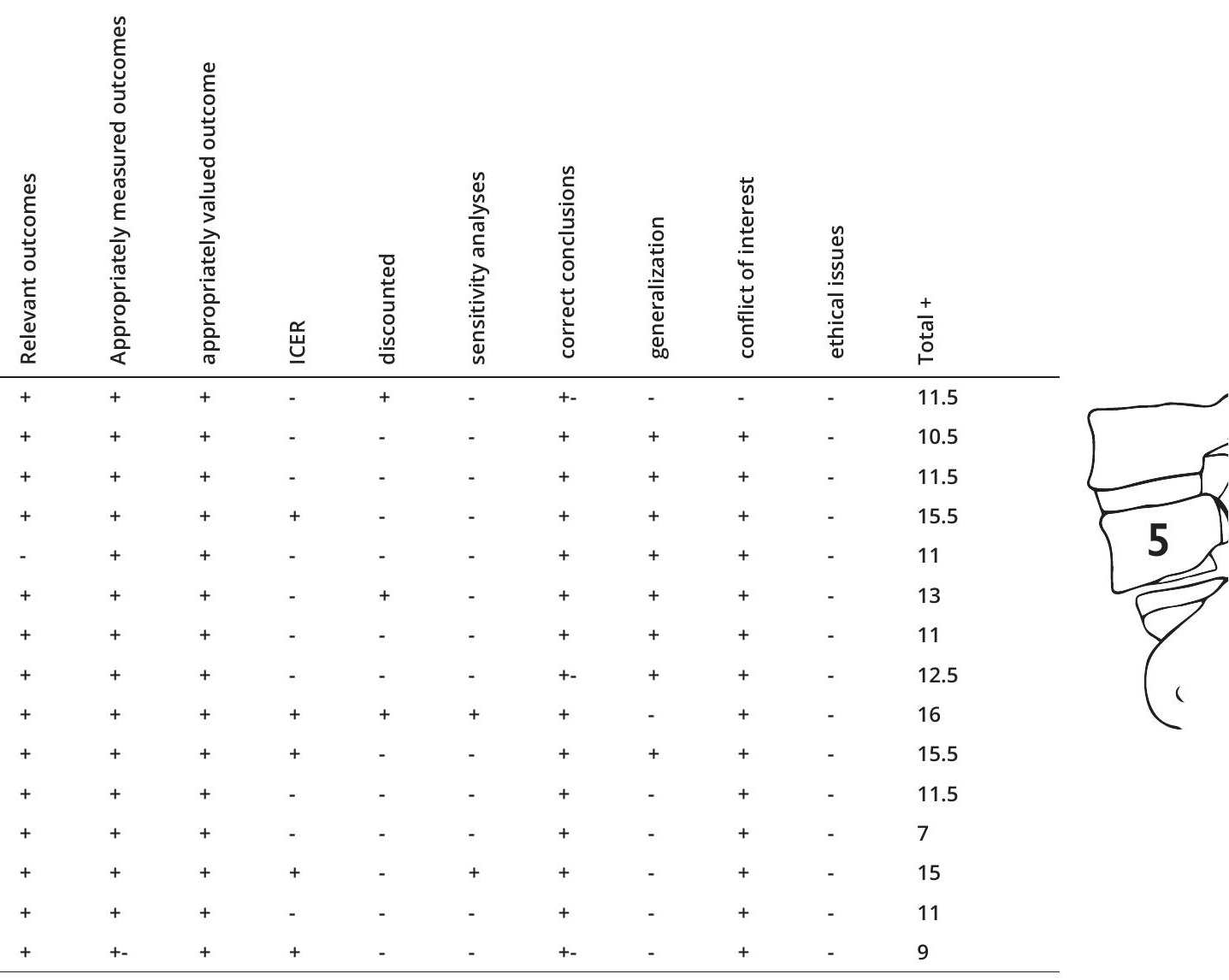


\section{REFERENCES}

1. Rajaee SS, Bae HW, Kanim LEA, Delamarter RB. Spinal Fusion in the United States. Spine (Phila Pa 1976). 2012;37(1):67-76. doi:10.1097/BRS.0b013e31820cccfb.

2. Harms J, Rolinger H. A one-stager procedure in operative treatment of spondylolistheses: dorsal traction-reposition and anterior fusion. Z Orthop Ihre Grenzgeb. 1981;120(3):343-347. doi:10.1055/s-2008-1051624.

3. Cloward RB. The treatment of ruptured lumbar intervertebral discs by vertebral body fusion. I. Indications, operative technique, after care. J Neurosurg. 1953;10(2):154-168. doi:10.3171/jns.1953.10.2.0154.

4. Cole CD, McCall TD, Schmidt MH, Dailey AT. Comparison of low back fusion techniques: Transforaminal lumbar interbody fusion (TLIF) or posterior lumbar interbody fusion (PLIF) approaches. Curr Rev Musculoskelet Med. 2009;2(2):118-126. doi:10.1007/s12178-009-9053-8.

5. Asil K, Yaldiz C. Retrospective Comparison of Radiological and Clinical Outcomes of PLIF and TLIF Techniques in Patients Who Underwent Lumbar Spinal Posterior Stabilization. Medicine (Baltimore). 2016;95(17):1-7. doi:10.1097/MD.0000000000003235.

6. de Kunder SL, Rijkers K, van Hemert WLW, Willems PCPH, ter Laak - Poort MP, van Santbrink H. Transforaminal versus posterior lumbar interbody fusion as operative treatment of lumbar spondylolisthesis, a retrospective case series. Interdiscip Neurosurg. 2016;5:64-68. doi:10.1016/j.inat.2016.07.001.

7. Fariborz S, Gharedaghi M, Khosravi A, et al. Comparison of Results of 4 Methods of Surgery in Grade 1 Lumbosacral Spondylolisthesis. Neurosurg Q. 2016;26(1):14-18. doi:10.1097/WNQ.0000000000000197.

8. Han S, Xiao Q, Zhu G, Dai J, Tang X, Sun H. Comparison between transforaminal lumbar interbody fusion and posterior lumbar interbody fusion in treatment of lumbar spondylolisthesis. Int J Clin Exp Med. 2016;9(2):3932-3938.

9. Liu J, Deng H, Long X, Chen X, Xu R, Liu Z. A comparative study of perioperative complications between transforaminal versus posterior lumbar interbody fusion in degenerative lumbar spondylolisthesis. Eur spine J. 2015. doi:10.1007/s00586-015-4086-8.

10. Sakeb N, Ahsan K. Comparison of the early results of transforaminal lumbar interbody fusion and posterior lumbar interbody fusion in symptomatic lumbar instability. Indian J Orthop. 2013;47(3):255. doi:10.4103/0019-5413.111484.

11. Yan DL, Pei FX, Li J, Soo CL. Comparative study of PILF and TLIF treatment in adult degenerative spondylolisthesis. Eur Spine J. 2008;17(10):1311-1316. doi:10.1007/s00586-008-0739-1.

12. ParkJ-S, Kim Y-B, Hong H-J, Hwang S-N. Comparison between Posterior and Transforaminal Approaches for Lumbar Interbody Fusion. J Korean Neurosurg Soc. 2005;37:340-344.

13. Yang E-Z, Xu J-G, Liu X-K, et al. An RCT study comparing the clinical and radiological outcomes with the use of PLIF or TLIF after instrumented reduction in adult isthmic spondylolisthesis. Eur Spine J. 2016;25(5):1587-1594. doi:10.1007/s00586-015-4341-z.

14. de Kunder SL, van Kuijk SM, Rijkers K, et al. Transforaminal lumbar interbody fusion (TLIF) versus posterior lumbar interbody fusion (PLIF) in lumbar spondylolisthesis, a systematic review and meta-analysis. Spine J. 2017;17(11):1712-1721. doi:10.1016/j.spinee.2017.06.018.

15. van Mastrigt G, Hiligsmann M, Arts J et al. How to prepare a systematic review of economic evaluations for informing evidence-based healthcare decisions: a five-step approach (part 1/3). Expert Rev Pharmacoecon Outcomes Res. 2016. doi:10.1080/14737167.2016.1246960.

16. Thielen FW, Van Mastrigt G, Burgers $L$ et al. How to prepare a systematic review of economic evaluations for clinical practice guidelines: database selection and search strategy development (part 2/3). Expert Rev Pharmacoecon Outcomes Res. 2016. doi:10.1080/14737167.2016.1246962.

17. Wijnen B, Van Mastrigt G, Redekop W, Majoie H, De Kinderen R, Evers S. How to prepare a systematic 
review of economic evaluations for informing evidence-based healthcare decisions: data extraction, risk of bias, and transferability (part 3/3). Expert Rev Pharmacoecon Outcomes Res. 2016;0(0):1-10. doi:10.108 0/14737167.2016.1246961.

18. Moher D, Liberati A, Tetzlaff J, Altman DG, Grp P. Preferred Reporting Items for Systematic Reviews and Meta-Analyses: The PRISMA Statement (Reprinted from Annals of Internal Medicine). Phys Ther. 2009;89(9):873-880. doi:10.1371/journal.pmed.1000097.

19. Liberati A, Altman DG, Tetzlaff J, et al. The PRISMA statement for reporting systematic reviews and meta-analyses of studies that evaluate healthcare interventions: explanation and elaboration. Bmj. 2009;339(jul21 1):b2700-b2700. doi:10.1136/bmj.b2700.

20. Shemilt I, Thomas J, Morciano M. A web-based tool for adjusting costs to a specific target currency and price year. Evid Policy AJ Res Debate Pract. 2010;6(1):51-59. doi:10.1332/174426410X482999.

21. Higgins JPT AD. Chapter 8. Assessing risk of bias in included studies. In: Higgins JPT, Green S (editors). Cochrane Handbook for systematic Reviews of Interventions. Version 5.1.0 [updated March 2011]. Cochrane Collab. 2011.

22. Howick J, Chalmers I, Glasziou P, et al. The Oxford 2011 Levels of Evidence. Oxford Centre Evidence-Based Medicine. Vol 1.; 2011.

23. Evers S, Goossens M, de Vet H, van Tulder M, Ament A. Criteria list for assessment of methodological quality of economic evaluations: Consensus on Health Economic Criteria. Int J Technol Assess Health Care. 2005;21:240-245. doi:10.1017/S0266462305050324.

24. Moatz B, Tortolani PJ. Transforaminal lumbar interbody fusion and posterior lumbar interbody fusion utilizing BMP-2 in treatment of degenerative spondylolisthesis: neither safe nor cost effective. Surg Neurol Int. 2013;4(Suppl 2):S67-S73. doi:10.4103/2152.

25. Jiang S-D, Chen J-W, Jiang L-S. Which procedure is better for lumbar interbody fusion: anterior lumbar interbody fusion or transforaminal lumbar interbody fusion? Arch Orthop Trauma Surg. 2012;132:12591266. doi:10.1007/s00402-012-1546-z.

26. Parker SL, Adogwa O, Bydon A, Cheng J, McGirt MJ. Cost-effectiveness of minimally invasive versus open transforaminal lumbar interbody fusion for degenerative spondylolisthesis associated low-back and leg pain over two years. World Neurosurg. 2012;78(1-2):178-184. doi:10.1016/j.wneu.2011.09.013.

27. Cheng J, Park P, Le $\mathrm{H}$ et al. Short-term and long-term outcomes of minimally invasive and open transforaminal lumbar interbody fusions: is there a difference? J Neurosurg. 2013;35. doi:10.3171/2013.5. FOCUS1377.

28. Wang MY, Cummock MD, Yu Y, Trivedi RA, Sn FRCS(. An analysis of the differences in the acute hospitalization charges following minimally invasive versus open posterior lumbar interbody fusion. J Neurosurg Spine. 2010;12:694-699. doi:10.3171/2009.12.SPINE09621.

29. Adogwa O, Parker SL, Davis BJ, et al. Cost-effectiveness of transforaminal lumbar interbody fusion for Grade I degenerative spondylolisthesis. J Neurosurg Spine J Neurosurg Spine. 2011;15(15):138-143. doi:10.3171/2011.3.SPINE10562.

30. Christensen A, Høy K, Bünger $C$, et al. Transforaminal lumbar interbody fusion vs. posterolateral instrumented fusion: cost-utility evaluation along side an RCT with a 2-year follow-up. Eur Spine J. 2014;23(5):1137-1143. doi:10.1007/s00586-014-3238-6.

31. Parker SL, Mendenhall SK, Shau DN, et al. Minimally Invasive versus Open Transforaminal Lumbar Interbody Fusion for Degenerative Spondylolisthesis: Comparative Effectiveness and Cost-Utility Analysis. World Neurosurg. 2014;82(1-2):230-238. doi:10.1016/j.wneu.2013.01.041.

32. Sulaiman WAR, Singh M. Minimally invasive versus open transforaminal lumbar interbody fusion for degenerative spondylolisthesis grades 1-2: Patient-reported clinical outcomes and cost-utility analysis. Ochsner J. 2014;14(1):32-37. doi:10.1043/1524-5012-14.1.32. 
33. Gandhoke GS, Shin HM, Chang YF, et al. A cost-effectiveness comparison between open transforaminal and minimally invasive lateral lumbar interbody fusions using the incremental cost-effectiveness ratio at 2-year follow-up. Neurosurgery. 2016;78(4):585-593. doi:10.1227/NEU.0000000000001196.

34. Carreon LY, Glassman SD, Ghogawala Z, Mummaneni PV, Mcgirt MJ, Asher AL. Modeled cost-effectiveness of transforaminal lumbar interbody fusion compared with posterolateral fusion for spondylolisthesis using N2QOD data. J Neurosurg Spine. 2016;24:916-921. doi:10.3171/2015.10.SPINE15917.

35. Whitecloud TSI, Roesch WW, Ricciardi JE. Transforaminal Interbody Fusion Versus Anterior-Posterior Interbody Fusion of the Lumbar Spine: A Financial Analysis. J Spinal Disord. 2001;14(2):100-103.

36. Pelton MA, Phillips FM, Singh K. A Comparison of Perioperative Costs and Outcomes in Patients With and Without Workers' Compensation Claims Treated With Minimally Invasive or Open Transforaminal Lumbar Interbody Fusion. Spine (Phila Pa 1976). 2012;37(22):1914-1919. doi:10.1097/BRS.0b013e318257d490.

37. Lucio JC, VanConia RB, deLuzio KJ, Lehmen JA, Rodgers JA, Rodgers WB. Economics of less invasive spinal surgery: An analysis of hospital cost differences between open and minimally invasive instrumented spinal fusion procedures during the perioperative period. Risk Manag Healthc Policy. 2012;(5):65-74. doi:10.2147/RMHP.S30974.

38. Andres TM, Park J, Ricart Hoffiz PA, McHugh BJ, Warren DT, Errico TJ. Cost analysis of anterior-posterior circumferential fusion and transforaminal lumbar interbody fusion. Spine J. 2013. doi:10.1016/j. spinee.2012.11.055.

39. Singh K, Nandyala S V, Marquez-Lara A, et al. A perioperative cost analysis comparing single-level minimally invasive and open transforaminal lumbar interbody fusion. Spine J. 2014;14:1694-1701. doi:10.1016/j. spinee.2013.10.053.

40. Fei H, Xu J, Wang S, Xie Y, Ji F, Xu Y. Comparison between posterior dynamic stabilization and posterior lumbar interbody fusion in the treatment of degenerative disc disease: a prospective cohort study. $J$ Orthop Surg Res. 2015;10(87). doi:10.1186/s13018-015-0231-7.

41. Godil SS, Parker SL, Zuckerman SL, Mendenhall SK, McGirt MJ. Accurately measuring the quality and effectiveness of cervical spine surgery in registry efforts: Determining the most valid and responsive instruments. Spine J. 2014;(14):2885-2891. doi:10.1016/j.spinee.2013.07.444.

42. RED BOOK | Healthcare Drug Pricing Resource.

43. Medicare.gov: the official U.S. government site for Medicare.

44. Hout WB van den. The value of productivity: human-capital versus friction-cost method. Ann Rheum Dis. 2010;69(1):i89-91. doi:10.1136/ard.2009.117150.

45. Hjollund NH, Larsen FB, Andersen JH. Register-based follow-up of social benefits and other transfer payments: Accuracy and degree of completeness in a Danish interdepartmental administrative database compared with a population-based survey. Scand J Public Health. 2007;35(5):497-502. doi:10.1080/14034940701271882.

46. Welte R, Feenstra T, Jager $H$, Leidl R. A decision chart for assessing and improving the transferability of economic evaluation results between countries. Pharmacoeconomics. 2004. doi:10.2165/00019053200422130-00004.

47. Bai G, Anderson GF. Extreme Markup: The Fifty US Hospitals With The Highest Charge-To-Cost Ratios. Health Aff. 2015;34(6):922-928. doi:10.1377/hlthaff.2014.1414.

48. McCarthy M. Some US hospitals charge 10 times the cost of services, study finds. BMJ. 2015;350:h3285-h3285. doi:10.1136/bmj.h3285.

49. Finkler SA. The distinction between cost and charges. Ann Intern Med. 1982;96(1). doi:10.1059/0003-481996-1-102.

50. Okike K, O'Toole R V., PollakAN, et al. Survey finds few orthopedic surgeons know the costs of the devices they implant. Health Aff. 2014;33(1):103-109. doi:10.1377/hlthaff.2013.0453. 
51. Elmallah RK, Chughtai M, Khlopas A, et al. Determining Cost-Effectiveness of Total Hip and Knee Arthroplasty Using the Short Form-6D Utility Measure. 2016. doi:10.1016/j.arth.2016.08.006.

52. Rampersaud YR, Tso P, Walker KR, et al. Comparative outcomes and cost-utility following surgical treatment of focal lumbar spinal stenosis compared with osteoarthritis of the hip or knee: Part 2 - Estimated lifetime incremental cost-utility ratios. Spine J. 2014. doi:10.1016/j.spinee.2013.11.011.

53. Irina C, Mattias N, Nancy T, Laet Chris D, Mark L. Drempelwaarden voor kosteneffectiviteit in de gezondheidszorg.

54. Hirth RA, Chernew ME, Miller E, Fendrick AM, Weissert WG. Willingness to Pay for a Quality-adjusted Life Year In Search of a Standard. Med Decis Mak. 2000. doi:10.1177/0272989X0002000310. 



\section{Chapter 6}

\section{A protocol of a randomized controlled multicenter trial for surgical treatment of lumbar spondylolisthesis: The Lumbar Interbody Fusion Trial (LIFT)}

SL de Kunder, K Rijkers, SMJ van Kuijk, SMAA Evers, RA de Bie and $H$ van Santbrink 


\section{ABSTRACT}

\section{Background}

With a steep increase in the number of instrumented spinal fusion procedures, there is a need for comparative data to develop evidence based treatment recommendations. Currently, the available data on cost and clinical effectiveness of the two most frequently performed surgeries for lumbar spondylolisthesis, transforaminal lumbar interbody fusion (TLIF) and posterior lumbar interbody fusion (PLIF), are not sufficient. Therefore, current guidelines do not advise which is the most appropriate surgical treatment strategy for these patients. Non-randomized studies comparing TLIF and PLIF moreover suggest that TLIF is associated with fewer complications, less blood loss, shorter surgical time and hospital duration. TLIF may therefore be more cost-effective. The results of this study will provide knowledge on short- and long-term clinical and economical effects of TLIF and PLIF procedures, which will lead to recommendations for treating patients with lumbar spondylolisthesis.

\section{Methods}

Multicenter blinded Randomized Controlled Trial (RCT; blinding for the patient and statistician, not for the clinician and researcher). A total of 144 patients over 18 years old with symptomatic single level lumbar degenerative, isthmic or iatrogenic spondylolisthesis whom are candidates for LIF (lumbar interbody fusion) surgery through a posterior approach will be randomly allocated to TLIF or PLIF. The study will consist of three parts: 1) a clinical effectiveness study, 2) a cost-effectiveness study, and 3) a process evaluation. The primary clinical outcome measures are: change in disability measured with Oswestry Disability Index (ODI) and change in quality adjusted life years (QALY) measured with EQ-5D-5L. Secondary clinical outcome measures are: Short Form (36) Health Survey (SF36), VAS back pain, VAS leg pain, Hospital Anxiety Depression Scale (HADS), complications, productivity related costs (iPCQ) and medical costs (iMCQ). Measurements will be carried out at five fixed time points (pre-operatively and at 3, 6, 12 and 24 months).

\section{Discussion}

It is hypothesized that TLIF, compared to PLIF, has similar clinical outcome or is possibly better in reducing disability. Moreover, direct medical costs are expected to be lower due to less surgical morbidity, shorter hospital stay and shorter surgical time. Indirect costs are assumed to be lower for TLIF as well, because we suspect less working days are lost. Currently, prospective data comparing clinical and cost-effectiveness of both techniques are not available. Therefore, in clinical practice both techniques are used and the choice for technique is greatly based on surgeon's preference. The demand for spinal fusion surgery has risen steeply over the last 10 years and is expected to increase even further 
in the near future. As a result, the burden on society (and the working population) will increase. In case our hypothesis is confirmed, treatment guidelines will be adapted, and TLIF will be recommended as first choice surgical treatment of lumbar spondylolisthesis. Ultimately this will lead to reduction of (direct and indirect) costs and better clinical outcome for spondylolisthesis patients eligible for instrumented spinal surgery.

\section{Trial registration number}

Netherlands Trial Registry, number 5722 (registration date March 30, 2016). 


\section{BACKGROUND}

Neurogenic leg pain is a frequent complaint in the general population. This pain is can be caused by compression or stretch of nerve roots or cauda equina fibers (lumbar radiculopathy or neurogenic claudication respectively). Lumbar disc herniation and spinal canal stenosis are the classic and most common causes. An other cause of neurogenic leg pain is becoming more and more prevalent, namely lumbar spondylolisthesis ${ }^{1}$. If conservative treatment for neurogenic leg pain fails, surgical treatment can be considered. In case of lumbar disc herniation or spinal canal stenosis, decompression surgery is executed. In case of spondylolisthesis, decompression alone is not sufficient, and additional spinal fusion is recommended and common practice nowadays. In the US, between 1998 and 2008 the national bill for instrumented spinal fusion has increased 7.9-fold ${ }^{2,3}$. This only will increase further in the next decades with an aging population. A number of surgical techniques for spinal fusion are available. Of these, transforaminal lumbar interbody fusion (TLIF) and posterior lumbar interbody fusion (PLIF) are most frequently performed in the Netherlands. Both procedures consist of pedicle screw placement. In the TLIF procedure, this is followed by placement of one cage in the intervertebral space using a unilateral approach. The PLIF procedure consists of placement two identical cages bilaterally in the intervertebral space using a bilateral approach. There are no strict indications for using either techniques, because a number of prospective studies have shown that both methods effectively reduce leg pain ${ }^{3-7}$. As a result, the choice of technique is greatly based on surgeon's preference. Even though these techniques are assumed to be equal, nonrandomized studies and one small RCT comparing TLIF and PLIF suggest that TLIF is associated with fewer complications, less blood loss, shorter surgical time and hospital duration ${ }^{8-10}$. Our own retrospective data of 254 TLIF and PLIF patients confirm this, and additionally reveal that TLIF patients score better on different quality of life related outcome parameters (SF- 36, ODI) compared to PLIF ${ }^{11}$. These findings have not been confirmed in a randomized controlled trial. However, with a steep increase in the number of instrumented spinal fusion procedures there is a need for comparative data to develop evidence based treatment recommendations. This study proposes to analyse in a high quality design (multicenter prospective randomized controlled trial) effectiveness and cost-effectiveness of the TLIF technique compared to PLIF technique for patients with leg pain caused by single level lumbar spondylolisthesis. 


\section{METHODS}

This study consists of three parts, each with its own research question:

I. Clinical effectiveness

1. Is transforaminal lumbar interbody fusion (TLIF) effective in reducing disability in comparison to posterior lumbar interbody fusion (PLIF) in patients with single level lumbar spondylolisthesis?

II. Cost-effectiveness

2. Is transforaminal lumbar interbody fusion (TLIF) cost-effective in comparison to posterior lumbar interbody fusion (PLIF) in patients with single level lumbar spondylolisthesis from a societal perspective?

III. Process evaluation

3. What are the experiences and opinions of patients and professionals regarding TLIF?

\section{Design}

A nationwide, prospective, multicenter, patient blinded, randomized controlled superiority trial. Patients will be randomized into one of two parallel groups (1) TLIF and (2) PLIF in a 1:1 ratio. The study inclusion period will be approximately 2 years, and the follow-up period 2 years (total study duration 4 years). Informed consent will be acquired from all participants. The study has been approved by the local institutional medical ethical committee (Medical Research Ethics Committee Zuyderland, METC 16-T-36) and has been registered with the Netherlands Trial Registry, part of the Dutch Cochrane Centre (number 5722).

\section{Study population}

One hundred forty-four eligible lumbar spondylolisthesis patients will be included in this study. Eligible are patients with:

- Indication for LIF (lumbar interbody fusion) surgery through a posterior approach.

- Clinical mono uni- or bilateral lumbar radiculopathy or intermittent neurogenic claudication caused by a single level isthmic, degenerative or iatrogenic spondylolisthesis grade I, II or III at level L3L4, L4L5 or L5S1.

- Single level spondylolisthesis with central or foraminal stenosis on MRI (or CT), of which the anatomical level is corresponding the clinical syndrome.

- Age over 18 years.

- Psychosocially, mentally, and physically able to fully comply with this study protocol.

- Written informed consent prior to this study. 
Patients will be excluded of participation in this study when any of the following criteria are met:

- Previous radiotherapy at the intended surgical level.

- $\quad$ (Progressive) motor failure and/or anal sphincter disorders which urges instant intervention.

- Active infection.

- $\quad$ Immature bone (ongoing growth).

- $\quad$ Active malignancy.

- Pregnancy.

- Symptomatic osteoporosis.

- Contra-indications for anesthesia or surgery.

- Inadequate command of the Dutch language.

\section{Setting and recruitment}

This is a cooperating project involving six Dutch hospitals (Maastricht University Medical Center - Maastricht, Zuyderland Medical Center - Heerlen, University Medical Center Groningen - Groningen, Radboud University Medical Center - Nijmegen, Canisius Wilhelmina Hospital - Nijmegen and Isala - Zwolle). These hospitals have been chosen because of their high volume of instrumented spine surgery and their familiarity with TLIF and PLIF. Patients referred to the outpatient clinic with an indication for LIF surgery are eligible to participate in the study, and will be referred by colleagues to the researchers.

Researchers will inform the patient verbally and in writing. When the patient is willing to participate (patients are allowed to use a cooling off period of one week) an informed consent form will be signed by the patient and the researcher, and patients will be allocated randomly to either the TLIF or PLIF group.

\section{Sample size calculation}

The difference in ODI improvement is defined as primary endpoint and will be used for calculating sample size. An improvement of seven points is considered a minimal clinically important difference ${ }^{12}$. Based on own retrospective data, ODI improvement after TLIF was 17.5 points (35\%), and 9.5 points (19\%) after PLIF. The response within each subject group was normally distributed with standard deviation of 16 . Assuming that a true difference between the experimental and control group-means is at least eight, we will need to study 64 experimental subjects and 64 control subjects to be able to reject the null hypothesis that the population means of the experimental and control groups are equal with probability (power) of 0,8. The Type I error probability associated with this test of this null hypothesis is 0,05. Based on a $10 \%$ loss to follow-up, we intend to include 144 patients (72 patients per group). 


\section{Randomization}

Participants will be randomly assigned by the researcher to either the TLIF or PLIF group with an 1:1 allocation using a web based computer generated randomization schedule stratified by treatment hospital and type of spondylolisthesis by variable block algorithm with random blocks of four, six or eight. Patients are kept blinded for the allocated treatment during the follow-up period of two years. At the end of the follow-up the blind can be lifted upon the patient's request. The statistician is blinded as well.

\section{Interventions}

\section{TLIF group}

The patient undergoes standard surgical treatment of degenerative listhesis with central spinal canal stenosis, or of isthmic listhesis with foramen stenosis. All patients receive antibiotic prophylaxis according to local hospital protocol. After receiving antibiotic prophylaxis, the patient is brought under general anesthesia and positioned prone. A midline or paramedian posterior approach is performed, exposing the posterior lumbar elements including the facet joints. Poly-axial pedicle screws are placed bilaterally, using fluoroscopic guidance or navigation, depending on preference of the surgeon. In case of spinal canal stenosis, the central part of the spinal canal is decompressed by laminectomy. Unilateral exposure to the intervertebral disc is assured by total unilateral facetectomy, decompressing the descending and leaving roots. In the case of bilateral symptomatic leg pain, the side of the unilateral approach is free of choice for the surgeon. Unilateral facetectomy is performed to gain access to the intervertebral disc. Discectomy is performed. Endplate cartilage is prepared to provide a host bed of bleeding subchrondral bone for placement of the cage. The TLIF cage size is determined by a trial cage and fluoroscopy. The definitive cage is filled with autologous bone or allograft and is tamped into place. Its position is checked radiologically. After placement of the TLIF cage, the remainder of the disc space is filled with autologous bone, obtained from the decompression. A titanium rod interconnects the screws on each side. The spreader is removed and the wound is thoroughly irrigated and closed in several layers without suction drainage.

\section{PLIF group}

Pedicle screw placement and if necessary, laminectomy as in the TLIF group. Bilateral access to the intervertebral disc assured by resection of the pars articularis inferior and partial resection of the pars superior of the facet joint. Bilateral discectomy is performed. Subsequently, endplate cartilage is prepared to provide a host bed of bleeding subchrondral bone for placement of the cages. Determination of cage size by trail cages and fluoroscopy. Before placement of the definitive cages, the disc space is partially filled with autologous bone, obtained from decompression. The definitive cages are also filled with autologous bone or allograft and are tamped into place with fluoroscopic guidance. 
Their position is checked radiologically. A titanium rod interconnects the screws bilaterally. The wound is closed in the same matter as in the TLIF group. The flow of patients through the study is summarized in figure 1.

\section{Post-surgical care}

Standardly there is no postoperative administration of IV antibiotics. Position of the implants will be checked by means of lumbar spine X-ray (anterior-posterior and lateral). Patients are encouraged to mobilise, initially with guidance of a physiotherapist, and resume daily activities as soon as possible. No additional physical therapy at home is advised.

\section{(Clinical) effectiveness}

To assess the (clinical) effectiveness of both procedures, patients are asked to fill out web based questionnaires concerning Patient Related Outcome Measurements (PROMS) at five fixed time-points, namely preoperatively and 3, 6, 12 and 24 months postoperatively.

\section{Primary outcomes}

Change in disability measured using the Oswestry Disability Index (ODI) and change in quality adjusted life years (QALY) assed with EQ-5D-5L 13,14.

\section{Secondary outcomes}

Quality of life will be further assed using the Short Form (36) Health Survey (SF-36) ${ }^{15}$. Pain will be measured using the Visual Analogue Scale (VAS) score for back pain and leg pain 16. The degree/presence of preoperative anxiety and depression will be measured using the Hospital Anxiety Depression Scale (HADS) ${ }^{17}$. Societal costs will be measured retrospectively with the Medical Cost Questionnaire (iMCQ) and the Productivity related Cost Questionnaire (iPCQ) ${ }^{18}$. Direct and indirect surgical complications including dural tear, postoperative infection, deep venous thrombosis, hematoma, hardware failure, neurological deficits, medical other complications as pneumonia or urinary tract infection will be registered.

\section{Other study parameters}

Sex, age, BMI, smoking habits, occurrence of diabetes, diagnosis, level, grade of spondylolisthesis, previous back surgery and ASA classification. Perioperative morbidity will be correlated to use of antibiotics, duration of surgery, intraoperative blood loss and duration of hospitalization. 


\section{Economic evaluation}

The economic evaluation will assess cost-effectiveness (CEA) and cost-utility (CUA) from a societal and health care perspective. Costs will be related to change in disability measured with ODI and change in cost-effectiveness analysis and to changes in quality-adjusted life years (QALYS) with EQ-5D-5L in the cost-utility analysis. The analysis will be performed with a time horizon of two years. Data are collected in web based CRFs (case report forms) and by means of questionnaires. Included costs consist of: 1) health care costs, 2) patient and family costs and 3) other costs. Healthcare costs are for example costs of surgical intervention (either TLIF or PLIF), hospital care (including costs for treating complications), medication, outpatient visits and resource use outside the hospital such as general practitioner visits and physical therapist visits. Among patient and family costs are travel costs, informal care and home care. Other costs are costs such as productivity losses due to absence from work. Information on these costs will be collected with a questionnaire designed for consumption of healthcare in the Dutch system (Medical Consumption Questionnaire - iMCQ) and a questionnaire designed for productivity costs in the Dutch system (Productivity Costs Questionnaire iPCQ). Both questionnaires have a recall period of 3 months and will be administered repeatedly at five fixed time points.

\section{Process evaluation}

To assess the experiences and opinions of patients and professionals with TLIF a process evaluation according to the framework provided by Saunders will be performed ${ }^{19}$. This framework consists of a stepwise approach in which important characteristics for the process-evaluation plan are identified along seven basic components, namely: fidelity (quality), dose delivered (completeness), dose received (exposure), dose received (satisfaction), reach (participation rate), recruitment and context. For this process evaluation both qualitative and quantitative data will be collected. At the end of the study a short interview will be held with the principal investigator of every participating center, where the investigator can reflect on his/her experiences with the surgical techniques. A patient board is set up to ensure patient representation. Patients will be questioned using a semistructured questionnaire covering the topics identified in the framework provided by Saunders et al. ${ }^{19}$.

\section{Analysis \\ Clinical effectiveness}

Data will be analysed according to the intention-to-treat principle. Difference in ODI change and EQ-5D-5L between baseline and subsequent measurements will be analysed using analysis of covariance (ANCOVA) to correct the effect of intervention as compared to controls for potential baseline differences and to gain precision in the effect estimates. In addition, we will use linear mixed models to analyse changes within the treatment 
groups as well as differences between the intervention and control group in the ODI and EQ-5D-5L over time. Linear mixed models will also be used to analyse changes on secondary outcome measurements over time both within and between groups (Short Form (36) Health Survey, VAS back pain and leg pain and Hospital Anxiety Depression Scale (HADS)). Multivariable linear regression analysis will be performed to determine differences in change scores between the two groups at fixed time points. Differences in the proportion of participants that report complications over the study period (up to 24 months), will be evaluated by means of logistic regression analysis. All results will be presented as absolute mean differences with $95 \%$ confidence intervals, or odds ratios with $95 \%$ confidence intervals.

\section{Economical evaluation}

Costs will be linearly interpolated to estimate total costs covered by the time period between consecutive assessments. Unit prices will be determined according to Dutch guidelines, expressed in 2016 Euros and will be indexed if necessary using consumer price indices. Otherwise, integral cost-prices will be obtained from the Maastricht University Medical Center, or cost-price calculations will be performed.

\section{Patient outcome analysis}

The primary clinical outcome is the change in disability measured with ODI, over the course of a two year follow-up period, to which total societal costs will be related in the CEA. For the CUA, utilities are assessed using the EQ-5D-5L ${ }^{14}$. These utilities will be converted following the area under the curve method into QALYs using the United Kingdom social tariffs. Changes in QALYS over the course of the two-year follow-up period will be related to total societal costs in the CUA ${ }^{20}$. Costs and effects will be discounted according to Dutch pharmaco-economic guidelines. Standard sensitivity analyses and bootstrap analysis will be performed to investigate the uncertainty surrounding the cost-effectiveness ratios ${ }^{21}$. Based on the bootstrap results, cost-effectiveness acceptability curves will be constructed, showing threshold values for a wide range of cost-effectiveness, the probability that TLIF is more cost-effective. In addition to the CEA and CUA, a model-based simulation approach will be used to assess generalizability of the findings. The Budget Impact Analyses (BIA), alongside the CEA, will be performed to address the financial consequences of implementing the most cost-effective treatment as intervention of choice in patients with lumbar spondylolisthesis. The BIA is based on the results of the clinical trial and will be conducted according to the ISPOR guidelines and Dutch guideline for executing economic evaluations in health care from various perspectives: (i) wider societal perspective, i.e. including productivity losses; (ii) a narrower perspective of the public purse (in Dutch: Budgettair Kader Zorg (BKZ)); (iii) the perspective of the health care insurer 20,22. All scenarios will be compared with a reference scenario which consists of the current standard of performing 
both TLIF and PLIF. The BIA will be estimated for various implementation levels (10, 25, 50 and $100 \%$ of the intended target group). Furthermore, scenarios will be modelled in which the timeline of implementing the most cost-effective treatment as intervention of choice in $100 \%$ of the hospitals is varied between direct implementation to implementation in five years.

\section{Process evaluation}

Quantitative data will be analysed with appropriate statistical testing; descriptive statistics, Chi square tests and ANOVA. Data from focus groups and interviews will be categorized, so relevant themes can be identified. 


\section{DISCUSSION}

This study will determine the clinical effectiveness and cost-effectiveness of TLIF compared to PLIF for patients with leg pain caused by single level lumbar spondylolisthesis. The demand for spinal fusion surgery has risen steeply over the last ten years and is expected to increase even further in the near future. In times of rising health care costs and resulting budget limitations, there is a need for solid, comparative, cost-effectiveness studies to be able to recommend the best choice, clinically as well as cost-effectively, of surgery for these patients. It is hypothesized that TLIF, compared to PLIF, is superior in reducing disability and thus has a better clinical outcome. Moreover, health care costs are suspected to be lower due to less surgical morbidity, shorter hospital stay and shorter surgical time. Productivity losses are assumed to be lower for TLIF as well, because less working days are lost. Currently, the choice for technique is greatly based on surgeon's experience and preference. The strength of this multicenter study is that because of randomization, the preference of the surgeon no longer determines which technique is used. Also this study is, to our knowledge, the first where cost-effectiveness of both procedures will be explored and compared. One of the limitations of this study is the sample size. We do expect to be able to draw conclusions on the primary outcomes. However, for some of the secondary outcomes (for example complications) the sample size will be too small. We aim to see if results are comparable with those previously reported in literature. Additionally, we will perform a process evaluation to assess the experiences and opinions of patients and professionals with TLIF. In case our hypothesis is confirmed, this could lead to reduction of (healthcare and productivity losses) costs and better clinical outcome for spondylolisthesis patients eligible for instrumented spinal surgery. Recommendations considering the best choice will be very helpful for spine surgeons in the future and lead to adaptation of the current Dutch guidelines. 

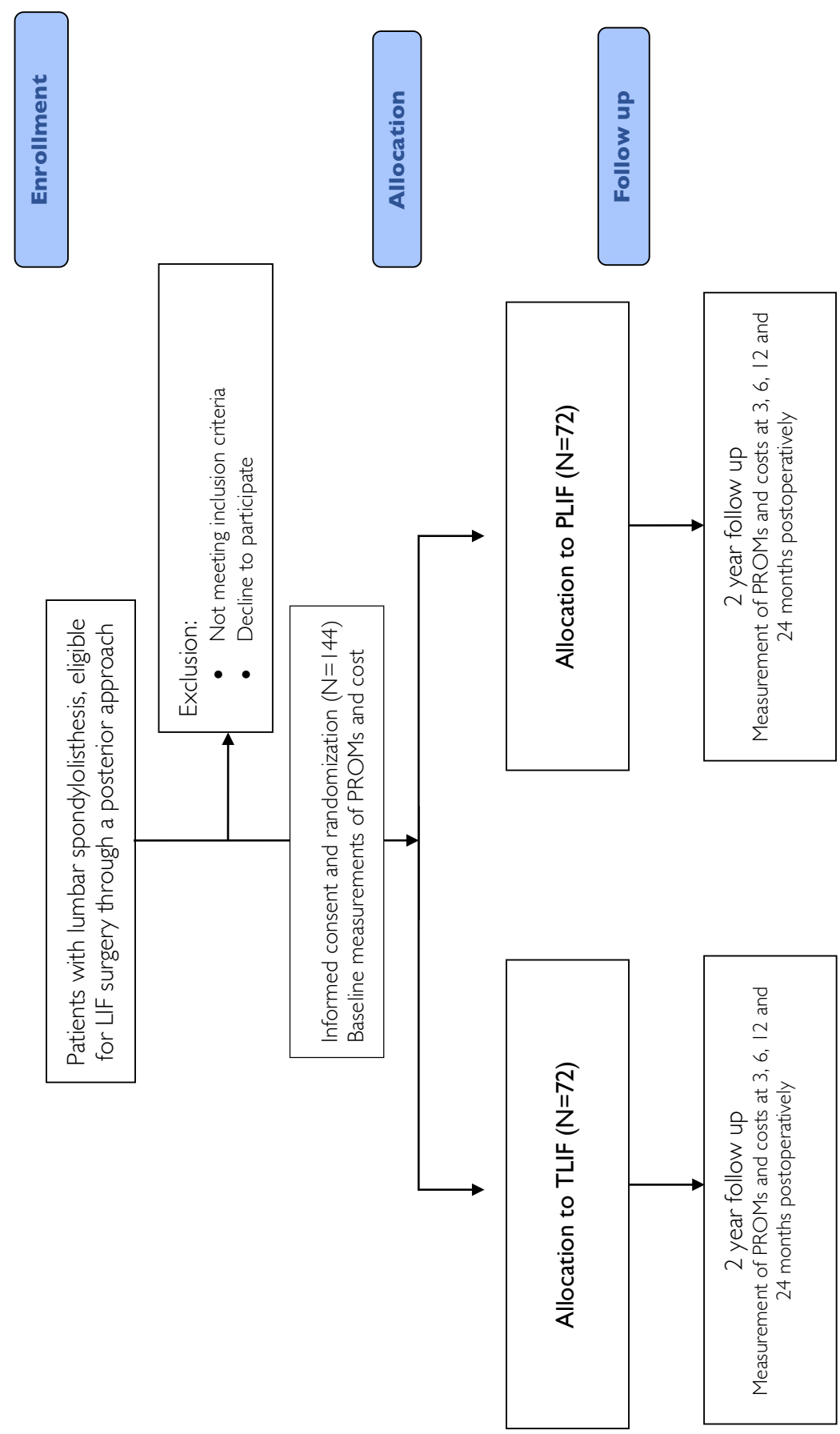


\section{REFERENCES}

1. Beutler WJ, Fredrickson BE, Murtland A, Sweeney C, Grant W, Baker D. The natural history of spondylolysis and spondylolisthesis. Spine (Phila Pa 1976). 2003;28(10):1027-1035. doi:10.1097/01. BRS.0000061992.98108.A0.

2. Rajaee SS, Bae HW, Kanim LEA, Delamarter RB. Spinal Fusion in the United States. Spine (Phila Pa 1976). 2012;37(1):67-76. doi:10.1097/BRS.0b013e31820cccfb.

3. Tosteson ANA, Lurie JD, Tosteson TD, et al. Surgical treatment of spinal stenosis with and without degenerative spondylolisthesis: cost-effectiveness after 2 years. Ann Intern Med. 2008;149(12):845-853. doi:10.7326/0003-4819-149-12-200812160-00003.

4. Adogwa O, Parker SL, Davis BJ, et al. Cost-effectiveness of transforaminal lumbar interbody fusion for Grade I degenerative spondylolisthesis.J Neurosurg Spine. 2011;15(2):138-143. doi:10.3171/2011.3.SPINE10562.

5. Jalalpour K, Neumann P, Johansson C, Hedlund R. A Randomized Controlled Trial Comparing Transforaminal Lumbar Interbody Fusion and Uninstrumented Posterolateral Fusion in the Degenerative Lumbar Spine. Glob Spine J. 2015;5(4):322-328. doi:0.1055/s-0035-1549033.

6. Bydon M, Macki M, Abt NB, et al. The cost-effectiveness of interbody fusions versus posterolateral fusions in 137 patients with lumbar spondylolisthesis. Spine J. 2015;15(3):492-498. doi:10.1016/j. spinee.2014.10.007.

7. Zhou Z-J, Zhao F-D, Fang X-Q, Zhao X, Fan S-W. Meta-analysis of instrumented posterior interbody fusion versus instrumented posterolateral fusion in the lumbar spine. J Neurosurg Spine. 2011;15(3):295-310. doi:10.3171/2011.4.SPINE10330.

8. Kunze B, Drasseck T, Kluba T. Posteriore und transforaminale lumbale interkorporelle Fusion (PLIF/ TLIF) zur Therapie des lokalisierten Segmentaufbrauchs der LWS. Z Orthop Unfall. 2011;149(3):312-316. doi:10.1055/s-0030-1250689.

9. Humphreys SC, Hodges SD, Patwardhan AG, EckJC, Murphy RB, Covington LA. Comparison of posterior and transforaminal approaches to lumbar interbody fusion. Spine (Phila Pa 1976). 2001;26(5):567-571. doi:10.1097/00007632-200103010-00023.

10. Yang E-Z, Xu J-G, Liu X-K, et al. An RCT study comparing the clinical and radiological outcomes with the use of PLIF or TLIF after instrumented reduction in adult isthmic spondylolisthesis. Eur Spine J. 2016;25(5):1587-1594. doi:10.1007/s00586-015-4341-z.

11. de Kunder SL, Rijkers K, van Hemert WLW, Willems PCPH, ter Laak - Poort MP, van Santbrink H. Transforaminal versus posterior lumbar interbody fusion as operative treatment of lumbar spondylolisthesis, a retrospective case series. Interdiscip Neurosurg. 2016;5:64-68. doi:10.1016/j.inat.2016.07.001.

12. Parker SL, McGirt MJ. Determination of the Minimum Improvement in Pain, Disability, and Health State Associated With Cost-Effectiveness. Neurosurgery. 2012;71(6):1149-1155. doi:10.1227/ NEU.0b013e318271ebde.

13. Fairbank JC, Pynsent PB. The Oswestry Disability Index. Spine (Phila Pa 1976). 2000;25(22):2940-52; discussion 2952. doi:10.1097/00007632-200011150-00017.

14. Versteegh MM, Vermeulen KM, Evers SM, de Wit GA, Prenger R, Stolk EA. Dutch Tariff for the Five-Level Version of EQ-5D. Value Heal. 2016;19(4):343-352. doi:10.1016/j.jval.2016.01.003.

15. Aaronson NK, Muller M, Cohen PDA, et al. Translation, validation, and norming of the Dutch language version of the SF-36 Health Survey in community and chronic disease populations. J Clin Epidemiol. 1998;51(11):1055-1068. doi:10.1016/S0895-4356(98)00097-3.

16. Hawker GA, Mian S, Kendzerska T, French M. Measures of adult pain: Visual Analog Scale for Pain (VAS Pain), Numeric Rating Scale for Pain (NRS Pain), McGill Pain Questionnaire (MPQ), Short-Form McGill Pain 
Questionnaire (SF-MPQ), Chronic Pain Grade Scale (CPGS), Short Form-36 Bodily Pain Scale (SF. Arthritis Care Res (Hoboken). 2011;63 Suppl 1:S240-52. doi:10.1002/acr.20543.

17. Spinhoven P, Ormel J, Sloekers P, Kempen G, Speckens A, Van Hemert A. A validation study of the Hospital Anxiety and Depression Scale (HADS) in different groups of Dutch subjects. Psychol Med. 1997;27:363370.

18. Bouwmans C, Krol M, Severens H, Koopmanschap M, Brouwer W, Hakkaart-van Roijen L. The iMTA Productivity Cost Questionnaire: A Standardized Instrument for Measuring and Valuing Health-Related Productivity Losses. Value Health. 2015;18(6):753-758. doi:10.1016/j.jval.2015.05.009.

19. Saunders RP. Developing a Process-Evaluation Plan for Assessing Health Promotion Program Implementation: A How-To Guide. Health Promot Pract. 2005;6(2):134-147. doi:10.1177/1524839904273387.

20. Zorginstituut Nederland. Richtlijn Voor Het Uitvoeren van Economische Evaluaties in de Gezondheidszorg.; 2016.

21. Barber JA, Simon G. Thompson. Analysis of cost data in randomized trials: an application of the non-parametric bootstrap. Stat Med. 2000;19(23):3219-3236. doi:10.1002/10970258(20001215)19:23<3219::AID-SIM623>3.0.CO;2-P.

22. Briggs AH, Weinstein MC, Fenwick EAL, Karnon J, Sculpher MJ, Paltiel a. D. Model parameter estimation and uncertainty: A report of the ISPOR-SMDM modeling good research practices task force-6. Value Heal. 2012;15(6):835-842. doi:10.1016/j.jval.2012.04.014. 



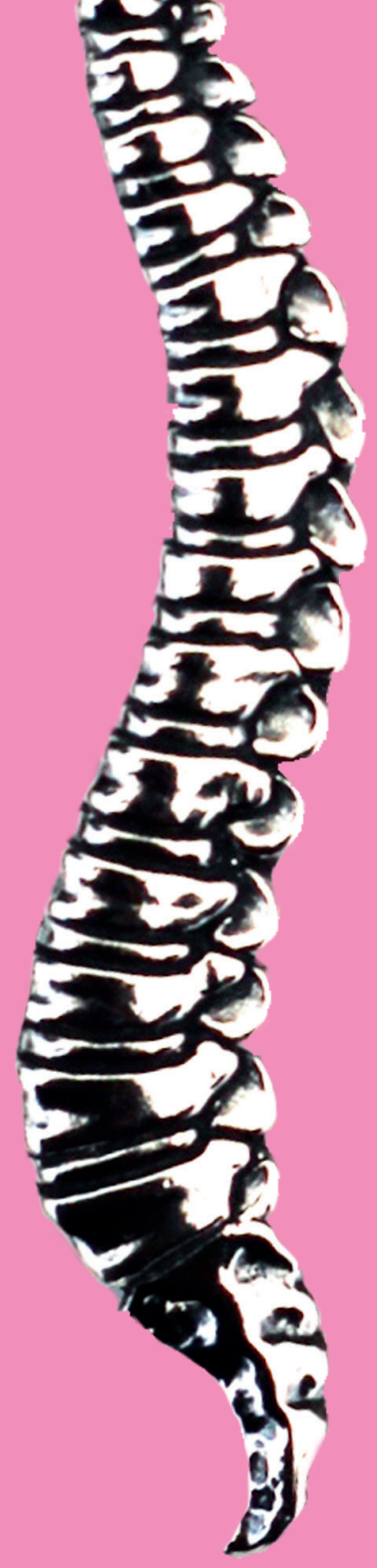

Chapter 7

General discussion 

Patients with symptomatic isthmic or degenerative lumbar spondylolisthesis can be treated with several surgical spinal fusion techniques when conservative methods fail. TLIF and PLIF are the two spinal fusion techniques discussed in this thesis. The aim of this thesis was to compare the effectiveness of TLIF and PLIF for patients with lumbar spondylolisthesis. The first part of this thesis explores historical developments and provides an historical overview. The second part of this thesis investigates clinical and cost-effectiveness of TLIF and PLIF. A protocol of the LIFT study, a randomized controlled trial comparing clinical and cost-effectiveness of TLIF and PLIF is described in the third part of this thesis.

\section{PART 1: HISTORICAL OVERVIEW}

To elucidate the historical development of various spinal fusion techniques this thesis starts with an historical overview. As discussed in chapter $\mathbf{2}$ various spinal fusion techniques became available over the last decades, but the true development of instrumented spine surgery emerged in the $18^{\text {th }}$ and $19^{\text {th }}$ century. The discovery of general anesthesia, antisepsis and X-ray opened a whole new window of surgical opportunities ${ }^{1-3}$. These technical developments on the one hand, and an increasing number of patients with Pott's disease (spinal tuberculosis) on the other, led to the development of surgical spinal stabilization techniques ${ }^{4}$. At that time the assumption was that the origins of pain and movement restriction were due to deformities and instability ${ }^{5-14}$. Therefore, the ultimate aim of spine surgery was to correct deformities, and one assumed that a high level of fusion was necessary to obtain maximal stability. Development of new surgical techniques focused on increasing the level of bony fusion and to reduce non-union ${ }^{15,16}$. New discov-

eries were done by pioneering surgeons, who shared their insights and inventions with colleagues through (personal) meetings and journals 6,17-21. However, mostly case series were described and execution of research was not done by strict methodological rules compared to todays' standards, e.g. randomized controlled trials paradigm. Those case series mostly focused on aspects as technique description and bony fusion. Knowledge of new techniques was transferred from surgeon to resident and the choice of technique was based on the surgeon's preference and experience. Over the years, insights in spine surgery changed; novel biomechanical concepts of spinal instability led to a shift of focus. Fusion was no longer the sole goal, also maintaining natural balance of the spine became important $14,22,23$. The biomechanical two column concept led to a permanent shift in general thinking about the spine, namely the acknowledgement of load sharing; pedicle screw fixation was combined with interbody fusion to optimize balance through the anterior column. New surgical systems were designed and the biomechanical aspects of the spine were explicitly considered ${ }^{24-26}$. Whereas in the early days surgeons, besides performing the surgery, also developed techniques and materials, the industry took over this role 
later on, and the influence of industry slowly but surely became more and more prominent. The possibilities for instrumented spinal fusion grew and clinical results improved tremendously, hence a considerable increase in number of procedures was seen over the past decades. Absolute indications for lumbar interbody surgery were and are lumbar spondylolisthesis, severe scoliosis, spinal tuberculosis, and fractures. More recently, relative indications including back pain, degenerative disc disease and spinal stenosis are becoming indications for spinal fusion surgery as well ${ }^{27}$. Still, all of these developments are mostly based on case series and generally have a theoretical base; randomized trials on the effectiveness of these types of surgery are virtually non-existent.

\section{PART 2: CLINICAL AND COST-EFFECTIVENESS OF TLIF AND PLIF PROCEDURES}

Nowadays, the choice of technique for spinal fusion is still largely based on the surgeon's preference and experience. There are no strict indications for using either TLIF or PLIF, because retrospective studies have shown that both methods effectively reduce leg or back pain ${ }^{28-37}$. Efficacy studies comparing both TLIF and PLIF are sparse. For the systematic literature review and meta-analysis concerning the effectiveness of TLIF compared to PLIF, as described in chapter 3, only nine studies were included; one prospective and eight retrospective studies. Clinical outcomes of TLIF and PLIF were similar, no significant differences were found in VAS or ODI scores. This was confirmed in our retrospective study, as described in chapter 4. We did find a difference in overall complication rate; for TLIF this was fifty percent lower than for PLIF (TLIF 8.7\% (range 0-25.0\%), PLIF 17.0\% (range 4.7-28.8\%). This significant difference in complication rate may be explained by the higher a priori chance of tissue damage in case of the bilateral (PLIF) instead of unilateral (TLIF) approach, while in case of TLIF the resection of bony structures is more extensive. Due to less extensive resection of bony structures in PLIF, there may be a bigger chance of nerve root traction during insertion of the PLIF cages ${ }^{38}$; in TLIF surgery the more extensive resection provides more space to insert the cage, so nerve root damage and dural tearing is less likely. The lower number of hardware problems in TLIF could have resulted from a more equal distribution of the axial load of the spinal column and unilateral preservation of the facet joint, as a result of the shape and placement of the cage ${ }^{39,40}$. Moreover, in literature duration of surgery was generally shorter and blood loss was generally less in TLIF. We confirmed the shorter duration of surgery for TLIF in our retrospective study (chapter 4). Other presumed advantages of TLIF over PLIF as overall complication rate or estimated blood loss could not be verified in our retrospective patient series, possibly due the fact that group size was not sufficient to obtain statistical significance. 
The observed level of evidence of the studies is low. This is a returning issue in other studies a well; mostly due the retrospective nature and small sample sizes. Yet, new developments are presented by the industry in rapid succession, but randomized trials on the effectiveness of implants and techniques are virtually non-existent, leading to a lack of control and overview. Of note, often when solid prospective research is proposed and conducted, a new product is ready on the shelf, replacing the just analyzed one. This rapid succession leads to numerous systems and possibilities for spinal fusion surgery, resulting in an enormous increase in variation of instrumented spinal surgery. Moreover, the number of instrumented spinal surgeries increases as well because of the shift towards relative indications for surgery, including back pain, degenerative disc disease and spinal stenosis.

With growing possibilities in health care, at the same time the question arises whether the increasing costs due to new expensive treatment options are justified in perspective to limited financial resources, especially where evidence of effectiveness is lacking. Instrumented spinal surgery has gone through a five-fold increase in number of procedures between 1990 to 2011, and a 30-fold increase of industry sales from \$225 million in 1994 to \$6.6 billion in 2011 in the USA ${ }^{41}$. Increase of the aging population ensures that demand for spinal surgery will rise further in the near future. Therefore, the expected further rise in healthcare expenses, especially in spine surgery urges decision makers to demand health care providers to evaluate the (cost-)effectiveness of these types of treatment.

So far, cost-effectiveness data on instrumented spinal surgery are sparse. In the systematic literature review comparing cost-effectiveness of TLIF and PLIF as described in chapter $\mathbf{5}$ we have summarized this. Although TLIF and PLIF are both frequently used techniques for similar indications, no economic evaluations directly comparing both techniques are available. Therefore, it is not possible to draw solid conclusions and thus to conclude what technique is most cost-effective. Nevertheless, this review shows that instrumented spine surgery with TLIF and PLIF are expensive techniques within our healthcare system. Since TLIF is associated with less complications, less blood loss, shorter surgical time and sometimes shorter hospital duration, TLIF is the candidate to be more cost-effective than PLIF, with similar effectiveness.

The influence and pursuit of profit of the industry in the area of instrumented spine surgery is undeniable, and the discussion of conflict of interest in industry-sponsored clinical research is ongoing ${ }^{42}$. Moreover, we must bear in mind that instrumented spinal fusion is not always necessary: recent studies have shown that decompression alone suffices in a considerable part of patients with lumbar spondylolisthesis ${ }^{43,44}$. Physicians are obliged to use the best, but also most cost-effective methods, to keep healthcare affordable. 


\section{PART 3: PROTOCOL OF THE LIFT STUDY}

In order to measure clinical effectiveness as well as cost-effectiveness, validated instruments for quality of life and economical evaluations should be standard part of treatment. This enables physicians and decision makers to objectify clinical results and fill knowledge gaps.

Furthermore, we need prospective randomized controlled trials and economical evaluations to obtain high levels of evidence. Therefore, we have initiated the LIFT study, as mentioned in chapter 6. 144 patients with isthmic or degenerative single level lumbar spondylolisthesis will be included. The aim of this randomized multicenter study comparing PLIF and TLIF is to evaluate clinical effectiveness, cost-effectiveness and to conduct a process evaluation.

\section{Implications for clinical practice}

Since TLIF and PLIF are expensive techniques surgeons should be critical when indicating instrumented spinal fusion surgery, especially since instrumented spinal fusion is not always necessary: recent studies have shown that decompression alone suffices in the majority of patients with lumbar spondylolisthesis ${ }^{43,44}$. Because retrospectively obtained clinical outcomes of TLIF and PLIF were similar in this thesis, but TLIF has a smaller overall complication rate, TLIF could be the preferred technique for patients with lumbar spondylolisthesis.

Furthermore, it is important to realize that patient expectations and satisfaction after spinal surgery are sometimes far from realistic ${ }^{45}$. It is the surgeons job to carefully discuss benefits and risks to be expected from surgery, and to involve the patient in this process. With this involvement, and thus shared decision-making, the chance of success due to realistic expectations is much higher. There are even preoperative patient-specific factors, varying from sex to anxiety, which are indicative of treatment effectiveness available from predictive models ${ }^{46,47}$. These predictive models have enormous potential to assist the surgeon in the process of shared decision-making and at the same time to engage the patient. Consequently, registration of patient characteristics and quality of life reports with validated instruments as ODI, SF-36 or EQ-5D should be a standard part of treatment, to enable physicians to objectify the clinical results and to improve predictive models. Also, complication reports should be detailed and extensive, to obtain a realistic complication rate.

To limit the influence of the medical industry, several initiatives have been developed in the field of spine surgery, for example membership of the Association for Medical Ethics. This association has the intention of reducing the medical industry's influence on doctors who 
are paid consultants, and promotes transparent and legitimate collaboration. One has to realize; it remains important to enable doctors to be involved in development in spine surgery because of their hands on experience. A transparent balance between interests of both the medical industry and medical specialists should be pursued.

\section{Future perspectives}

The possible gain in further development for interbody surgery lies in a strict selection of eligible patients, a focus on restoring natural balance and mobility and to do as little harm as possible to the spinal musculature and neural tissue, all tailored to the patients' specific needs. It is possibly not desirable and achievable to study all methods of instrumented spine surgery in large randomized controlled trails. Moreover, the patient group is becoming more and more heterogeneous due to the fact of broadening of indications on one hand while on the other hand the number of patients needed to obtain sufficient statistical power is simply too high. In this light, personalized medicine comes forward. Personalized medicine is the tailoring of treatment to the unique anatomical, molecular or genetic mapping of individual patients and how these unique features contribute to the occurrence of certain disease pattern and progression. Those patient characteristics can also be obtained from alternative approaches; including retrospective cohort and case control studies.

In the end a refocus on the available data, a change in standard healthcare and broadening of horizon is necessary to be able to provide the best possible care for patients with symptomatic lumbar spondylolisthesis in future. To be able to achieve this we need critical and dedicated spine surgeons. 


\section{REFERENCES}

1. Lister J. Antiseptic Principle In The Practice Of Surgery. Br Med J. 1867;2(351):246-248.

2. Robinson DH, Toledo AH. Historical Development of Modern Anesthesia. J Investig Surg. 2012;25(3):141149. doi:http://dx.doi.org/10.3109/08941939.2012.690328.

3. Underwood E. Wilhelm Conrad Röntgen (1845-1923) and the Early Development of Radiology. Proc R Soc Med. 1945;38 (12):697-706.

4. Daniel TM. The history of tuberculosis. Respir Med. 2006;100(11):1862-1870. doi:10.1016/j. rmed.2006.08.006.

5. Hadra BE. The Classic: Wiring of the vertebrae as a means of immobilization in fracture and Potts' disease. Clin Orthop Relat Res. 2007;460:11-13. doi:10.1097/BLO.0b013e318068692a.

6. Peltier LF. Orthopedics: A History and Iconography. Norman Publishing; 1993.

7. Lange F. Support for the Spondylitic Spine by Means of Buried Steel Bars, Attached to the Vertebrae. Clin Orthop Relat Res. 1986; February(203):3-6.

8. Albee FH. The Classic: Transplantation of a portion of the tibia into the spine for Pott's disease: a preliminary report. Clin Orthop Relat Res. 2007;460:14-16. doi:10.1097/BLO.0b013e3180686a0f.

9. Hibbs RA. The Classic: An Operation for Progressive Spinal Deformities. Clin Orthop Relat Res. 2007;460:1720. doi:10.1097/BLO.0b013e3180686b30.

10. Obituary. Willis Cohoon Campbell 1880-1941.J Bone Jt Surg Am. 1941;23(3):716-717.

11. Campbell W. An operation for extra-articular fusion of sacroiliac joint. Surg Gynecol Obs. 1939;45:218-219. Hibbs R. A report of fifty-nine cases of scoliosis treated by fusion operation. J Bone Jt Surg. 1924;6:3-34. King D. Internal Fixation for Lumbosacral Fusion. J Bone Jt Surg Am. 1948;30-A(3):560-578. Mostofi SB. Who's Who in Orthopedics. Springer International Publishing; 2005.

Thompson WAL, Ralson EL. Pseudoarthrosis following spine fusion. J Bone Jt Surg Am. 1949;31(2):400-405. Briggs H, Milligan PR. Chip fusion of the low back following exploration of the spinal canal. J Bone Jt Surg Am. 1944;26(1):125-130. Harrington P, Dickson J. Spinal instrumentation in the treatment of severe progressive spondylolisthesis. Clin Orthop Relat Res. 1976;(117):157-163. Harrington P, Tullos H. Reduction of Severe Spondylolisthesis in Children. South Med J. 1969;62(1):1-7. Cloward RB. Posterior lumbar interbody fusion updated. Clin Orthop Relat Res. 1985;(193):16-19.

Cloward RB. The treatment of ruptured lumbar intervertebral discs by vertebral body fusion. I. Indications, operative technique, after care. J Neurosurg. 1953;10(2):154-168. doi:10.3171/jns.1953.10.2.0154.

21. Steffee AD, Sitkowski DJ. Posterior lumbar interbody fusion and plates. Clin Orthop Relat Res. 1988;227(6):99-102.

22. Holdsworth F. Fractures, dislocations, and fracture-dislocations of the spine. J Bone Joint Surg Am 1970;52(8):1534-1551.

23. Panjabi MM, White AA. Basic biomechanics of the spine. Neurosurgery. 1980;7(1):76-93.

24. Kuslich SD, Ulstrom CL, Griffith SL, Ahern JW, Dowdle JD. The Bagby and Kuslich Method of Lumbar Interbody Fusion: History, Techniques, and 2-Year Follow-up Results of a United States Prospective, Multicenter Trial. Spine (Phila Pa 1976). 1998;23(11):1267-1279.

25. Ray CD. Threaded titanium cages for lumbar interbody fusions. Spine (Phila Pa 1976). 1997;22(6):667-7980 .

26. Brantigan JW, Steffee AD, Lewis ML, Quinn LM, Persenaire JM. Lumbar interbody fusion using the Brantigan I/F cage for posterior lumbar interbody fusion and the variable pedicle screw placement system: two-year results from a Food and Drug Administration investigational device exemption clinical trial. Spine 
(Phila Pa 1976). 2000;25(11):1437-1446. doi:10.1097/00007632-200006010-00017.

27. Deyo RA, Nachemson A, Mirza SK. Spinal-Fusion Surgery - The Case for Restraint. N Eng/J Med. 2004;350(7):722-726. doi:10.1056/NEJMsb031771.

28. Asil K, Yaldiz C. Retrospective Comparison of Radiological and Clinical Outcomes of PLIF and TLIF Techniques in Patients Who Underwent Lumbar Spinal Posterior Stabilization. Medicine (Baltimore). 2016;95(17):1-7. doi:10.1097/MD.0000000000003235.

29. de Kunder SL, Rijkers K, van Hemert WLW, Willems PCPH, ter Laak - Poort MP, van Santbrink H. Transforaminal versus posterior lumbar interbody fusion as operative treatment of lumbar spondylolisthesis, a retrospective case series. Interdiscip Neurosurg. 2016;5:64-68. doi:10.1016/j.inat.2016.07.001.

30. Fariborz S, Gharedaghi M, Khosravi A, et al. Comparison of Results of 4 Methods of Surgery in Grade 1 Lumbosacral Spondylolisthesis. Neurosurg Q. 2016;26(1):14-18. doi:10.1097/WNQ.0000000000000197.

31. Han S, Xiao Q, Zhu G, Dai J, Tang X, Sun H. Comparison between transforaminal lumbar interbody fusion and posterior lumbar interbody fusion in treatment of lumbar spondylolisthesis. Int J Clin Exp Med. 2016;9(2):3932-3938.

32. Liu J, Deng H, Long X, Chen X, Xu R, Liu Z. A comparative study of perioperative complications between transforaminal versus posterior lumbar interbody fusion in degenerative lumbar spondylolisthesis. Eur spine J. 2015. doi:10.1007/s00586-015-4086-8.

33. Sakeb N, Ahsan K. Comparison of the early results of transforaminal lumbar interbody fusion and posterior lumbar interbody fusion in symptomatic lumbar instability. Indian J Orthop. 2013;47(3):255. doi:10.4103/0019-5413.111484.

34. Yan DL, Pei FX, Li J, Soo CL. Comparative study of PILF and TLIF treatment in adult degenerative spondyIolisthesis. Eur Spine J. 2008;17(10):1311-1316. doi:10.1007/s00586-008-0739-1.

35. ParkJ-S, Kim Y-B, Hong H-J, Hwang S-N. Comparison between Posterior and Transforaminal Approaches for Lumbar Interbody Fusion.J Korean Neurosurg Soc. 2005;37:340-344.

36. Yang E-Z, Xu J-G, Liu X-K, et al. An RCT study comparing the clinical and radiological outcomes with the use of PLIF or TLIF after instrumented reduction in adult isthmic spondylolisthesis. Eur Spine J. 2016;25(5):1587-1594. doi:10.1007/s00586-015-4341-z.

37. de Kunder SL, van Kuijk SM, Rijkers K, et al. Transforaminal lumbar interbody fusion (TLIF) versus posterior lumbar interbody fusion (PLIF) in lumbar spondylolisthesis, a systematic review and meta-analysis. Spine J. 2017;17(11):1712-1721. doi:10.1016/j.spinee.2017.06.018.

38. Mura PP, Costaglioli M, Piredda M, Caboni S, Casula S. TLIF for symptomatic disc degeneration: A retrospective study of 100 patients. Eur Spine J. 2011;20(SUPPL. 1):57-60. doi:10.1007/s00586-011-1761-2.

39. Tsitsopoulos PP, Serhan H, Voronov LI, et al. Would an Anatomically Shaped Lumbar Interbody Cage Provide Better Stability? An In Vitro Cadaveric Biomechanical Evaluation.J Spinal Disord Tech. 2012;25(8):1. doi:10.1097/BSD.0b013e31824c820c.

40. Cole CD, McCall TD, Schmidt MH, Dailey AT. Comparison of low back fusion techniques: Transforaminal lumbar interbody fusion (TLIF) or posterior lumbar interbody fusion (PLIF) approaches. Curr Rev Musculoskelet Med. 2009;2(2):118-126. doi:10.1007/s12178-009-9053-8.

41. Malhotra D, Kalb S, Rodriguez-Martinez N, et al. Instrumentation of the posterior thoracolumbar spine: From wires to pedicle screws. Neurosurgery. 2014;10(4):497-505. doi:10.1227/NEU.0000000000000489.

42. Hart RA. Acknowledging the elephant in the room: Conflict of interest in industry-sponsored clinical research. Spine J. 2011;11(8):703-704. doi:10.1016/j.spinee.2011.08.011.

43. Försth P, Ólafsson G, Carlsson T, et al. A Randomized, Controlled Trial of Fusion Surgery for Lumbar Spinal Stenosis. N Eng/ J Med. 2016;374(15):1413-1423. doi:10.1056/NEJMoa1513721.

44. Ghogawala Z, Dziura J, Butler WE, et al. Laminectomy plus Fusion versus Laminectomy Alone for Lumbar Spondylolisthesis. N Eng/J Med. 2016;374(15):1424-1434. doi:10.1056/NEJMoa1508788. 
45. Toyone T, Tanaka T, Kato D, Kaneyama R, Otsuka M. Patients' expectations and satisfaction in lumbar spine surgery. Spine (Phila Pa 1976). 2005;30(23):2689-2694. doi:10.1097/01.brs.0000187876.14304.15.

46. McGirt MJ, Bydon M, Archer KR, et al. An analysis from the Quality Outcomes Database, Part 1. Disability, quality of life, and pain outcomes following lumbar spine surgery: predicting likely individual patient outcomes for shared decision-making. J Neurosurg Spine. 2017:1-13. doi:10.3171/2016.11.SPINE16526.

47. Deyo R, Cherkin D, Weinstein J, Howe J, Ciol M, Mulley A. Involving patients in clinical decisions: impact of an interactive video program on use of back surgery. Med Care. 2000;38(9):959-969. 



In chapter 2, a historical overview of lumbar interbody fusion, which is one of the most commonly performed instrumented spinal fusion surgeries, was presented. Various spinal fusion techniques became available over the last decades. In this chapter the development of lumbar interbody fusion surgery, starting from the $19^{\text {th }}$ century with simple wiring until todays' possibilities with bioactive cages and pedicle screw fixation with patient-specific rods, was described. In the early 19th century the assumption was that the origin of pain and movement restriction was the result of deformities and instability. Therefore, the ultimate aim of spine surgery was to correct deformities, and one assumed a high level of fusion was necessary to obtain maximal stability. Accordingly, development of surgical techniques focused on increasing the level of bony fusion and to reduce non-union. Over the years, insights in spine surgery changed; novel biomechanical concepts of spinal instability led to a shift of focus. Fusion was no longer the sole goal, also restoring stability and maintaining natural balance became more and more important. The biomechanical two column concept led to the acknowledgement of load sharing; pedicle screw fixation was combined with interbody fusion to restore balance through the anterior column. Current practice is thus founded on all of these historical developments. The possibilities of instrumented spinal fusion grew over the past 100 years. Therefore, a considerable increase in instrumented spinal surgery was seen over the past decades. Today, gain lies in perfection of techniques and deliberate indication and development of guidelines. Therefore, more standardized and controlled studies on instrumented spinal surgery are needed and techniques should be personalized to the patients' specific needs.

Chapter 3 reports a systematic literature review and meta-analysis of the available literature comparing the effectiveness and complications of transforaminal lumbar interbody fusion (TLIF) and foraminal lumbar interbody fusion (PLIF) in lumbar spondylolisthesis. Studies comparing both TLIF and PLIF were sparse; nine studies were included in this study, of which one prospective and eight retrospective studies. Mostly due the retrospective nature of most studies the level of evidence found was limited. No clinical relevant difference was found in Oswestry Disability Index (ODI) score or visual analogue scale (VAS) pain score between TLIF or PLIF patients, although there was a significant difference in ODI score; the change was 3.46 points larger for TLIF. However, to be clinically important the change in ODI needs to be at least seven points. The found difference can be explained by a greater preservation of musculature of the lumbar spine by the unilateral approach of TLIF. It can quicken and improve the patient's recovery and thereby reduce postoperative disability, as measured with ODI. The complication rate of TLIF was fifty percent lower compared to PLIF. This significant difference was not only the case for surgery related complications as infections, nerve root damage and dural tearing, but also for hardware problems and other complications. The significant higher complication rate in PLIF compared to TLIF can be explained by the double a priori chance due to the 
bilateral approach in PLIF, besides the unilateral resection of bony structures is more extensive in TLIF with less chance of complications as result. In the case of TLIF there is a more extensive resection of bony components resulting in more room to insert the cage, so nerve root damage and dural tearing is less likely. Less hardware problems in TLIF could be the result of a more equal distribution of the axial load of the spinal column and preservation of the facet joint in TLIF compared to PLIF, as a result of the shape and placement of the cage and technique. Also for duration of surgery and estimated overall blood loss we found TLIF to be superior compared to PLIF.

In chapter 4 the clinical outcomes of a retrospective study of spondylolisthesis patients who underwent TLIF or PLIF surgery were reported. The results described in chapter 3 were partially confirmed in our retrospective study as discussed in chapter 4 . For this study we included 96 patients with isthmic or degenerative lumbar spondylolisthesis. Surgical time for TLIF was significantly shorter. The overall complication rate was similar in TLIF and PLIF. Also, we found no difference in blood loss, hospital duration or occurrence of postoperative pain contrary to the cumulative results of the meta-analysis. Possibly we did not find statistical significance due to the small sample size of our patient group.

In the systematic literature review of the available literature comparing the cost-effectiveness of TLIF and PLIF as described in chapter $\mathbf{5}$ we evaluated the cost-effectiveness of TLIF and PLIF. Cost-effectiveness was limitedly and differently reported in the 15 included studies. The reported healthcare related costs and societal costs varied greatly and were not always transparent. The overall quality of the studies was low concerning bias relating to overall design and economic evaluation. Although TLIF and PLIF are both frequently used techniques for similar indications, no economic evaluations are available directly comparing both techniques. Therefore, it is not possible to draw firm conclusions and being able to discern which technique is most cost-effective. Nevertheless, this review shows that instrumented spine surgery with TLIF and PLIF are expensive techniques within our healthcare system. Since TLIF is associated with less complications, less blood loss, shorter surgical time and sometimes shorter hospital duration, TLIF is theoretically the better candidate to be more cost-effective compared to PLIF with similar clinical efficacy.

In chapter 6 the study protocol of the LIFT (Lumbar Interbody Fusion Trial) study, comparing (cost-) effectiveness of TLIF and PLIF for patients with lumbar spondylolisthesis was presented. Currently, the available data on cost and clinical effectiveness of the two most frequently performed surgeries for lumbar spondylolisthesis, TLIF and PLIF, are not sufficient. As a result current guidelines do not advise which is the most appropriate surgical treatment strategy for these patients. Therefore, in clinical practice both techniques are used and the choice for the technique to be used is largely based on surgeon's prefer- 
ence. In this multicenter randomized controlled trial 144 patients with symptomatic single level lumbar degenerative, isthmic or iatrogenic spondylolisthesis will be randomly allocated to TLIF or PLIF. The study will consist of three parts: 1) a clinical effectiveness study, 2) a cost-effectiveness study, and 3) a process evaluation. The primary clinical outcome measures are: change in disability measured with ODI and change in quality adjusted life years (QALY) measured with EQ-5D-5L. Secondary clinical outcome measures are: Short Form (36) Health Survey (SF-36), VAS back pain, VAS leg pain, Hospital Anxiety Depression Scale (HADS), complications, productivity related costs (iPCQ) and medical costs (iMCQ). Measurements will be carried out at five fixed time points (pre-operatively and at 3, 6, 12 and 24 months). 



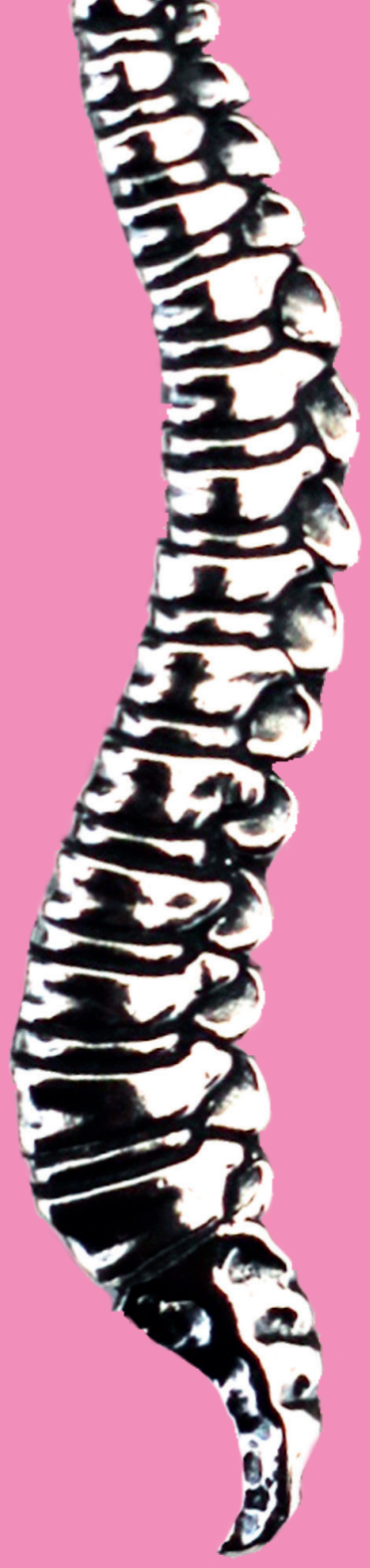

\section{Chapter 9}

Nederlandse samenvatting 

In hoofdstuk 2 werd een historisch overzicht gepresenteerd van de lumbale interbody fusie, één van de meest uitgevoerde geïnstrumenteerde spinale fusie ingrepen. In dit hoofdstuk werd de ontwikkeling van lumbale interbody fusie-chirurgie beschreven, vanaf de $19 \mathrm{e}$ eeuw met eenvoudige wiring techniek tot de uitgebreide mogelijkheden van vandaag met bioactieve cages en pedikelschroef fixatie toegesneden op de individuele patiënt. Aan het begin van de 19 e eeuw werd gedacht dat de oorsprong van pijn en bewegingsbeperking het gevolg was van misvormingen en instabiliteit. Daarom was het uiteindelijke doel van wervelkolomoperaties het corrigeren van misvormingen. Men ging ervan uit dat er een hoge mate van benige fusie noodzakelijk was om maximale stabiliteit te verkrijgen. Als gevolg was de ontwikkeling van chirurgische technieken gericht op het verhogen van mate van benige fusie en het verminderen van pseudo arthrose. In de loop der jaren zijn de inzichten in de wervelkolomchirurgie veranderd; nieuwe biomechanische concepten van spinale instabiliteit leidden tot een verandering van inzicht. Maximale benige fusie was niet langer het enige doel, ook het herstellen van de stabiliteit en het in stand houden van de natuurlijke balans werd steeds belangrijker. Het biomechanische twee kolommen concept leidde tot de erkenning van belastingverdeling; pedikelschroef fixation werd gecombineerd met interbody fusie om de natuurlijke balans te herstellen. De huidige praktijk is dus gestoeld op al deze historische ontwikkelingen. De mogelijkheden van geïnstrumenteerde spinale fusie groeiden explosief de afgelopen 100 jaar. Daarom werd de afgelopen decennia een aanzienlijke toename gezien van geïnstrumenteerde wervelkolomoperaties. Tegenwoordig is winst te halen uit de perfectie van technieken en bewuste indicatiestelling voor operatie en ontwikkeling van richtlijnen. Daarom moeten meer gestandaardiseerde studies over geïnstrumenteerde wervelkolomchirurgie worden uitgevoerd en moeten de technieken worden aangepast aan de specifieke behoeften van de patiënt.

In hoofdstuk 3 werd een systematische literatuurstudie en meta-analyse van de beschikbare literatuur beschreven, waarbij de effectiviteit en complicaties van TLIF en PLIF bij lumbale spondylolisthesis vergeleken werden. Echter, studies welke beide technieken vergeleken waren schaars; er werden negen studies opgenomen in deze studie, waarvan één prospectieve en acht retrospectieve studies. Het niveau van het gevonden bewijs was beperkt, meestal vanwege het retrospectieve karakter van de meeste onderzoeken. Er werd geen klinisch relevant verschil gevonden in ODI-score of VAS-score tussen TLIF- of PLIF-patiënten. Er was een significant verschil in ODI-score; de scoreverandering was 3,46 punten groter voor TLIF. Hoewel dit verschil statistisch significant is, is het niet klinisch relevant, omdat de verandering in ODI ten minste zeven punten moet zijn om een minimaal klinisch belangrijk verschil te bereiken. Het gevonden verschil kan worden verklaard doordat het spierkorset van de lumbale wervelkolom door de eenzijdige benadering van TLIF beter wordt behouden. Het kan het herstel van de patiënt versnellen en verbeteren en daardoor de postoperatieve invaliditeit verminderen. Het complicatiepercentage van 
TLIF lag 50\% lager in vergelijking met PLIF. Dit significante verschil was niet alleen het geval voor chirurgische complicaties zoals infecties, zenuwwortelschade en durascheuren, maar ook voor materiaal problemen en andere complicaties. Het significante verschil in complicatiepercentage kan worden verklaard door de hogere a priori kans vanwege een bilaterale in plaats van eenzijdige benadering en in het geval van TLIF is de resectie van benige structuren uitgebreider vergeleken met PLIF. De uitgebreide resectie van benige structuren bij TLIF, resulteert in meer ruimte om de cage in te brengen, dus zenuwschade en durascheuren zijn minder waarschijnlijk. Minder materiaal problemen in het geval van TLIF kunnen het gevolg zijn van een gelijkere verdeling van de axiale belasting van de wervelkolom en behoud van de facetverbinding in TLIF in vergelijking met PLIF, mede door de vorm van de cage en plaatsing techniek. Ook voor de duur van de operatie en het geschatte totale bloedverlies vonden we dat TLIF superieur is in vergelijking met PLIF.

In hoofdstuk 4 werden de klinische resultaten gerapporteerd van een retrospectieve studie van spondylolisthesis patiënten die een TLIF of PLIF operatie ondergingen. De resultaten beschreven in hoofdstuk 3 werden gedeeltelijk bevestigd in ons retrospectief onderzoek zoals besproken in hoofdstuk 4. Voor deze studie includeerden we 96 patiënten met lytische of degeneratieve lumbale spondylolisthesis. De operatietijd voor TLIF was aanzienlijk korter. Het totale complicatiepercentage was vergelijkbaar voor TLIF en PLIF. Ook vonden we geen verschil in geschatte totale bloedverlies, duur van de ziekenhuisopname of het optreden van postoperatieve pijn, in tegenstelling tot de cumulatieve resultaten van de meta-analyse. Mogelijk vonden we geen statistische significantie vanwege de kleine steekproefomvang van onze patiëntengroep.

In de systematische literatuurstudie waarin de kosteneffectiviteit van TLIF en PLIF wordt vergeleken, zoals beschreven in hoofdstuk 5, hebben we de kosteneffectiviteit van TLIF en PLIF geëvalueerd. Kosteneffectiviteit was beperkt en verschillend gerapporteerd in de 15 opgenomen studies. De gerapporteerde kosten met betrekking tot gezondheidszorg en de maatschappelijke kosten liepen sterk uiteen en waren niet altijd transparant. De algehele kwaliteit van de opgenomen studies was laag, door de aanwezige bias betreffende studie design en economische evaluatie. Hoewel TLIF en PLIF beide vaak gebruikte technieken zijn voor vergelijkbare indicaties, zijn er geen economische evaluaties beschikbaar die beide technieken rechtstreeks vergelijken. Daarom is het niet mogelijk om stevige conclusies te trekken en te kunnen onderscheiden welke techniek het meest kosteneffectief is. Desalniettemin laat deze beoordeling zien dat geïnstrumenteerde wervelkolomoperaties met TLIF en PLIF dure technieken zijn binnen ons gezondheidszorgsysteem. Omdat TLIF geassocieerd is met minder complicaties, minder bloedverlies, kortere operatieduur en soms kortere ziekenhuisduur, is TLIF theoretisch de betere kandidaat om kosteneffectiever te zijn in vergelijking met PLIF met vergelijkbare klinische resultaten. 
In hoofdstuk 6 werd het studieprotocol van de LIFT (Lumbar Interbody Fusion Trial) studie, waarin de (kosten) effectiviteit van TLIF en PLIF voor patiënten met lumbale spondylolisthesis wordt vergeleken, gepresenteerd. Momenteel zijn de beschikbare gegevens over de kosten en de klinische effectiviteit van de twee meest frequent uitgevoerde operaties voor lumbale spondylolisthesis, TLIF en PLIF, niet voldoende. Dientengevolge adviseren de huidige richtlijnen niet wat de meest geschikte chirurgische behandelingsstrategie voor deze patiënten is. Daarom worden in de klinische praktijk beide technieken gebruikt en de keuze voor de te gebruiken techniek is grotendeels gebaseerd op de voorkeur van de chirurg. In deze multicenter gerandomiseerde studie zullen 144 patiënten met symptomatische single-level lumbale degeneratieve, lytische of iatrogene spondylolisthesis willekeurig worden toegewezen aan TLIF of PLIF. De studie zal uit drie delen bestaan: 1) een klinische effectiviteitsstudie, 2) een kosteneffectiviteitstudie en 3) een procesevaluatie. De primaire klinische uitkomstmaten zijn: verandering in handicap gemeten met ODI en verandering in kwaliteit gecorrigeerde levensjaren (QALY) gemeten met EQ-5D-5L. Secundaire klinische uitkomstmaten zijn: Short Form (36) Gezondheidsenquête (SF-36), VAS-rugpijn, VAS-pijn in de benen, ziekenhuisangst-depressieschaal (HADS), complicaties, productiviteitgerelateerde kosten (iPCQ) en medische kosten (iMCQ). De metingen worden uitgevoerd op vijf vaste tijdstippen (pre-operatief en op 3, 6, 12 en 24 maanden). 


The historical study described in chapter 2 showed that spinal diseases and injuries have been known since the common era, but treatment was limited due the lack of surgical possibilities. Due to new discoveries, great steps forward have been made over the past 100 years in the development of lumbar interbody fusion surgery, culminating in exceptional growth and possibilities in instrumented spinal fusion procedures today. Low back pain, with or without leg pain, is a common complaint in the general population. It causes disability and other health care problems in the work force, and consequently poses a large economic burden on society. In The Netherlands, spine complaints are responsible

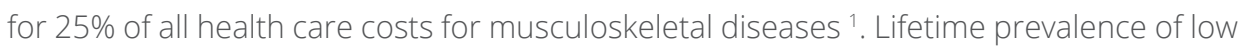
back pain is $70 \%$. The prevalence of accompanying leg pain varies greatly with a range of $1-43 \%{ }^{2}$. In a number of cases these complaints are caused by lumbar spondylolisthesis (incidence 6\%) ${ }^{3}$. Most often, this leg pain is caused by compression and/or stretch of neurogenic structures. If conservative treatment fails, an instrumented spinal fusion procedure can be considered. In case of lumbar spondylolisthesis, the aim of surgery is decompressing neurogenic structures and preventing progression of the spondylolisthesis by additional lumbar pedicle screw fixation and spinal fusion using interbody cage(s). Several spinal fusion techniques are available. Of these, transforaminal lumbar interbody fusion (TLIF) and posterior lumbar interbody fusion (PLIF) are most frequently performed in The Netherlands and extensively described in this thesis. The TLIF procedure consists of placement of one cage in the intervertebral space using a unilateral approach. The PLIF procedure consists of placement two identical cages bilaterally in the intervertebral space using a bilateral approach. As described in chapter $\mathbf{3}$ the clinical effectiveness of both techniques is similar. We found TLIF to be superior over PLIF considering complication rate, duration of surgery and estimated overall blood loss. A shorter duration of surgery was also confirmed in our retrospective study (chapter 4). Current guidelines do not recommend neurosurgeons and/or orthopedic surgeons which surgical technique is preferred ${ }^{4}$. As a result, the choice of technique is largely based on surgeon's experience and preference. As described in chapter $\mathbf{5}$ evidence on the most cost-effective surgical treatment is lacking. With a steep increase in the number of instrumented spinal fusion procedures there is a need to develop evidence based treatment recommendations. For that, both clinical and cost-effectiveness data are needed. Each year approximately 100 single level TLIF and PLIF procedures for patients with spondylolisthesis are executed in the province of Limburg alone. By extrapolating this number based on population density, approximately 1.500 such procedures are carried out each year in The Netherlands 5,6. This number will increase in the near future; in the US, between 1990 and 2011 the number of instrumented spinal procedures has increased 5 fold, the national bill for instrumented spinal fusion has increased 7.9-fold (between 1998 and 2008) and industry sales rised from $\$ 225$ million in 1994 to $\$ 6.6$ billion in 2011 (a 30-fold increase) ${ }^{7-9}$. With an aging population this number will only increase further. For these reasons, the Dutch 
Neurosurgical and Orthopedic Associations (NVVN and NOV), as well as the Dutch Spine Society (DSS), declared 'instrumented spinal fusion' a point of particular interest.

This, with the findings described in chapter 2-5, led to the development of the LIFT study, as described in chapter 6 . This study proposes to analyse in a high quality design (multicentre prospective randomized controlled trial) effectiveness and cost-effectiveness of the TLIF technique compared to PLIF technique for patients with leg pain caused by single level lumbar spondylolisthesis. This study will be the first to fill the current knowledge gap between daily practice and (societal) need for evidence based medicine for all surgeons specialized in complex spine surgery.

For patients with spondylolisthesis who are eligible for single level lumbar interbody fusion (LIF) surgery through a posterior approach, participating in this study does not pose any extra risks since both techniques are standard practice. The burden for patients participating in this trial is low. They are asked to fill out web based questionnaires concerning Patient Related Outcome Measurements (PROMS) (HADS, ODI, EQ-5D-5L, SF-36, VAS) at five fixed time-points (pre-operatively, 3, 6, 12 and 24 months postoperatively). To determine cost effectiveness productivity related costs (iPCQ) and medical costs (iMCQ)) are recorded additionally at the five time-points.

The proposed RCT will lead to objective (cost) effectiveness results and conclusions, which can be implemented in current health care. With the results of this study, current guidelines will be adapted, thereby contributing to future provision of optimal, efficient, evidence-based treatments for patients with lumbar spondylolisthesis. Since surgeons specialized in complex spine surgery already perform both techniques, which are of similar technical difficulty, there will be limited education required to implement the most effective technique. Both techniques are covered by basic health insurance (same treatment code), therefore we do not expect that restructuring of financing is required before further implementation can proceed. The principal investigator and co-investigators have a broad network in the Netherlands and are (board)members of DSS, NOV and/ or NVvN and are in the lead to influence the adaptation of current national guidelines, and implementation of the preferred technique. An assessment-oriented process evaluation will be used to gauge how well the intervention is implemented. By performing both an economic evaluation and a model-based simulation study to project the results nation-wide and over a longer time horizon, the relevance of this study will be high. In case our hypothesis is confirmed, this could lead to a substantial saving to Dutch society of at least 3,2 million Euros annually. Due to shorter surgical time, shorter hospital duration and less expected complications, hospital costs for TLIF are expected to be lower. We additionally expect TLIF patients to recover quicker, leading to lower societal 
costs compared to PLIF. Reduction of hospital stay and societal costs will probably lead to an average saving of €3.179 per patient.

Also, the LIFT study should set an example of collection patient data in a standardized method, to enable physicians insight in the effectivity of their treatments. So hopefully in near future it is easier to obtain data and perform reliable retrospective research.

The execution of the LIFT study is in the capable hands of my fellow PhD student, I Caelers, MD. The inclusion started on September 1st 2017. Results of the LIFT study are expected in 2020. 


\section{REFERENCES}

1. RIVM - Volksgezondheid en Zorg in Nederland. http://www.volksgezondheidenzorg.info/onderwerp/ nek-en-rugklachten. Published 2016.

2. Konstantinou K, Dunn KM. Sciatica: review of epidemiological studies and prevalence estimates. Spine (Phila Pa 1976). 2008;33(22):2464-2472. doi:10.1097/BRS.0b013e318183a4a2.

3. Beutler WJ, Fredrickson BE, Murtland A, Sweeney C, Grant W, Baker D. The natural history of spondylolysis and spondylolisthesis. Spine (Phila Pa 1976). 2003;28(10):1027-1035. doi:10.1097/01. BRS.0000061992.98108.A0

4. Willems P, Hoebink E, van Royen B, et al. Richtlijn: Geïnstrumenteerde Spinale Wervelkolomchirurgie; 2017

5. CBS bevolking. http://www.cbs.nl/nl-NL/menu/themas/bevolking/nieuws/default.htm. Published 2014.

6. $\quad$ CBS arbeidsparticipatie. http://statline.cbs.nl/ Arbeidsparticipatie. Published 2015.

7. Rajaee SS, Bae HW, Kanim LEA, Delamarter RB. Spinal Fusion in the United States. Spine (Phila Pa 1976). 2012;37(1):67-76. doi:10.1097/BRS.0b013e31820cccfb.

8. Tosteson ANA, Lurie JD, Tosteson TD, et al. Surgical treatment of spinal stenosis with and without degenerative spondylolisthesis: cost-effectiveness after 2 years. Ann Intern Med. 2008;149(12):845-853. doi:10.7326/0003-4819-149-12-200812160-00003.

9. Malhotra D, Kalb S, Rodriguez-Martinez N, et al. Instrumentation of the posterior thoracolumbar spine: From wires to pedicle screws. Neurosurgery. 2014;10(4):497-505. doi:10.1227/NEU.0000000000000489. 





\section{DANKWOORD}

Afgelopen jaren heb ik met veel plezier als onderzoeker gewerkt. Hierbij kreeg ik hulp van een groot aantal mensen, zonder hen zou dit proefschrift niet mogelijk geweest zijn. Graag wil ik iedereen die heeft geholpen bij de totstandkoming van dit boekje bedanken, en een aantal van hen in het bijzonder:

Prof. dr. R.A. de Bie. Beste Rob, bedankt voor al je hulp en inzichten. Na een bezoek aan jou kon ik er altijd weer tegen aan. Je denkt in mogelijkheden in plaats van onmogelijkheden en dat was voor mij een grote steun.

Dr. H. van Santbrink. Beste Henk, bedankt voor je geloof in dit onderzoek en mijn proefschrift. Door jouw volharding ben ik in de gelegenheid gesteld dit proefschrift in af te ronden. Ik hoop dat de toekomst veel goeds brengt voor de LIFT studie.

Dr. K. Rijkers. Beste Kim, bedankt voor je eindeloze geduld en het herstructureren en aanvullen van al mijn teksten. Zonder jou was ik de moed ongetwijfeld verloren. Ik heb veel van je geleerd als onderzoeker en als arts, en ook al ben ik een andere richting op gegaan, dat zal ik altijd onthouden.

Prof. dr. L.W. van Rhijn, prof. dr. M.A. Joore, prof. dr. J.M.P. Kleijnen, prof. dr. R.H.M.A. Bartels en dr. W.A. van den Brink hartelijk dank voor het lezen en beoordelen van mijn proefschrift. Prof. dr. I.C. Heyligers en dr. G.A.P.G van Mastrigt bedankt voor uw zitting in de corona. leder van u heeft een vakgebied dat een groot raakvlak heeft met delen van mijn proefschrift. Ik kijk er dan ook naar uit om met u te mogen discussiëren over de inhoud en (on)mogelijkheden voor de toekomst tijdens mijn verdediging.

Prof. dr. S.M.A.A. Evers. Beste Silvia, de uurtjes op jouw kamer hebben mij veel inzicht gegeven in kosten effectiviteit in de zorg en wat je allemaal moet doen om een subsidie aanvraag in te kunnen dienen. Bedankt voor het wegwijs maken in de wereld die voor dit proefschrift nog een ver van mijn bed show was.

Dr. S. van Kuijk. Beste Sander, door jouw hulp vlogen ook de laatste loodjes van dit proefschrift voorbij. Je bent een kei in het vertalen van de vaag omlijnde statische vraag van een dokter, naar een goed onderbouwd statistisch concept. Bedankt voor al je hulp.

Dr. P. Willems en Dr. W. van Hemert, Beste Paul en Wouter, bedankt voor de orthopedische input voor enkele van mijn artikelen. Soms kijken jullie toch net wat anders tegen de zaken aan dan de neurochirurgen, wat een welkome aanvulling is geweest. 
Dr. P. Koehler, bedankt voor uw hulp bij het historische stuk. Ik was absoluut niet thuis in de historie van de geneeskunde of wervelkolomchirurgie, maar met uw aanwijzingen is het een mooi stuk geworden. Ik vond het erg leuk om het te schrijven!

Drs. I.J.M.H. Caelers. Beste Inge, ik vind het super dat jij mijn opvolger bent geworden. Van student die onderzoek wilde doen naar PhD student en coördinator van een multicenter studie. Ik wil je heel veel succes wensen en heb er alle vertrouwen in dat het goed gaat komen!

Mieke van de Wal, bedankt voor al je hulp met het zoeken naar de vragenlijsten, zonder jou was het me niet gelukt om alle benodigde informatie te vinden.

Dr. J. Maessen. Beste José, bedankt voor je hulp bij de ZonMW aanvraag.

Alle collega's van de neurochirurgie, bedankt voor jullie interesse in mijn onderzoek en de gezellige momenten zowel binnen als buiten de kliniek.

Mijn bijzondere dank is verschuldigd aan de dames van het secretariaat van de neurochirurgie. Trudy, Ann, Marie-José, Monique, Angelique, Monique, Carla en Regina, als ik weer eens een stempel, envelop, muis of wat dan ook nodig had waren jullie er altijd om mij te helpen.

Evelien Jagtman, heel erg bedankt voor het prachtige ontwerp van zowel de kaft als de binnenzijde van dit boekje. Ik ben er heel blij mee!

Alle collega's van Novicare Limburg; bedankt voor het warme bad waarin jullie mij verwelkomd hebben. Ik vond het ontzettend fijn en leerzaam om met jullie te werken.

En Vivian en Annemiek; bedankt voor alle gezellige Peace of Cake momenten! Altijd fijn om even bij te kletsen.

Alle collega's van Cicero; ik heb met veel plezier mijn eerste opleidingsjaar tot specialist ouderengeneeskunde bij jullie voltooid en kom graag over een jaartje weer terug!

Drs. Wijers, lieve Hilde, van wetenschap heb je naar eigen zeggen niet zoveel kaas gegeten, maar van opleiden des te meer! Ik heb heel veel geleerd en een superleuke tijd gehad. Bedankt voor alles.

Aan mijn collega's AIOS ouderengeneeskunde en docenten; bedankt voor jullie interesse tijdens de afrondende fase van mijn proefschrift. 
Alle collega's van de forensische geneeskunde GGD-Zuid Limburg; wat ontzettend leuk dat ik bij jullie terecht ben gekomen. Met heel veel plezier werk ik als forensisch arts en maak ik de meest interessante dingen mee. Ik vind jullie top collega's, met een enorme dosis flexibiliteit en humor, bedankt daarvoor!

Drs. Beckers. Lieve Rianne, wat leuk dat we in hetzelfde jaar een proefschrift af ronden en ook rond dezelfde tijd een kindje verwachten. Ik vind het heel leuk dit alles met jou te mogen delen, ik kijk ernaar uit om te walrussen over een paar maanden en daarna nog lang te genieten.

Drs. Zopfi. Lieve Rins, altijd heel fijn om je te zien en samen te borrelen. Ik vind het top dat je je hart hebt gevolgd en nu doet wat je écht leuk vind. Geniet ervan!

Drs. Kox. Lieve Jasper, bedankt voor alle kopjes koffie (en incidenteel bier) en gezelschap tussen het werken door. Je nuchterheid en stoïcijnse blik maakt mijn wereld een stuk eenvoudiger. Veel succes en dat proefschrift, dat komt wel.

Drs. Çelikel. Lieve Feyza. Ook al woon je tegenwoordig ver weg, als we elkaar spreken voelt het altijd als dichtbij. Nu krijg ik eindelijk tijd om jullie in Ankara te bezoeken! Ik wens jou, Fatih en Neva heel veel geluk en een prachtige toekomst toe.

Dr. Deliaert. Lieve An, je bent een inspiratie voor mij geweest om mijn proefschrift af te ronden. Je bent me voor gegaan en hebt me vertrouwen gegeven dat ik het ook kon. Ik geniet van onze avondjes eten en wijn en hoop dat we dat nog lang mogen volhouden!

Drs. van der Beek. Lieve Tim, mijn mattie sinds het eerste jaar. Ondanks het bewandelen van verschillende paden komen we heel veel overeen. Heerlijk om regelmatig met jou te ontspannen in het gezelschap van Michelin. Laten we dit vooral zo voortzetten!

Drs. Meuwissen. Lieve Joke, ook jou ken ik sinds ons eerste jaar. Ik vind het ontzettend leuk dat we nog steeds vriendinnetjes zijn. Ik ben vereerd dat jij mijn paranimf wilt zijn en ik vind het super dat we belangrijke momenten in het leven kunnen delen!

Drs. Wijenbergh. Boy, keeeend, wie had ik anders moeten vragen als paranimf! Het is een taak die jou op het lijf geschreven staat. Ik ken niemand die zo goed kan regelen en organiseren als jij! Ik geniet van onze vriendschap, op verschillende plaatsen in Europa en het is fijn om te weten dat je er altijd bent. 
Mijn schoonouders, Steef en Doriene en schoonzus en broer Kelly en Pascal (en Sieb). Bedankt voor jullie interesse in mijn werk en jullie aandacht en hulp in ons leven.

Mama, bedankt voor alles. Je eindeloze vertrouwen in mij en je hulp op momenten dat ik het nodig had. Zonder jou was ik niet zo ver gekomen. Nu dit werkstuk af is, op naar het volgende avontuur!

Lieve, lieve Dennis, mijn eeuwige optimist, mijn slechte grappenmaker en bovenal mijn ultieme team mate. Zonder jou zou mijn leven lang niet zoveel kleur hebben. Ik geniet elke dag van je en waardeer alles wat je voor ons doet. Ik hoop dat wij, de kleine veestapel en de aankomende mini, nog heel lang van elkaar mogen genieten. N'oublier jamais!
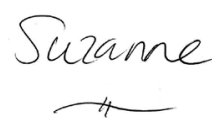




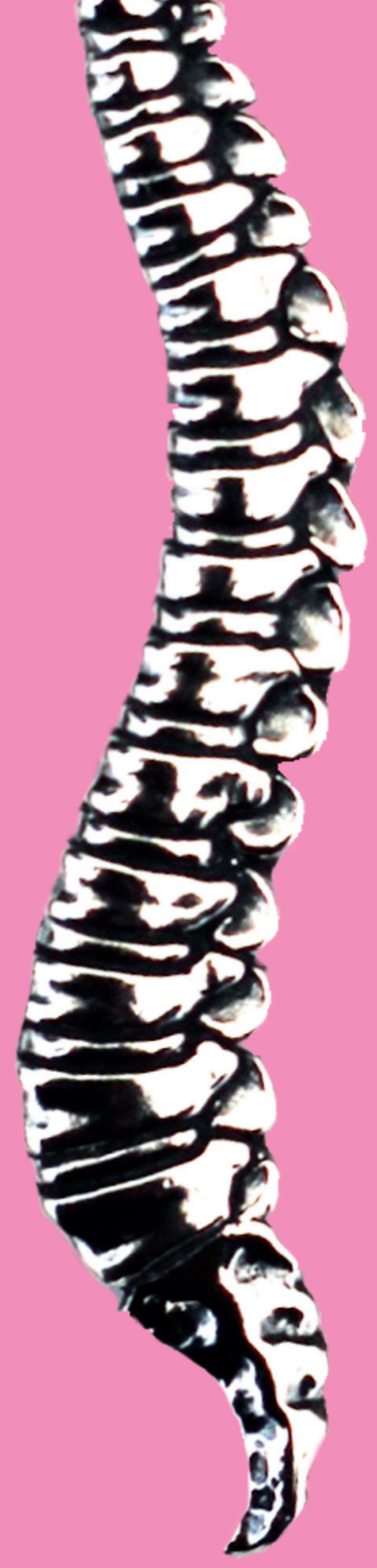

\section{Curriculum Vitae}





\section{CURRICULUM VITAE}

Suzanne Levina de Kunder was born on April 15th, 1984 in Borsele, the Netherlands. After graduating from high school in 2004, she started medical school in Leuven, Belgium. In 2007 she continued medical school in Maastricht, the Netherlands, and graduated in 2013. During her study there was always an interest in the human nervous system and the creativity of surgery also appealed to her during her internships. After graduation she worked as a resident at the neurosurgical department in Maastricht. During this residency an interest in spinal surgery emerged, and the opportunity arose to work as an PhD student on this subject (department of neurosurgery MUMC+/ school CAPHRI). During her work as a researcher she missed patient care and therefore she started working in nursing homes as an on call doctor. Elderly care medicine was a surprisingly nice and broad discipline with great opportunities and possibilities.

She decided to switch to elderly care medicine in 2016 and started her training in March 2017 (Cicero Brunssum, drs Wijers). Also, she started working in forensic medicine in May 2017 (GGD zl Heerlen, drs Van Hooren). Currently she combines both professions with great pleasure. She is living with her husband Dennis Cornelissen in Maastricht. They are expecting their first child in September 2018. 



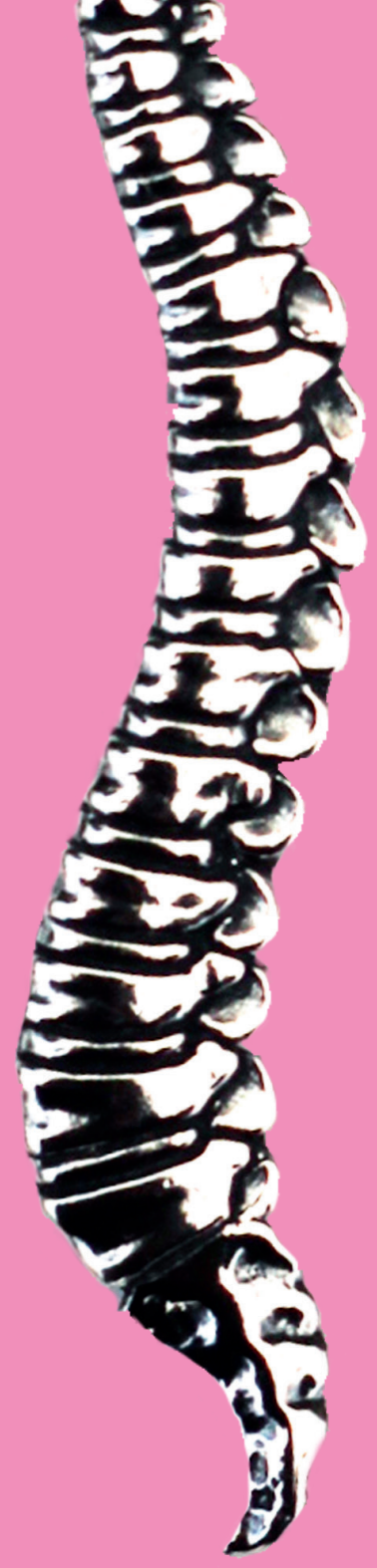

List of publications 



\section{LIST OF PUBLICATIONS}

1. de Kunder SL, Rijkers K, Caelers IJMH, de Bie RA, Koehler PJ, van Santbrink H. Lumbar Interbody Fusion, A Historical Overview and A Future Perspective. Spine (Phila Pa 1976). Published Ahead of Print. doi:10.1097/BRS.0000000000002534

2. de Kunder SL, van Kuijk SM, Rijkers K, et al. Transforaminal lumbar interbody fusion (TLIF) versus posterior lumbar interbody fusion (PLIF) in lumbar spondylolisthesis, a systematic review and meta-analysis. Spine J. 2017;17(11):1712-1721. doi:10.1016/j. spinee.2017.06.018.

3. de Kunder SL, Rijkers K, van Kuijk SMJ, Evers SMAA, de Bie RA, van Santbrink H. A protocol of a randomized controlled multicenter trial for surgical treatment of lumbar spondylolisthesis: the Lumbar Interbody Fusion Trial (LIFT). BMC Musculoskelet Disord. 2016;17(1):417. doi:10.1186/s12891-016-1280-8.

4. de Kunder SL, Rijkers K, van Hemert WLW, Willems PCPH, ter Laak - Poort MP, van Santbrink $H$. Transforaminal versus posterior lumbar interbody fusion as operative treatment of lumbar spondylolisthesis, a retrospective case series. Interdiscip Neurosurg. 2016;5:64-68. doi:10.1016/j.inat.2016.07.001.

5. de Kunder SL, ter Laak - Poort MP, Nicolai J, Vles JSH, Cornips EMJ. Fever after intraventricular neuroendoscopic procedures in children. Child's Nerv Syst. 2016;32(6):1049-1055. doi:10.1007/s00381-016-3085-3.

6. Wesseling FWR, de Kunder SL, Schijns OEMG, Baumert BG, Postma AA. Tubular Tumor Growth Along Entire Biopsy Track of Brain Metastasis. J Thorac Oncol. ;7(6):1058. doi:10.1097/JTO.0b013e31824fea2c. 